Mascimiliano de los Santos Maly

\title{
AVALIAÇÃO DA TÉCNICA DA ELETRORRESISTIVIDADE NO MAPEAMENTO DE SEDIMENTOS RASOS ASSOCIADOS A OCORRÊNCIAS DE GÁS NO SACO DO MAMANGUÁ E NA ENSEADA DE PARATY-MIRIM
}

\begin{abstract}
Dissertação apresentada ao Instituto Oceanográfico da Universidade de São Paulo, como parte dos requisitos para a obtenção do título de Mestre em Ciências, Programa de PósGraduação em Oceanografia, área de Oceanografia Geológica.
\end{abstract}

Orientador: Prof. Dr. Luigi Jovane

São Paulo 
Universidade de São Paulo

Instituto Oceanográfico

\begin{abstract}
AVALIAÇÃO DA TÉCNICA DA ELETRORRESISTIVIDADE NO MAPEAMENTO DE SEDIMENTOS RASOS ASSOCIADOS A OCORRÊNCIAS DE GÁS NO SACO DO MAMANGUÁ E NA ENSEADA DE PARATY-MIRIM
\end{abstract}

Mascimiliano de los Santos Maly

Dissertação apresentada ao Instituto Oceanográfico da Universidade de São Paulo, como parte dos requisitos para a obtenção do título de Mestre em Ciências, área de Oceanografia Geológica.

Julgada em:

$\operatorname{Prof}(\mathrm{a}) . \operatorname{Dr}(\mathrm{a})$

Conceito

Prof(a). Dr(a).

Conceito

Prof(a). Dr(a).

Conceito 


\section{Sumário}

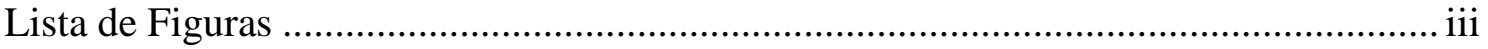

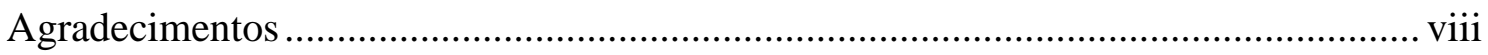

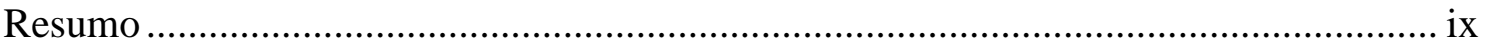

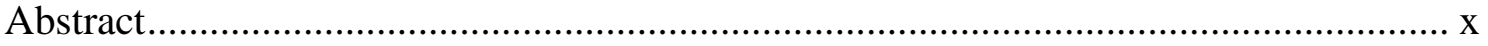

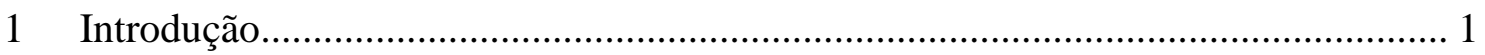

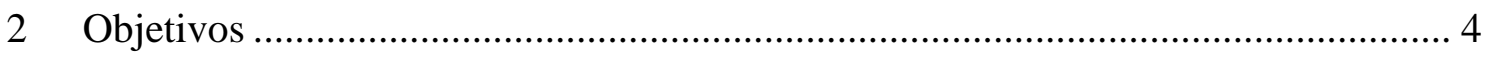

3 Área de estudo ........................................................................................... 5

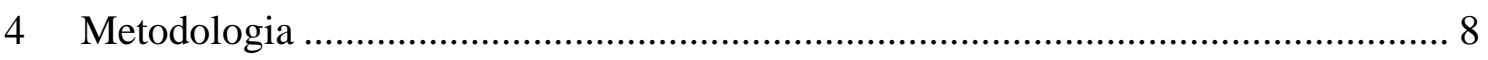

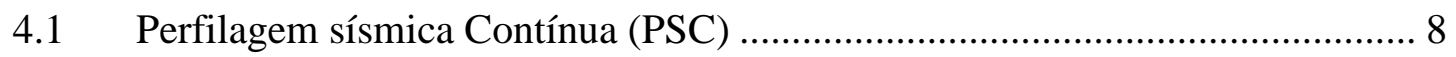

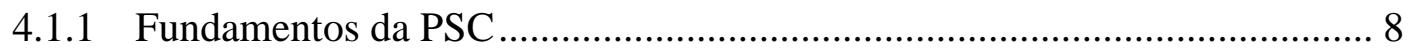

4.1.1.1 Esforço e deformação .................................................................... 9

4.1.1.2 Tipos de ondas sísmicas............................................................. 12

4.1.1.3 Velocidade de ondas sísmicas........................................................ 13

4.1.1.4 Reflexão e transmissão em meios estratificados.................................. 14

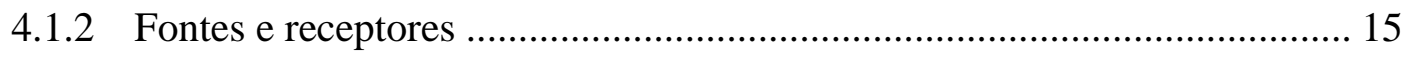

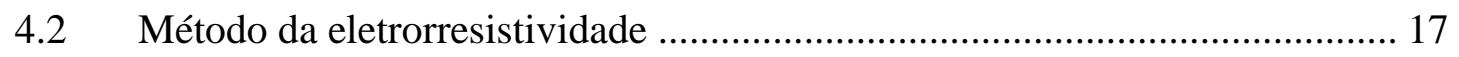

4.3 Arranjo Schlumberger reverso ou recíproco............................................ 23

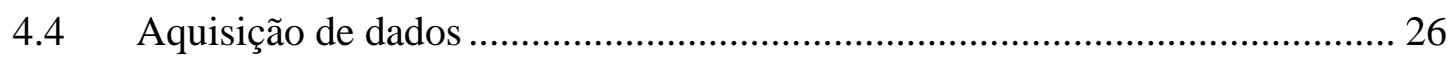

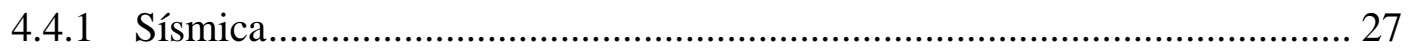

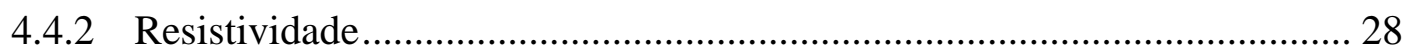

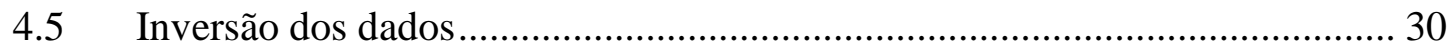

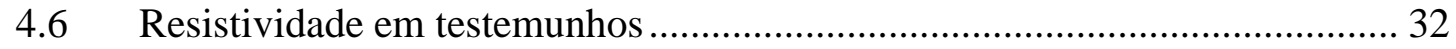

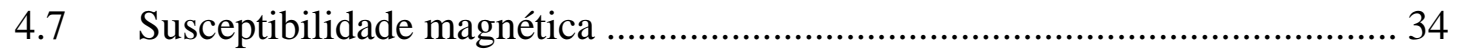

4.8 Parâmetros que incidem na variação da resistividade ................................... 34

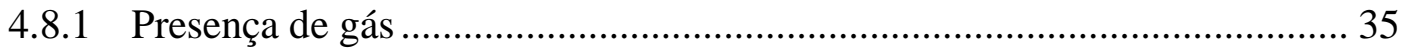




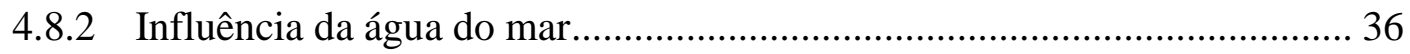

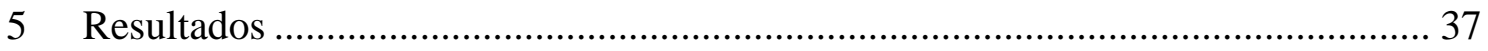

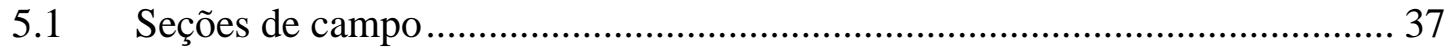

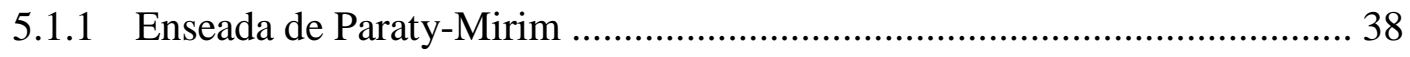

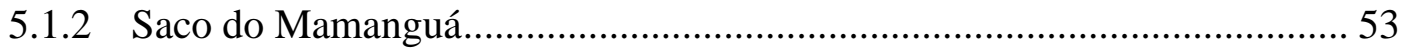

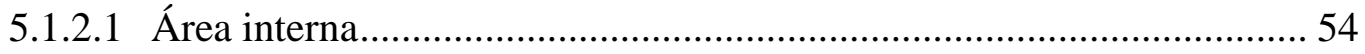

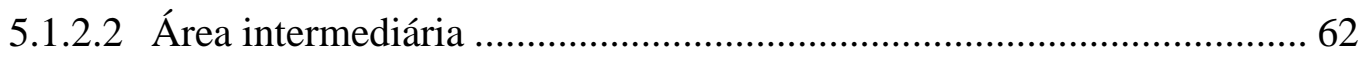

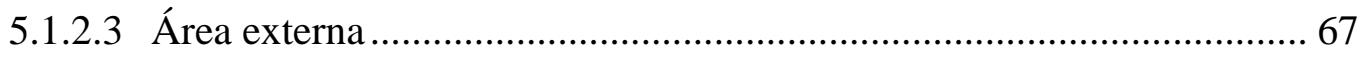

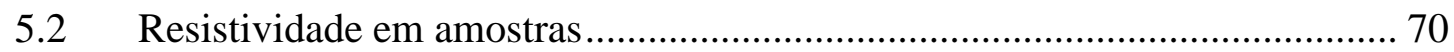

5.3 Susceptibilidade magnética …................................................................ 71

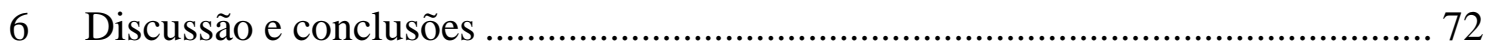

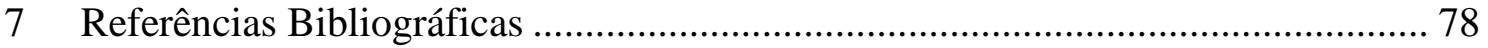




\section{Lista de Figuras}

Figura 1: Área de estudo (projeção UTM - datum WGS84) ...................................................5

Figura 2. Mapa geológico dos terrenos emersos da área de estudo. Fonte CPRM. ................... 6

Figura 3. Curva típica de esforço-deformação para um corpo sólido. ...................................... 10

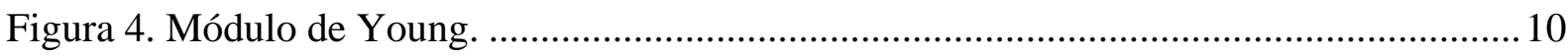

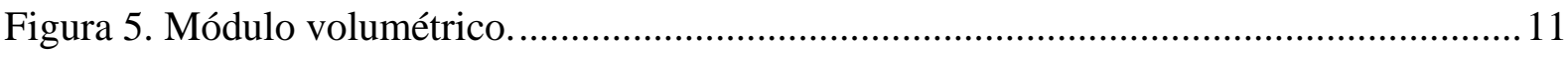

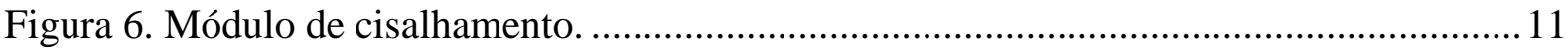

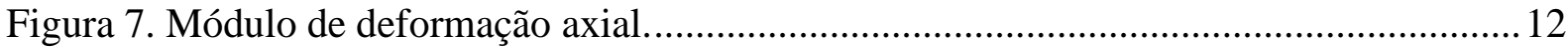

Figura 8. Deformação elástica e movimento de partícula relacionados à passagem de ondas de corpo.

Figura 9. Raios refletidos e incidentes associados a incidência normal de uma onda compressiva

Figura 10: Esquema conceitual do princípio de funcionamento do método eletrorresistivo. Os eletrodos $\mathrm{AB}$ injetam corrente, enquanto os eletrodos $\mathrm{MN}$ efetuam a leitura da diferença de potencial estabelecida entre eles. 18

Figura 11. Fonte pontual em meio homogêneo e isotrópico. Modificado de Telford et al., 1990.

Figura 12. Fonte pontual de corrente situada na superfície de um semiespaço homogêneo e isotrópico. Modificado de Telford et al., 1990.

Figura 13. Arranjo para aquisição de dados de eletrorresistividade. A corrente circula entre os dipolo A-B e a tensão é medida entre os eletrodos M-N. 22

Figura 14: Seção de campo. Este é o tipo de pseudoseção de resistividade observada durante a aquisição dos dados.

Figura 15: Diagrama do arranjo de eletrodos Schlumberger reverso. Os eletrodos de injeção de corrente $\mathrm{AB}$ permanecem estáticos com relação aos eletrodos de leitura de potencial MN....24 Figura 16: Representação esquemática dos pontos amostrados em subsuperfície, por meio da execução de um caminhamento elétrico. As cruzes indicam os pontos teóricos de leitura de resistividade aparente. 25

Figura 17: Pseudoseção de resistividade. A resistividade aparente varia de 0,183 a 0,373 Ohm.m 26

Figura 18: Mapa da área de estudo mostrando a malha de aquisição sísmica (amarelo) e a malha de aquisição de dados de eletrorresistividade (vermelho). 
Figura 19: Esquerda, chirp fixado na borda da embarcação; direita, carenagem de proteção do transdutor.

Figura 20: Cabo multieletrodos rebocado na superfície da água.

Figura 21: Eletrorresistivímetro Syscal Switch Pro.

Figura 22: Painel de edição do RES2DINV mostrando dez níveis de investigação. Os pontos que apresentam variações abruptas de resistividade em um mesmo nível (spikes) são removidos.

Figura 23: Matriz de discretização dos valores de resistividade aparente amostrados em subsuperfície. Idealmente, a cada célula da matriz corresponderá um único valor de resistividade aparente.

Figura 24: Escala de cores comum a todas as seções de imageamento elétrico. A resistividade elétrica varia de $0.05 \mathrm{Ohm} . \mathrm{m}$, até $17 \mathrm{Ohm} . \mathrm{m}$. 32

Figura 25 - Arranjo para medição da resistividade elétrica em amostras cilíndricas de sedimentos. O resistivímetro SYSCAL - R2 é utilizado tanto como comutador do sentido da corrente - para evitar que o meio seja polarizado- como para realizar a leitura do potencial entre os eletrodos MN

Figura 26: Adição de bolhas de acrílico na amostra, para simulação de bolhas de gás.

Figura 27: Localização das linhas analisadas: A - Enseada de Paraty-Mirim. B - Saco do Mamanguá.

Figura 28: Perfil sísmico (A), SIG em escala de cores automática (B) e SIG em escala de cores comum (C), correspondentes à linha L01. Observa-se a ocorrência de um horizonte de gás em $12 \mathrm{~m}$ de profundidade e plumas de escape na coluna sedimentar. A SIG apresenta relativa heterogeneidade com importante variação lateral quando comparada com SIGs adjacentes. A camada superior mais condutiva é mais espessa nas extremidades da seção.

Figura 29: Perfil sísmico (A), SIG em escala de cores automática (B) e SIG em escala de cores comum (C), correspondentes à linha L02. Observa-se a ocorrência de uma cortina acústica abaixo de $10 \mathrm{~m}$ de profundidade e plumas de escape na coluna sedimentar. A SIG apresenta o padrão típico para esta área de aumento da resistividade com a profundidade e espessamento da camada mais condutiva nas extremidades da seção.

Figura 30: Perfil sísmico (A), SIG em escala de cores automática (B) e SIG em escala de cores comum (C), correspondentes à linha L03. Observa-se a ocorrência de uma cortina acústica abaixo de $10 \mathrm{~m}$ de profundidade e plumas de escape na coluna sedimentar. A SIG apresenta o 
padrão típico para esta área de aumento da resistividade com a profundidade e afinamento da camada mais condutiva na direção do aumento da profundidade.

Figura 31: Perfil sísmico (A), SIG em escala de cores automática (B) e SIG em escala de cores comum (C), correspondentes à linha L04. A coluna sedimentar se mostra acusticamente homogênea. Porém, a SIG apresenta o padrão típico para esta área: aumento da resistividade com a profundidade e espessamento da camada mais condutiva nas porções mais rasas........42 Figura 32: Perfil sísmico (A), SIG em escala de cores automática (B) e SIG em escala de cores comum (C), correspondentes à linha L05. A coluna sedimentar se mostra acusticamente homogênea. Porém, a SIG apresenta o padrão típico para esta área: aumento da resistividade com a profundidade e espessamento da camada mais condutiva nas áreas mais rasas.

Figura 33: Perfil sísmico (A), SIG em escala de cores automática (B) e SIG em escala de cores comum (C), correspondentes à linha L06. As cortinas acústicas indicativas de presença de gás ocorrem abaixo do limite de penetração do método geoelétrico.

Figura 34: Perfil sísmico (A), SIG em escala de cores automática (B) e SIG em escala de cores comum (C), correspondentes à linha L07. A ocorrência de lumas intrassedimentares está mais concentrada nos $450 \mathrm{~m}$ inicias. A cortina acústica ocorre abaixo de $9 \mathrm{~m}$ de profundidade, coincidindo com a interface de $0.35 \mathrm{Ohm} . \mathrm{m}$

Figura 35: Perfil sísmico (A), SIG em escala de cores automática (B) e SIG em escala de cores comum (C), correspondentes à linha L08. A cortina acústica dá lugar ao predomínio de um refletor reforçado em 11,5 m de profundidade, coincidindo com o aumento lateral no valor da resistividade, da camada geoelétrica com base em $9 \mathrm{~m}$

Figura 36: Perfil sísmico (A), SIG em escala de cores automática (B) e SIG em escala de cores comum (C), correspondentes à linha L09. A resposta acústica do meio não tem correspondência direta com as SIGs.

Figura 37: Perfil sísmico (A), SIG em escala de cores automática (B) e SIG em escala de cores comum (C), correspondentes à linha L10. A camada geoelétrica menos resistiva está ausente.

Figura 38: Perfil sísmico (A), SIG em escala de cores automática (B) e SIG em escala de cores comum $(\mathrm{C})$, correspondentes à linha L11. Observa-se boa correlação entre a variação de refletividade acústica e a resistividade.

Figura 39: Perfil sísmico (A), SIG em escala de cores automática (B) e SIG em escala de cores comum (C), correspondentes à linha L13. Observa-se boa correlação entre a variação de refletividade acústica e a resistividade. 
Figura 40: Divisão do Saco do Mamanguá em setores de análise.

Figura 41: Perfil sísmico (A), SIG em escala de cores automática (B) e SIG em escala de cores comum $(\mathrm{C})$, correspondentes à linha L14.

Figura 42: Perfil sísmico (A), SIG em escala de cores automática (B) e SIG em escala de cores comum (C), correspondentes à linha L15. O aumento de resistividade observado nas extremidades inferiores da SIG pode estar relacionado à ocorrência de gás observada no perfil sísmico. 56

Figura 43: Perfil sísmico (A), SIG em escala de cores automática (B) e SIG em escala de cores comum $(\mathrm{C})$, correspondentes à linha L16. A camada de resistividade maior que 0,20 Ohm.m aparece espessada em um canal.

Figura 44: Perfil sísmico (A), SIG em escala de cores automática (B) e SIG em escala de cores comum (C), correspondentes à linha L17. A camada de resistividade maior que 0,20 Ohm.m aparece espessada na porção mais profunda da seção. 58

Figura 45: Perfil sísmico (A), SIG em escala de cores automática (B) e SIG em escala de cores comum $(\mathrm{C})$, correspondentes à linha L26.

Figura 46: Perfil sísmico (A), SIG em escala de cores automática (B) e SIG em escala de cores comum $(\mathrm{C})$, correspondentes à linha L27. A variação lateral das feições acústicas não tem correspondência na assinatura elétrica.

Figura 47: Perfil sísmico (A), SIG em escala de cores automática (B) e SIG em escala de cores comum (C), correspondentes à linha L28. A anomalia resistiva observada na camada superior da SIG coincide com a área de afloramento da estrutura em domo do perfil sísmico.

Figura 48: Perfil sísmico (A), SIG em escala de cores automática (B) e SIG em escala de cores comum (C), correspondentes à linha L18. A SIG apresenta variações de resistividade que não possuem correlação com a resposta sísmica homogênea da camada sedimentar.

Figura 49: Perfil sísmico (A), SIG em escala de cores automática (B) e SIG em escala de cores comum (C), correspondentes à linha L19. A SIG mostra variações de resistividade que não possuem correlação com a resposta sísmica homogênea da camada sedimentar.

Figura 50: Perfil sísmico (A), SIG em escala de cores automática (B) e SIG em escala de cores comum (C), correspondentes à linha L29. A uniformidade lateral da seção geoelétrica não se corresponde com a ocorrência da feição acústica observada no perfil sísmico.

Figura 51: Perfil sísmico (A), SIG em escala de cores automática (B) e SIG em escala de cores comum (C), correspondentes à linha L30. A comparação das linhas transversais e longitudinais 
nos respectivos pontos de cruzamento, mostra uma boa coerência entre os valores de resistividade. A resistividade aumenta no sentido da declividade do fundo. 66

Figura 52: Perfil sísmico (A), SIG em escala de cores automática (B) e SIG em escala de cores comum (C), correspondentes à linha L24. A SIG apresenta anomalias resistivas em fundo de 0,20-0,35 Ohm.m.

Figura 53: Perfil sísmico (A), SIG em escala de cores automática (B) e SIG em escala de cores comum $(\mathrm{C})$, correspondentes à linha L25. A resistividade diminui com sentido SE. 68 Figura 54: Perfil sísmico (A), SIG em escala de cores automática (B) e SIG em escala de cores comum $(\mathrm{C})$, correspondentes à linha L33.

Figura 55: Esquerda: Gráfico da variação da resistividade elétrica em função da profundidade a partir da superfície do fundo para amostras de sedimentos inalteradas. Centro: Gráfico da variação da resistividade em função da profundidade a partir da superfície do fundo para amostras dessalinizadas. Direita: Variação da resistividade, para uma mesma amostra, com a adição de bolhas 70

Figura 56: Gráfico de variação da susceptibilidade magnética de três amostras dessalinizadas. As três amostras apresentaram diminuição da susceptibilidade com a retirada do sal............. 71

Figura 57: Cruzamentos das SIGs transversais L18 a L23, com a SIG L30. .......................... 72

Figura 58: Cruzamentos das SIGs transversais L18 a L23, com a SIG L31 .......................... 72

Figura 59: Seção geoelétrica adquirida em trecho de lâmina d'água superior a $11,5 \mathrm{~m}$..........73 Figura 60: Distribuição granulométrica de sedimentos superficiais no SM. Modificado de Olpe (2015). .74

Figura 61. Mapa do teor de argila de sedimentos superficiais. 75 


\section{Agradecimentos}

Agradeço, em primeiro lugar, a Rodrigo Machado e Adriano Marchioreto da empresa Alta Resolução, por terem disponibilizado os equipamentos para o levantamento geoelétrico, a infraestrutura e o espaço para a inversão dos dados e pelo tempo dedicado no acompanhamento dos trabalhos de campo e na discussão das questões que foram aparecendo pelo caminho.

Ao professor Francisco Yukio Hiodo e a Andrea Ustra, por todas as ideias e ajuda concedidas, além do entusiasmo demonstrado durante e após as experiências de laboratório.

Ao Dr. Luiz Antonio Pereira de Souza (Laps), sempre disposto a uma boa conversa sobre ambientes marinhos rasos.

A Igor Carrasqueira, pelos fundamentos em susceptibilidade magnética.

A meu orientador, o professor Luigi Jovane, pelas oportunidades únicas que tem propiciado para meu desenvolvimento profissional, pela confiança depositada e pelas portas abertas.

E muito especialmente à minha esposa, Fabiana Baêta, por sua fortaleza, apoio e amor incondicional. 


\section{Resumo}

A constante pressão exercida sobre os ambientes costeiros por parte das diferentes atividades humanas, em conjunto com novas necessidades relacionadas a estudos ambientais particularmente no que diz respeito à geração de gases de efeito estufa em sedimentos marinhos, têm gerado uma crescente demanda por conhecimento dos processos de geração, acúmulo e liberação desses gases. Dado esse desafio, torna-se necessário o desenvolvimento de novas aplicações de ferramentas geofísicas que forneçam informações além das propriedades acústicas do meio. Dessa forma, o presente trabalho tem como objetivo a avaliação do método eletrorresistivo no mapeamento estratigráfico e na detecção de feições geoelétricas indicativas da presença de gás em sedimentos rasos. Para isso, foram analisadas seções geoelétricas adquiridas no Saco do Mamanguá e na Enseada de Paraty-Mirim por meio da comparação com perfis sísmicos de alta resolução e da medição de resistividade em amostras de sedimentos. Nessas amostras foi simulada a presença de bolhas de gás e analisada a variação da resistividade com a diminuição da salinidade da água intersticial. Observou-se que um volume de bolhas de $0,20 \%$ do volume total é suficiente para aumentar em um fator de 1,8 a resistividade de uma amostra saturada em água do mar. Também verificou-se que a resistividade medida é dependente da resistividade da água intersticial. Medidas de susceptibilidade magnética mostraram, neste local, que a variação da resistividade não é devida a variações mineralógicas. As seções geoelétricas mostraram boa correlação com os perfis sísmicos até $9 \mathrm{~m}$ de profundidade a partir da superfície da água, onde ocorre uma camada geoelétrica de resistividade $<0,35 \mathrm{Ohm} . \mathrm{m}$. Nessa profundidade, observa-se uma interface entre camadas de resistividade elétrica possivelmente causada por uma mudança no teor de água ou de matéria orgânica. Essa interface coincide com o topo da turbidez acústica produzida pela presença de gás.

Palavras-chave: métodos geoelétricos, gás raso, perfilagem sísmica, susceptibilidade magnética, eletrorresistividade, Saco do Mamanguá. 


\begin{abstract}
Given the constant pressure exerted over coastal environments by different human activities, in addition to the need for more knowledge concerning environmental issues, particularly with respect to greenhouse gases generation in marine sediments have generated an increasing demand for more information regarding the generation, accumulation and seepage of these gases. Faced with this challenge, there is a necessity to develop new applications to geophysical tools that provide more information than merely the acoustic properties of the medium. This work aims to the evaluation of the geoelectric method in stratigraphic mapping and the detection of geoelectric features of shallow gas. For that purpose, geoelectric sections acquired in the ria of Saco do Mamanguá and Paraty-Mirim were compared with high resolution seismic profiles and resistivity measurements in sediment samples. Presence of gas bubbles inside the sedimentary matrix was simulated and resistivity variation analyzed against the decrease of interstitial water salinity. It was observed that a bubble volume of $0.20 \%$ of the total volume is sufficient to increase the resistivity by a factor of 1.8. It was also confirmed that the sample resistivity is dependent on interstitial water resistivity. Magnetic susceptibility measurements showed that resistivity variation is not due to mineralogical variations. The geoelectric sections showed good correlation with the seismic profiles up to $9 \mathrm{~m}$ depth from the water surface, where occurs a geoelectric layer of resistivity $<0.35 \mathrm{Ohm} . \mathrm{m}$. At this depth, it is observed an interface between resistivity layers possibly caused by a change in water or organic matter content. This interface matches the top of the acoustic turbidity produced by shallow gas occurrences.
\end{abstract}

Keywords: geoeletric methods, shallow gas, seismic profiling, magnetic susceptibility, electrical resistivity, Saco do Mamanguá. 


\section{Introdução}

O estudo de ambientes deposicionais costeiros vem cobrando cada vez mais relevância, tanto do o ponto de vista do uso e ocupação para atividades humanas (Souza, 2006), quanto do de pesquisas ambientais de base. Neste sentido, é de vital importância a investigação relacionada à emissão de gases de efeito estufa com origem em sedimentos marinhos (Judd et $a l, 2002)$.

Ambientes de baixa energia como o Saco do Mamanguá (SM) e a Enseada de ParatyMirim (EPM) configuram locais propícios para o acúmulo de matéria orgânica que, ao entrar em decomposição, dá lugar à geração de gás (Whitman et al, 2006). Estes sistemas podem ser considerados laboratórios naturais para o estudo dos mecanismos de geração, acúmulo, migração e escape de gás metano (García-Gil, 2003).

No entanto, a variabilidade espacial dos sistemas de acúmulo de gás raso exige uma densa malha de dados geofísicos, a fim de se obter uma correta amostragem (Duarte et al. 2007). Nesse sentido, os métodos acústicos de investigação são os mais largamente utilizados (Jørgensen \& Fossing, 2011).

Porém, pouco se conhece sobre a distribuição vertical, padrões de migração e quantidade de gás acumulado (Tóth et al., 2014a). O gás livre impõe um limite à propagação de sinais acústicos em função das bolhas que atuam como 'espalhadores', produzindo forte atenuação da energia das ondas acústicas, especialmente as de alta frequência (Tóth et al., 2014b). De modo geral, os métodos acústicos permitem unicamente o reconhecimento do topo da camada onde o gás se acumula, não sendo úteis nem para realizar qualquer análise sobre a distribuição vertical das ocorrências de gás, nem para fornecer uma caracterização acústica das camadas sedimentares subjacentes.

Dessa forma, dada a relevância ambiental e consequentemente econômica dos estudos de ambientes costeiros, torna-se necessário o aprimoramento do uso de ferramentas geofísicas que forneçam alguma informação além das propriedades acústicas dos depósitos sedimentares.

Os métodos geoelétricos de investigação (Orellana, 1972; Teldford et al.; 1990; Keary et al.; 2002; Reynolds, 1997) aparecem como uma alternativa capaz de contornar as limitações 
que enfrentam os métodos acústicos de investigação em ambientes submersos rasos (Lavoie $e t$ al., 1988).

Em locais onde a presença de gás nos sedimentos ou o contraste de impedância acústica comprometem a aplicabilidade dos métodos sísmicos, os métodos elétricos aparecem como opções viáveis para a investigação de ambientes com essas características (Jones, 1999).

Orlando (2013) analisou a eficácia dos métodos elétricos em investigação de ambientes submersos, mediante a comparação entre o uso de eletrodos fixos na superfície do fundo e flutuantes. A partir desses estudos, a autora concluiu que é possível utilizar o Imageamento Elétrico como complemento ou inclusive como substituto dos métodos sísmicos para mapeamento de feições e caracterização dos sedimentos das camadas próximas à superfície do fundo.

David et al (2009), utilizaram a técnica de tomografia de resistividade elétrica para mapeamento de beachrocks que se estendem desde a zona emersa, onde ocorrem soterrados embaixo de sedimentos de praia, até embaixo de sedimentos da porção submersa da praia.

Machado (2008), utilizando a técnica de eletrorresistividade, fez um mapeamento extensivo no Rio São Francisco em trecho da divisa entre os estados da Bahia e Pernambuco, no sítio de implantação da barragem do Aproveitamento Hidroelétrico Riacho Seco. Nesse trabalho, foi possível identificar a ocorrência de camadas sedimentares no subfundo do rio, assim como verificar a presença de anomalias elétricas correlacionáveis com zonas de fratura no maciço rochoso.

Apostolopoulos et al. (2006) utilizaram a técnica de tomografia de resistividade com arranjo Schlumberger e pólo-pólo em mapeamento do embasamento rochoso para subsídio às escavações para implantação de um novo porto na Ilha de Chios, Grécia. Através desses estudos, os autores demonstraram que é possível mapear a topografia do embasamento conhecendo a batimetria do local.

Comparando dados obtidos por meio da técnica de resistividade elétrica, testemunhos e classificadores de fundo em área costeira do Golfo do México, Lavoie et al. (1988) obtiveram uma boa correlação tanto no que se refere a sedimentos superficiais, como em análise estratigráfica. Os estudos foram conduzidos em três áreas com diferentes tipos de sedimentos: lama, lama com gás e areia. 
A maior parte do gás presente nos sedimentos é um subproduto da atividade metabólica de bactérias metanogênicas (Floodgate \& Judd, 1992). A concentração de gás metano na água intersticial aumenta até atingir o ponto de saturação, quando começam a se formar bolhas (Wilkens \& Richardson, 1998). O gás contido nessas bolhas pode ser considerado eletricamente isolante.

Este estudo se baseia na hipótese de que a resposta global à passagem de corrente elétrica de uma camada de sedimentos rica em gás será mais resistiva que a resposta de uma camada sem gás. Portanto, espera-se que o contraste de resistividade elétrica entre camadas sedimentares ricas em gás e outras em que o mesmo está ausente, permitirá realizar uma caracterização geoelétrica da distribuição dos acúmulos de gás.

Essa hipótese está sustentada num trabalho de Mendonça et al, (2015), no qual obtiveram bons resultados na identificação de bolsões de gás metano em terrenos contaminados, inclusive estando esses bolsões abaixo do nível de saturação.

Contrariamente ao que acontece com os métodos eletromagnéticos desenvolvidos para ambientes marinhos (Cheesman et al, 1987; Chave et al, 1991; Edwards, 2005), a investigação eletrorresistiva de ambientes submersos rasos não é um assunto frequentemente tratado. Desse modo, este trabalho resulta num esforço pioneiro no desenvolvimento de uma nova aplicação de uma ferramenta amplamente consagrada na investigação geofísica. 


\section{Objetivos}

O presente trabalho visa a avaliação do desempenho da técnica de eletrorresistividade na obtenção de um modelo geoelétrico dos sedimentos rasos na EPM e no SM, através da integração com perfis sísmicos de alta resolução, medidas de resistividade elétrica e susceptibilidade magnética em amostras de sedimentos, analisando possíveis fatores que influenciam a variação da resistividade.

Os objetivos específicos são:

- Determinar a correlação entre a assinatura geoelétrica do topo da camada de gás e os correspondentes refletores sísmicos;

- Correlacionar as diferentes expressões sísmicas dos acúmulos de gás com as expressões geoelétricas;

- Correlacionar o modelo geoelétrico dos sedimentos da superfície do fundo com amostras já coletadas;

- Avaliar a viabilidade do emprego da técnica da eletrorresistividade para estudos estratigráficos em ambientes marinhos rasos; 


\section{3 Área de estudo}

O SM e a EPM (Figura 1) são duas enseadas adjacentes localizadas no extremo sudoeste da Baía da Ilha Grande, circundadas por uma das mais extensas feições geomorfológicas do Brasil: A Serra do Mar.

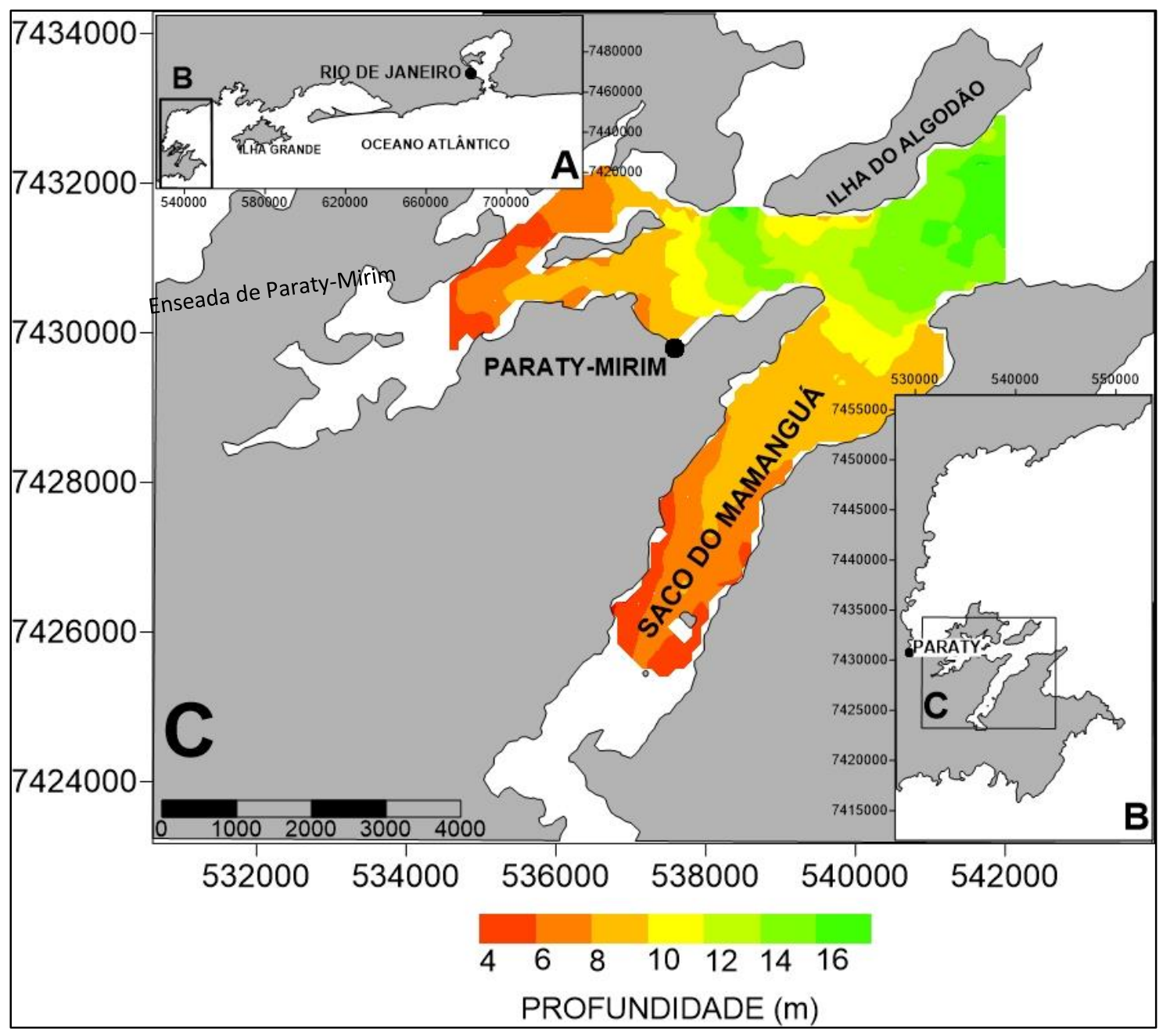

Figura 1: Área de estudo (projeção UTM - datum WGS84)

Enquanto o SM consiste em uma feição estreita e alongada de $11 \mathrm{~km}$ de comprimento por aproximadamente $2 \mathrm{~km}$ de largura, a EPM apresenta morfologia dendrítica. A profundidade varia de menos $2 \mathrm{~m}$ na área interna, até $25 \mathrm{~m}$ na porção externa do SM. 
O sistema formado pelo SM e pela EPM pode ser classificado como uma ría. Este termo é utilizado para definir vales afogados abertos para o mar (Bird, 2008) e, embora esse sistema seja às vezes considerado um estuário, apenas as áreas mais internas e próximas a drenagens continentais sofrem influências de processos estuarinos (Evans \& Prego, 2003).

A morfologia da área também coincide com a definição de ría de Castaing \& Guilcher (1995), que compreende antigos cursos de rios circundados por topografia elevada, afogados durante um evento transgressivo.

O terrenos emersos adjacentes estão formado por granitos e migmatitos precambrianos (Figura 2). Segundo Almeida \& Carneiro (1998), a variedade de litotipos expostos é fruto de uma complexa história geológica que teve lugar entre o Precambriano e o Eopaleozóico. Ainda conforme esses autores, as idades mais antigas do embasamento costeiro distribuem-se do Arqueano ao Proterozóico Inferior.

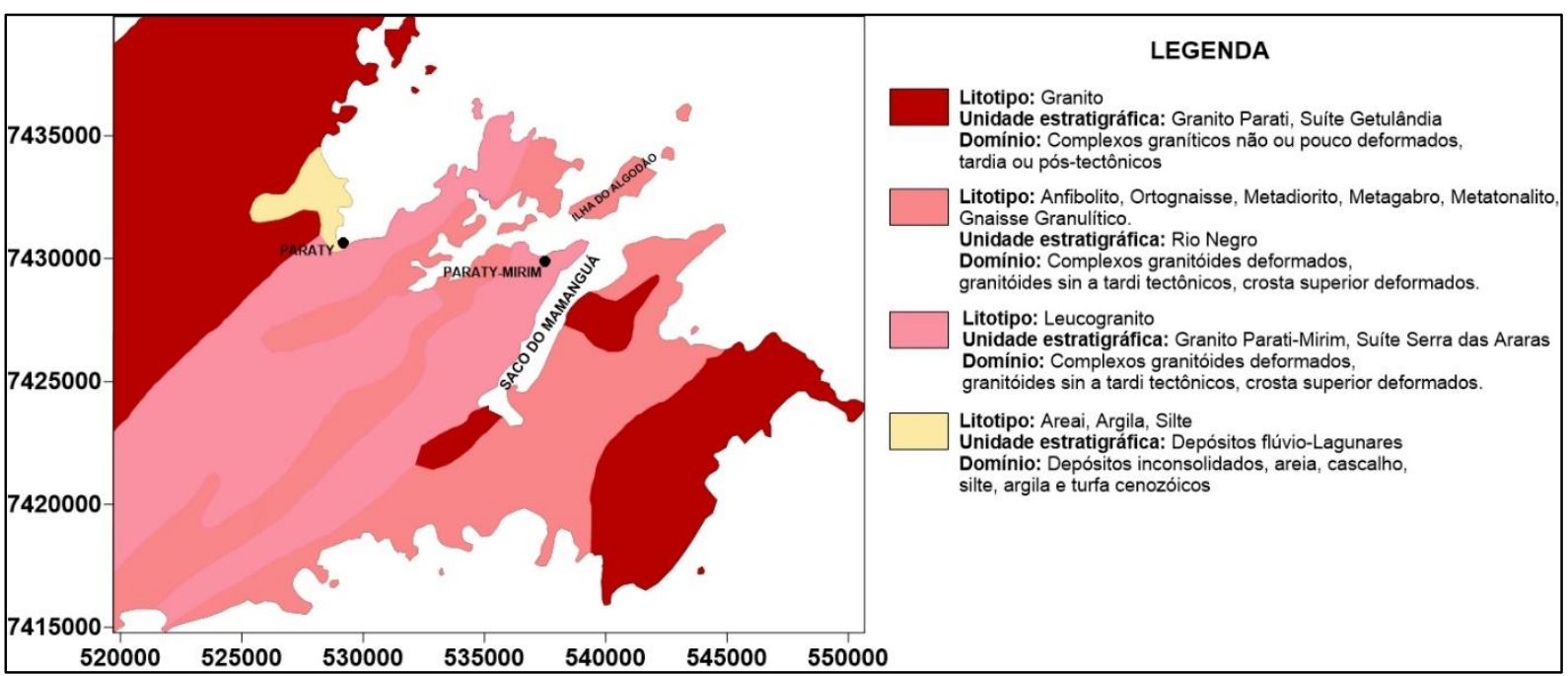

Figura 2. Mapa geológico dos terrenos emersos da área de estudo. Fonte CPRM.

A área de estudo apresenta regime de circulação restrita em ambiente de micro maré com periodicidade semidiurna (Olpe, 2016). A superfície do fundo se caracteriza por um relevo suave e está coberta por sedimentos finos, refletindo a baixa energia dos processos hidrodinâmicos atuantes que configuram a área como um depocentro (Bernardes, 1996). 
A arquitetura estratigráfica da área de estudo foi moldada pelas variações do nível do mar durante o Quaternário, cujas evidências podem ser encontradas no registro sedimentar na área da Baía de Ilha Grande, que Mahiques (1987) divide em 5 eventos principais:

Em 18.000 anos A.P., o mar se encontrava aproximadamente $90 \mathrm{~m}$ abaixo do nível atual, deixando exposta toda a superfície da Baía da Ilha Grande. Na porção Leste, existia uma planície costeira formada por sedimentos grosseiros, produto do ciclo regressivo. Entre 11.000 e 10.000 anos A.P., o nível do mar subiu 45 m, submergindo parcialmente a porção Oeste da baía e começando afogar os sistemas de drenagem que tinham se estabelecido no ciclo anterior. Nessa época, a parte Leste da baía ainda estava emersa, e seu afogamento só começou no terceiro evento, em 8.000 anos A.P. Durante o máximo transgressivo do Holoceno ( 5.000 anos A.P.), as áreas atualmente ocupadas por planícies costeiras estavam cobertas pelo mar. Foi nesse período que teve início a deposição de sedimentos pelíticos em áreas abrigadas, como é o caso do SM e a EPM. Finalmente, em 2.500 anos A.P., o nível do mar começou a se estabilizar na cota atual, dando lugar ao estabelecimento da paisagem tal como conhecemos hoje. Na extremidade Oeste da baía, os sedimentos pelíticos continuaram depositando-se sobre as areias do ciclo transgressivo, processo que continua até o presente. 


\section{Metodologia}

\subsection{Perfilagem sísmica Contínua (PSC)}

A caracterização de sedimentos de fundo, a identificação das camadas sedimentares, a determinação da profundidade do embasamento rochoso ou o mapeamento de estruturas geológicas submersas são exemplos de aplicação da PSC (Souza, 2006).

$\mathrm{Na}$ PSC utilizam-se normalmente fontes de energia de baixa potência quando comparadas com fontes utilizadas na investigação de hidrocarbonetos. Estas fontes lidam com espectros de frequência entre 500 e $45.000 \mathrm{~Hz}$ (Souza, 2014; Mosher \& Simpkin, 1999), dependendo do modelo e do objetivo do levantamento. As características destas fontes de energia estão intimamente relacionadas aos objetivos da investigação rasa, lembrando que as frequências dos sinais acústicos têm relação inversa com a penetração e direta com a resolução. Fontes que emitem sinais entre 500 e $2000 \mathrm{~Hz}$ permitem uma maior penetração nos estratos sedimentares e comumente são utilizadas para mapeamento do embasamento rochoso, enquanto que o uso de fontes que emitem frequências mais altas é mais apropriado para o estudo das camadas mais superficiais e que requerem maior resolução.

Para recepção do sinal sísmico emitido por estas fontes utiliza-se um conjunto de hidrofones ligados em série e rebocado na superfície da água, quando não é a própria fonte que atua também como receptor. Nesses casos, o dispositivo que atua como receptor e emissor é chamado de transdutor. Todo o processo de controle da fonte acústica e de gravação dos dados é gerenciado a partir de computadores instalados no interior da embarcação, que também são responsáveis pelo armazenamento dos dados.

\subsubsection{Fundamentos da PSC}

Uma das formas básicas de transferência de energia mecânica de um local a outro se dá por meio de ondas mecânicas, entre as quais se encontram as ondas sísmicas. Para a formação dessas ondas deve existir uma fonte que ocasione uma perturbação, um meio onde essa perturbação atua e uma conexão física entre partículas adjacentes desse meio (Robinson, 2008). 
Na PSC, o meio em questão é composto por diferentes camadas de sedimentos ou rochas, mais a lâmina d'água. É aqui onde uma fonte acústica provoca as oscilações iniciais das partículas em torno da sua posição de equilíbrio, de tal forma que essas oscilações se propagam de partícula em partícula através de todo o meio, transportando a perturbação inicial e, em consequência, transportando energia cinética.

Nos estudos que envolvem a sísmica, as ondas (especificamente, pulsos sonoros) são geradas por uma fonte controlada. Essas ondas se propagam em subsuperfície e algumas delas retornam à superfície após serem refletidas e/ou refratadas nas diferentes interfaces geológicas do substrato. Essas ondas que retornam à superfície são registradas por instrumentos que captam o movimento do solo, caso os sensores estejam nele afixados, ou no caso de sensores na coluna d'água, são registradas variações de pressão e, dessa maneira, são registrados os tempo de chegada das ondas emitidas pela fonte. Conhecendo-se a velocidade de propagação das ondas, esses tempos de chegada podem ser convertidos em valores de profundidade/espessura de camadas geológicas.

\subsubsection{Esforço e deformação}

Quando um corpo é submetido à ação de forças externas, aparecem em seu interior forças proporcionais às atuantes sobre ele. O esforço é uma medida da intensidade dessas forças e, considerando uma força $\vec{F}$ atuando sobre uma área $\vec{A}$ da superfície do corpo, o esforço é definido com a razão $\vec{F} / \vec{A}$. Esse esforço pode ser decomposto em uma componente normal à

superfície $\vec{A}$ (esforço normal), e em uma segunda componente sobre a superfície $\vec{A}$ (esforço de cisalhamento) (Telford, 1990).

Todo corpo submetido a um esforço sofre uma deformação proporcional ao esforço aplicado, dentro do limite elástico (Lei de Hooke (Lowrie, 2011)). Até esse ponto, o corpo retoma a sua forma e volume originais ao cessar ou esforço. Se o limite elástico for ultrapassado, a razão entre esforço e deformação deixa de ser linear e o corpo já não recupera as suas características originais quando cessam os esforços. Se os esforços forem ainda mais intensos, pode ser atingido o limiar de quebra (Figura 3). Na sísmica, as deformações produzidas no meio em regiões afastadas da fonte são extremamente pequenas e estão sempre dentro do limite elásticos dos materiais. 


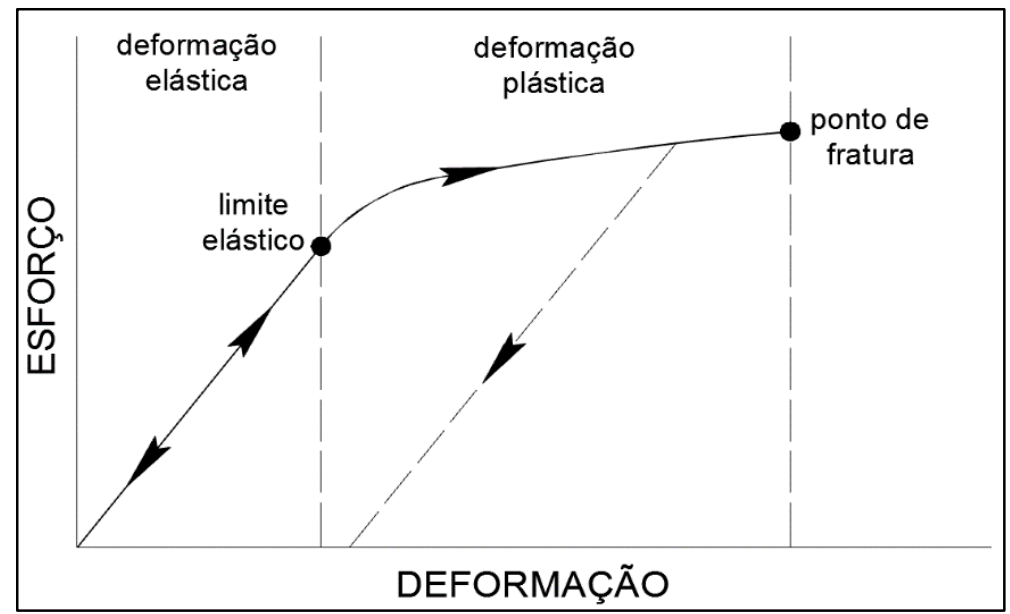

Figura 3. Curva típica de esforço-deformação para um corpo sólido.

Dados um determinado esforço e sua deformação resultante, existe uma relação linear definida pelo módulo elástico correspondente. Assim, consideremos uma barra de comprimento $l$ e seção transversal $A$ sobre a qual atua um esforço $F$, ocasionando uma extensão $\Delta l$, a grandeza que define a relação é o Módulo de Young $E$ (Figura 4).

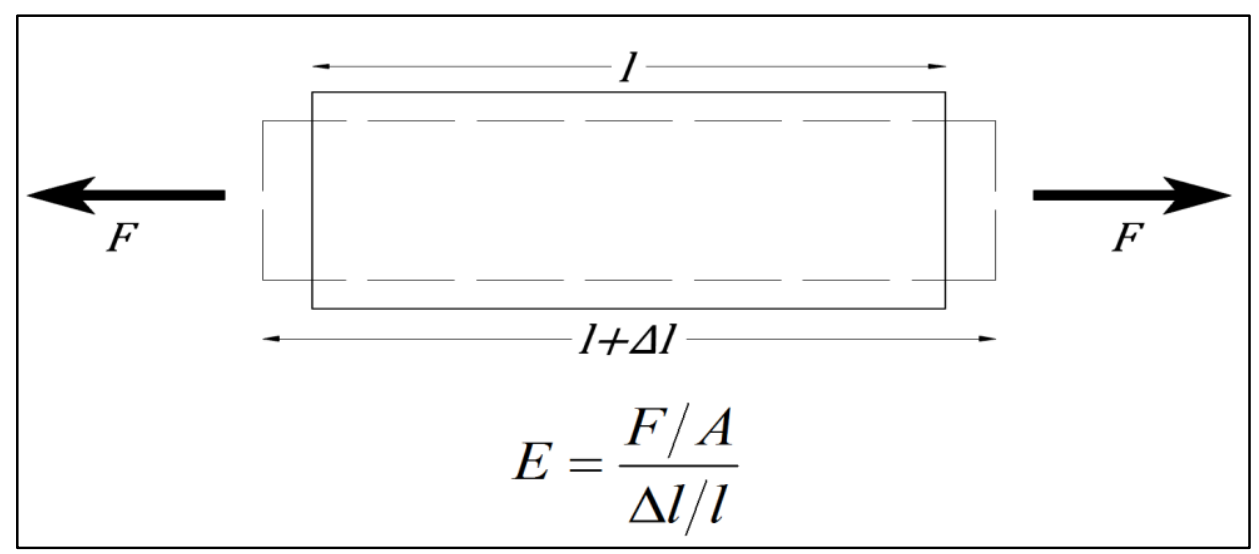

Figura 4. Módulo de Young.

No modelo da Figura 4 observa-se que ao mesmo tempo que o corpo sofre extensão em um direção, contrai na direção perpendicular. A razão entre a deformação lateral e a longitudinal recebe o nome de razão de Poisson $(\sigma)$. 
No caso de um corpo submetido a esforços em condições hidrostáticas, o mesmo não sofre deformação, senão apenas variação de volume $\Delta V$, e a razão entre o esforço $P$ e a diferença de volume dele resultante chama-se módulo volumétrico $K$ (Figura 5).

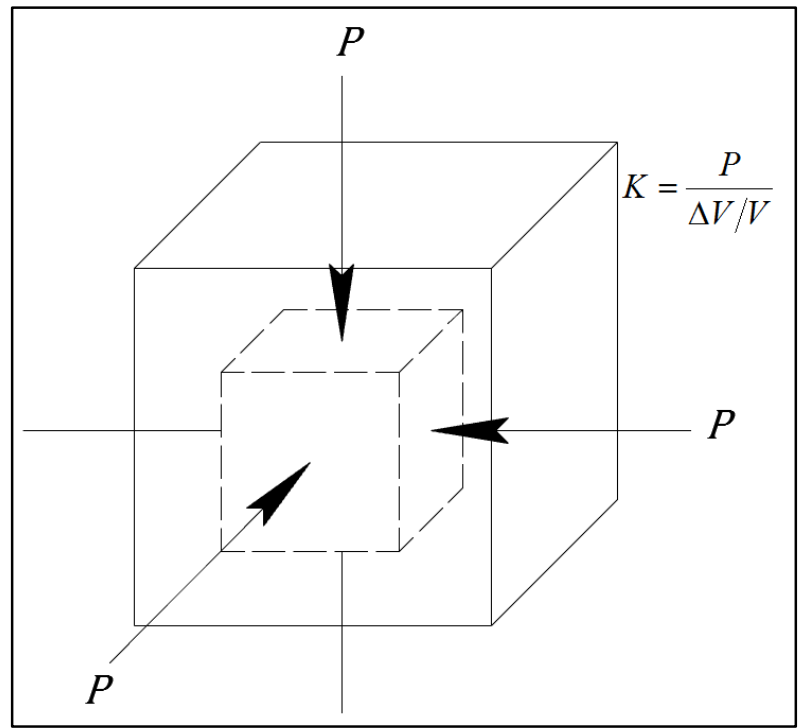

Figura 5. Módulo volumétrico.

Analogamente, o módulo de cisalhamento $(\mu)$ é definido com a razão entre os esforço de cisalhamento $(\tau)$ e a deformação resultante $(\tan \theta)$ (Figura 6).

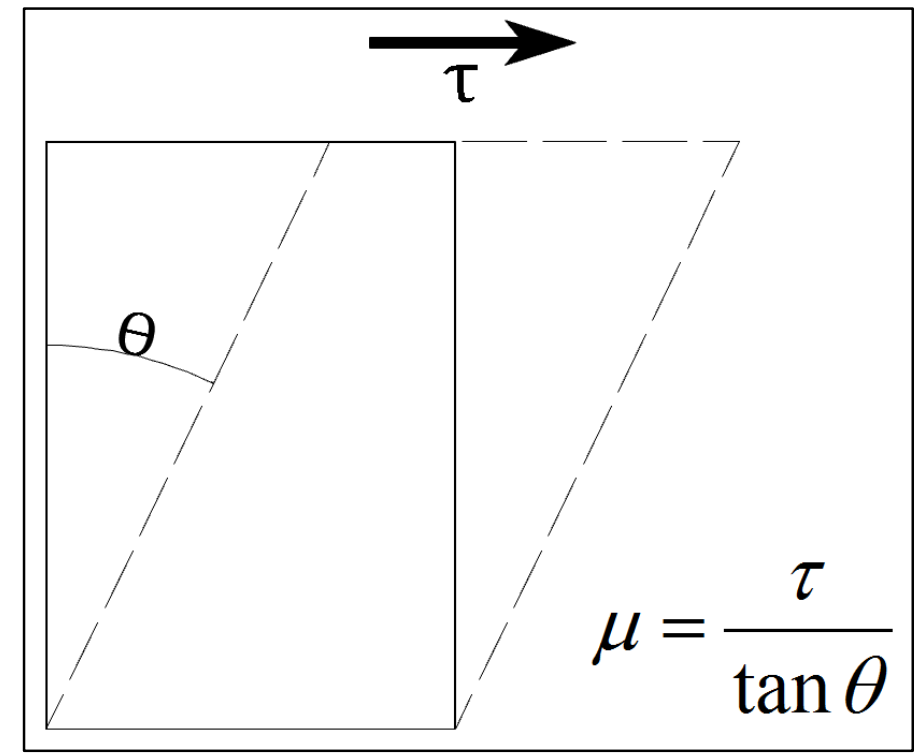

Figura 6. Módulo de cisalhamento. 
Um corpo submetido a um esforço $F$ pode sofrer apenas deformação na direção longitudinal de ação do esforço. Nesse caso, a razão entre o esforço e a deformação resultante chama-se módulo de deformação axial $\psi$ (Figura 7).

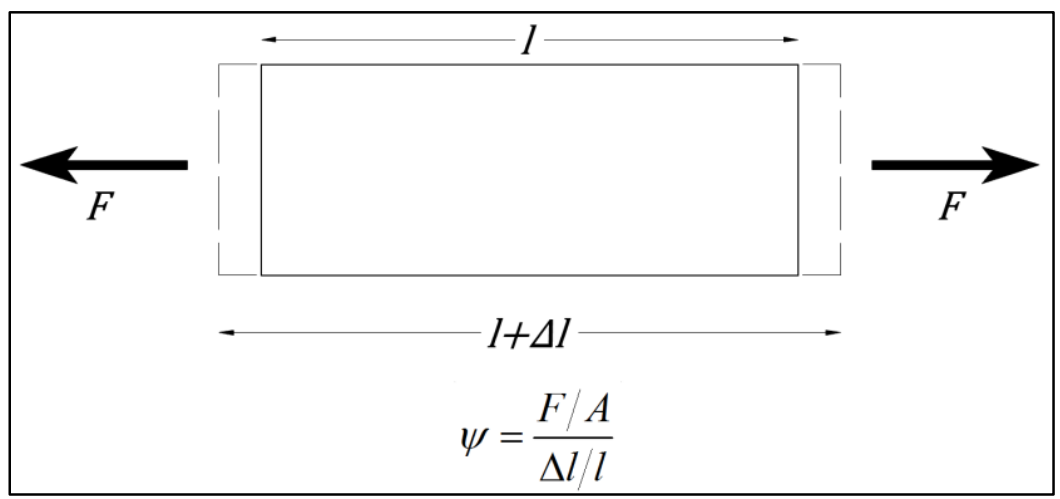

Figura 7. Módulo de deformação axial.

\subsubsection{Tipos de ondas sísmicas}

Ondas sísmicas são pequenos pacotes de energia de deformação elástica que se propagam a partir da fonte com velocidade determinada pelos módulos elásticos do meio e pela sua densidade. Existem dois tipos principais de ondas sísmicas: as ondas de corpo, que se propagam por todo o volume do meio, e as ondas de superfície, que se propagam pela interface entre meios de diferentes propriedades elásticas.

Por sua vez, as ondas de corpo subdividem-se em dois tipos conforme a deformação do meio, relativa à direção de propagação das ondas: ondas compressivas ou longitudinais, e ondas de cisalhamento ou transversais (Figura 8). 


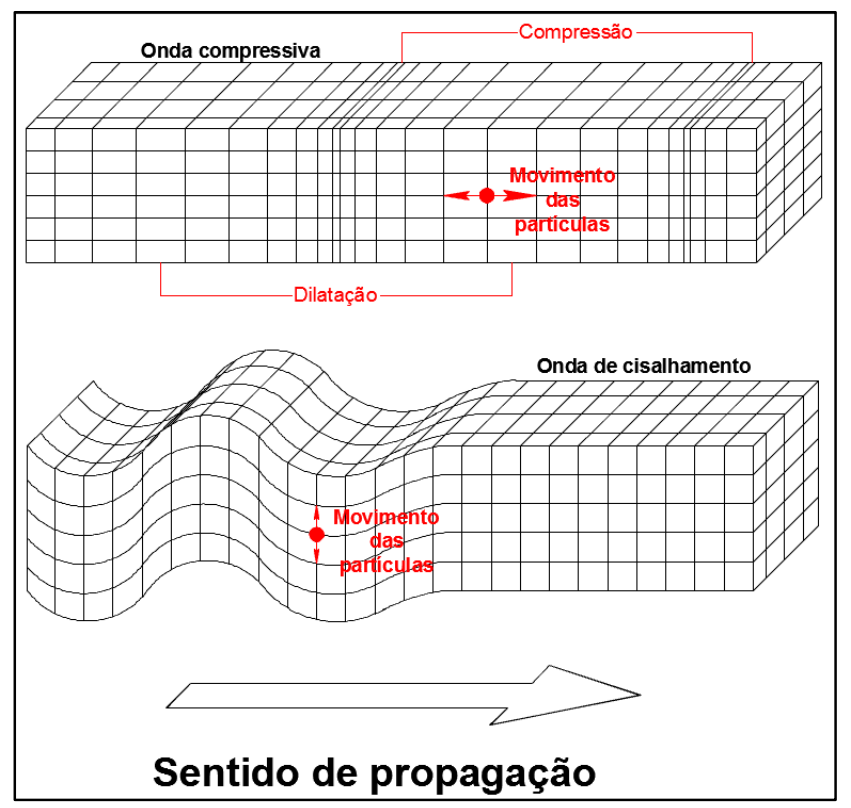

Figura 8. Deformação elástica e movimento de partícula relacionados à passagem de ondas de corpo.

\subsubsection{Velocidade de ondas sísmicas}

A velocidade de propagação de toda onda de corpo em um meio homogêneo e isotrópico é função da densidade do meio e do módulo elástico correspondente. Assim, a velocidade de propagação $v_{p}$ de uma onda de corpo compressiva que envolve deformação uniaxial do meio é dada pela seguinte expressão:

$$
v_{p}=\sqrt{\psi / \rho}
$$

A velocidade $v_{s}$ das ondas de corpo de cisalhamento vem definhada por:

$$
v_{s}=\sqrt{\mu / \rho}
$$

Da equação (2) deduz-se que as ondas de cisalhamento não se propagam em fluidos, já que o módulo de cisalhamento $\mu$ é nulo nesses meios (os fluidos não oferecem resistência aos esforções de cisalhamento).

Uma vez que os módulos elásticos depende de propriedades intermoleculares, é de se esperar que esses parâmetros não sejam sensíveis a variações de pressão. No entanto, o mesmo não pode ser esperado da densidade, que aumenta junto com a pressão. Dessa forma, a partir das equações (1) e (2), poder-se-ia pensar que à medida que aumenta o valor do numerador, 
com o aumento da profundidade de soterramento dos materiais, a velocidade tenderia diminuir. Porém, isto é exatamente o oposto ao observado na natureza.

Rochas sedimentares e sedimentos diferem de materiais sólidos homogêneos em um aspecto fundamental, que é que os primeiros possuem estrutura granular com espaços vazios entre os grãos - porosidade - e é ela o fator determinante na velocidade de propagação das ondas de corpo.

\subsubsection{Reflexão e transmissão em meios estratificados}

No caso de levantamentos acústicos marinhos, as ondas sonoras carregam uma certa quantidade de energia que é medida mediante um dispositivo chamado hidrofone, o qual mede as oscilações da pressão durante a passagem da onda. O tamanho dessa oscilação é a amplitude da onda.

Consideremos uma onda compressiva de amplitude $A_{0}$ incidindo de forma normal sobre a interface entre dois meios - 1 e 2 - de velocidade de propagação $v_{1}$ e $v_{2}$ densidade $\rho_{1}$ e $\rho_{2}$ respectivamente, uma onda de amplitude $A_{2}$ que se propaga pelo meio 2 no mesmo sentido de $A_{0}$ e uma terceira onda de amplitude $A_{1}$ que retorna pelo mesmo caminho de $A_{0}$ (Figura 9).

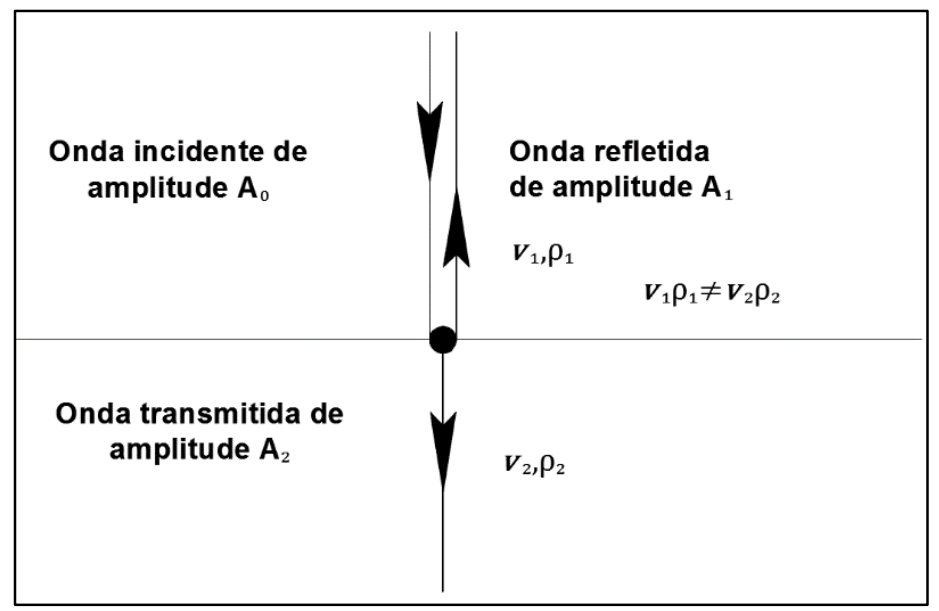

Figura 9. Raios refletidos e incidentes associados a incidência normal de uma onda compressiva.

O total de energia transmitida e refletida é igual à energia incidente, e a partição da energia na interface é determinada pelo contraste de impedância acústica $Z$ entre os meios. A 
impedância acústica é o produto da densidade $\rho$ do meio pela velocidade de propagação de ondas compressivas $v$ :

$$
Z=\rho v
$$

O contraste de impedância acústica determinará a fração de energia que será transmitida para as camadas mais profundas, e a que será refletida de volta para a superfície.

O coeficiente de reflexão $R$ é uma medida do efeito de uma interface na propagação de ondas e é calculado como a razão entre a amplitude da onda refletida $A_{1}$ e da incidente $A_{0}$ :

$$
R=\frac{A_{1}}{A_{0}}
$$

Para o caso de incidência normal, o coeficiente de reflexão pode ser escrito como

$$
R=\frac{\rho_{2} v_{2}-\rho_{1} v_{1}}{\rho_{2} v_{2}+\rho_{1} v_{1}}=\frac{Z_{2}-Z_{1}}{Z_{2}+Z_{1}}
$$

analogamente, o coeficiente de transmissão $T$ é a razão entre a amplitude da onda transmitida $A_{2}$ e da incidente $A_{0}$ :

$$
T=\frac{A_{2}}{A_{0}}
$$

que para o caso de incidência normal pode ser escrito em função da impedância acústica como:

$$
T=\frac{2 Z_{1}}{Z_{2}+Z_{1}}
$$

Nos casos extremos de $R=1$ ou -1 , tem-se que toda a energia incidente é refletida na interface, como o caso aproximado da interface água-ar. Valores típicos de $R$ raramente ultrapassam $\pm 0,2$, portanto, a maior parte da energia é transmitida para o substrato.

\subsubsection{Fontes e receptores}

Existe uma classificação de fontes sísmicas, feita por Verbeek \& McGeee (1995), que distingue duas categorias básicas de fontes de energia: ressonantes e impulsivas. Outros autores optam por chamá-las de fontes de forma de onda controlada e subdividem as impulsivas em aceleração de massa de água, explosivas e implosivas. 
As fontes ressonantes são aquelas cuja geração do sinal é feita por meio de um cristal piezelétrico que, ao se contrair e expandir repetidamente, cria um pulso de pressão sinusoidal com uma frequência condicionada pela frequência de ressonância do cristal. $\mathrm{O}$ chirp é uma fonte que funciona segundo esse princípio e o sinal gerado é chamado convencionalmente de pulsos de sonar.

Os dados analisados no presente trabalho foram adquiridos mediante o uso de um chirp. Consiste em um perfilador teoricamente capaz de fornecer uma resolução vertical em escala de decímetros (Quinn et al., 1998). A principal característica que destaca o chirp das outras fontes ressonantes é a sua forma de emissão: consiste em pulsos de frequência modulada (FM) que fazem uma "varredura" em diferentes intervalos de frequência, obtendo-se assim uma largura de banda necessária para alcançar a resolução temporal teoricamente prevista (Mosher \& Simpkin, op cit.). 


\subsection{Método da eletrorresistividade}

Uma das propriedades físicas dos materiais mais utilizadas para investigar as características dos solos, rochas e sedimentos, é a condutividade elétrica e seu inverso, a resistividade.

Existem três mecanismos principais de condução elétrica nos materiais em subsuperfície:

I. Condução eletrônica

Na superfície terrestre, este mecanismo de condução pode ser observado em materiais que possuem elétrons livres, como é o caso dos sulfetos metálicos.

II. Condução iônica ou eletrolítica

Neste mecanismo, os portadores de corrente são íons presentes na água intersticial que se movimentam através dos poros dos sedimentos, dos solos e das rochas. É notadamente a forma de condução dominante na maioria dos ambientes.

Pelo fato do transporte de corrente ser feito por meio de moléculas que têm excesso ou deficiência de elétrons, a resistividade varia em função da mobilidade, concentração e grau de dissociação dos íons.

III. Condução dielétrica

Esta forma de condução pode ser observada em materiais pobremente condutores, em que há poucos portadores de carga livre ou eles são inexistente. $\mathrm{Na}$ presença de um campo elétrico externo, os elétrons são levemente deslocados com relação ao núcleo do átomo. Esse desbalanceamento produzido entre cargas positivas e negativas, conhecido como polarização dielétrica, produz um tipo de corrente chamada corrente de deslocamento.

Mais detalhes sobre os mecanismos de condução elétrica podem sem encontrados em Orellana, 1972, Teldford et. al, 1990 e Reynolds, 1997. Alguns valores de resistividade de materiais terrestres e sedimentos marinhos são apresentados na Tabela 1.

Tabela 1. Valores típicos de resistividade em materiais terrestres e marinhos (Reynolds, 1997; Boyce, 1968)

\begin{tabular}{|c|c|c|c|c|c|c|c|c|c|}
\hline Material & Granito & Basalto & Gabro & Arenito & Folhelho & Argila & Aluvião & $\begin{array}{c}\text { Sedimentos } \\
\text { Marinhos } \\
\text { (argilas) }\end{array}$ & $\begin{array}{c}\text { Água } \\
\text { intersticial }\end{array}$ \\
\hline $\begin{array}{l}\text { Resistividade } \\
\text { (Ohm.m) }\end{array}$ & $10^{2}-10^{6}$ & $\begin{array}{c}10- \\
1,3 \times 10^{7}\end{array}$ & $10^{3}-10^{6}$ & $1-7,4 \times 10^{8}$ & $20-2 \times 10^{3}$ & $1-10^{2}$ & $10-8 \times 10^{2}$ & $0,29-0,58$ & $1,6-3,0$ \\
\hline
\end{tabular}


O método eletrorresistivo faz uso de fontes artificiais de corrente elétrica, a qual é injetada no terreno por meio de um par de eletrodos denominados A e B (Figura 10), ao mesmo tempo que um segundo par de eletrodos denominados $\mathbf{M}$ e $\mathbf{N}$ mede a diferença de potencial entre eles, na vizinhança do fluxo de corrente. Como o valor da corrente injetada também é conhecido, é possível conhecer a resistividade aparente $\left(\rho_{\mathrm{a}}\right)$, que é dada pela equação (8)

$$
\rho_{a}=K \frac{\Delta V}{I}
$$

onde $K$ (constante geométrica) é um coeficiente que depende das dimensões do quadripolo AMNB.

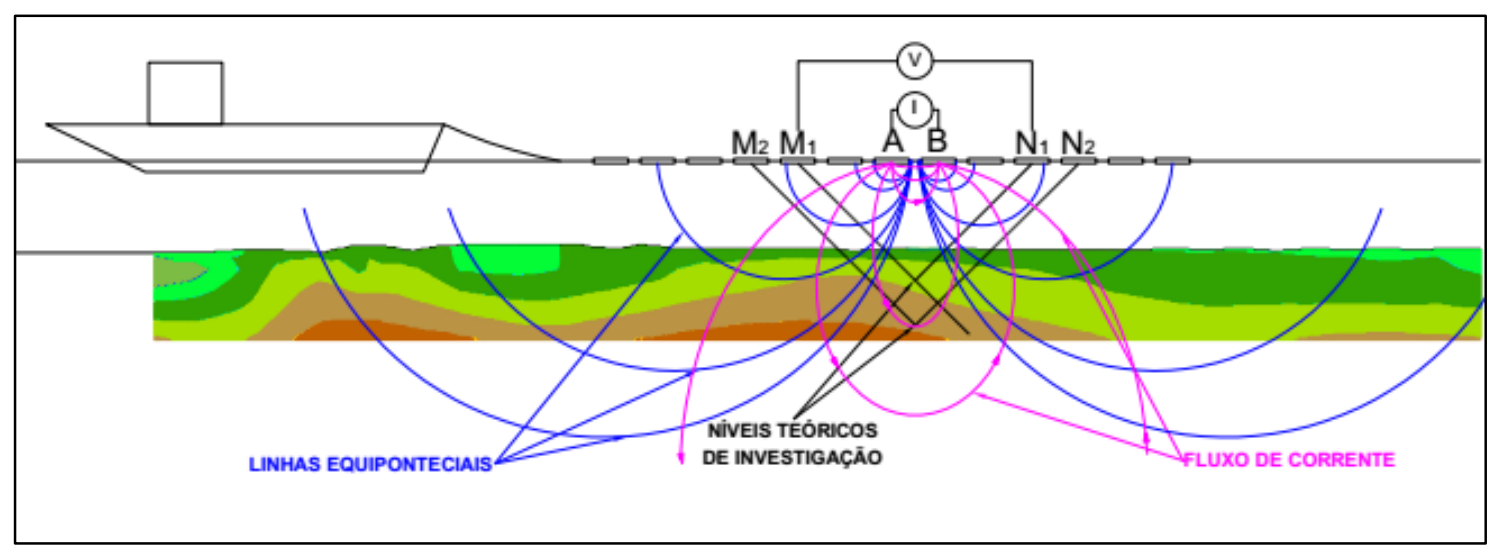

Figura 10: Esquema conceitual do princípio de funcionamento do método eletrorresistivo. Os eletrodos $A B$ injetam corrente, enquanto os eletrodos $\mathrm{MN}$ efetuam a leitura da diferença de potencial estabelecida entre eles.

O efeito de injetar corrente no terreno (assumindo um meio homogêneo e isotrópico), é o estabelecimento de um campo elétrico $\vec{E}$ que pode ser escrito como:

$$
\vec{E}=-\nabla V
$$

onde $\mathrm{V}$ é o potencial elétrico e $\nabla$ o operador gradiente.

Seja $\vec{J}$ a densidade de corrente dada em $A / m^{2}$. Pela lei de Ohm, a densidade de corrente $\vec{J}$ e o campo elétrico $\vec{E}$ se relacionam da seguinte maneira:

$$
\vec{J}=\sigma \vec{E}
$$

onde $\sigma$ é a condutividade elétrica do meio. Combinando as equações (6) e (7) temos que:

$$
\vec{J}=-\sigma \vec{\nabla} V
$$

Pela Lei de Ampère sabe-se que: 


$$
\nabla \times H=\vec{J}+\frac{\delta D}{\delta t}
$$

onde $D$ é a corrente de deslocamento.

O divergente do rotacional é igual a 0 , portanto

$$
\vec{\nabla} \cdot(\nabla \times H)=\nabla \cdot\left(\vec{J}+\frac{\delta D}{\delta t}\right)=\vec{\nabla} \cdot \vec{J}+\frac{\delta}{\delta t}(\nabla \cdot \mathrm{D})=0
$$

Como o divergente da densidade de corrente é equivalente à taxa de variação da densidade de carga, usando a equação. (13) podemos escrever:

$$
\vec{\nabla} \cdot \vec{J}=-\frac{\delta Q}{\delta t}=-\frac{\delta}{\delta t}(\vec{\nabla} \cdot D) \therefore \vec{\nabla} \cdot D=Q
$$

Em regiões de continuidade finita e condições estacionárias (não há acúmulo nem perda de carga), $Q=0$, dessa forma temos que

$$
\vec{\nabla} \cdot \vec{J}=0
$$

então, pela equação. (11)

$$
\vec{\nabla} \cdot(\sigma \vec{\nabla} V)=0 \rightarrow \vec{\nabla} \sigma \cdot \vec{\nabla} V+\sigma \nabla^{2} V=0
$$

Como o meio é isotrópico e homogêneo, $\sigma$ é constante. Dessa maneira, o primeiro termo da equação (16) é igual a 0 , portanto

$$
\nabla^{2} V=0
$$

que é a equação de Laplace. Isto significa que na presença de uma fonte pontual de corrente, em regiões afastadas da fonte onde o campo elétrico é conservativo, o potencial elétrico obedece à equação de Laplace.

Consideremos o circuito formado por um eletrodo A enterrado em um meio homogêneo e isotrópico e um segundo eletrodo B na superfície do terreno suficientemente afastado como para desconsiderar seus efeitos sobre o campo elétrico (Figura 11). 


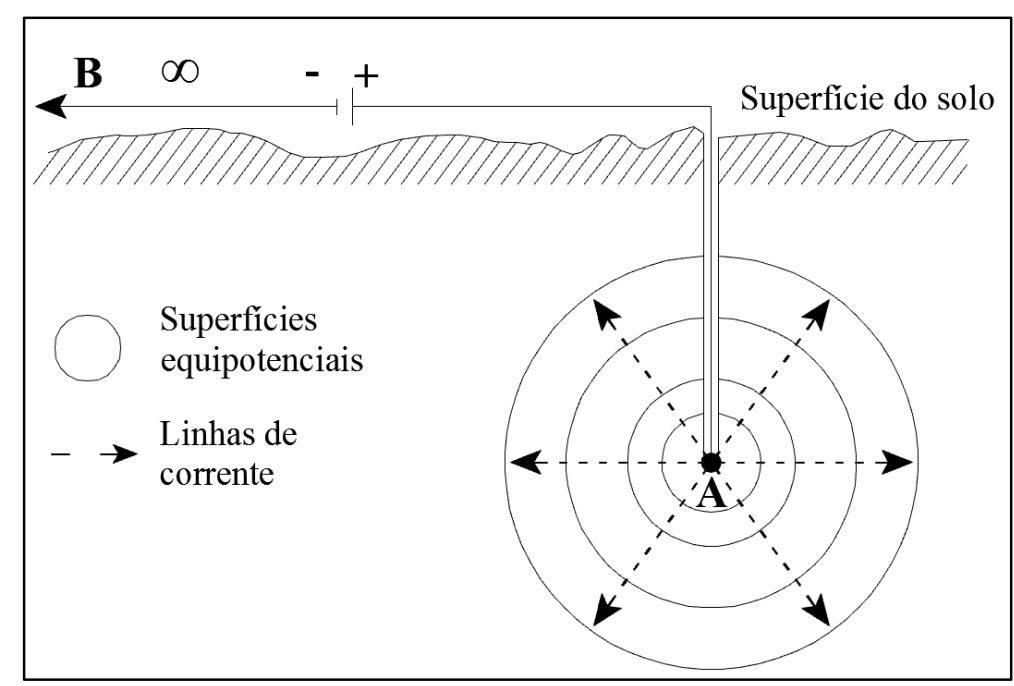

Figura 11. Fonte pontual em meio homogêneo e isotrópico. Modificado de Telford et al., 1990.

Escrevendo a equação (17) em coordenadas esféricas temos:

$$
\nabla^{2} V=\frac{1}{r^{2}} \frac{\delta}{\delta r}\left(r^{2} \frac{\delta V}{\delta r}\right)+\frac{1}{r^{2} \operatorname{sen} \theta} \frac{\delta}{\delta \theta}\left(\sin \theta \frac{\delta V}{\delta \theta}\right)+\frac{1}{r^{2} \operatorname{sen}^{2} \theta} \frac{\delta^{2} V}{\delta \phi^{2}}=0
$$

Pela simetria do problema, os termos dependentes de $\theta$ e $\phi$ se cancelam, restando o termo que depende de $r$

$$
\frac{1}{r^{2}} \frac{\delta}{\delta r}\left(r^{2} \frac{\delta V}{\delta r}\right)=0
$$

Esse resultado só é possível se o termo entre parêntesis for constante, então

$$
r^{2} \frac{\delta V}{\delta r}=A
$$

Integrando ambos os membros da equação (20) temos que

$$
V=-\frac{A}{r}+B
$$

As constantes $A$ e $B$ são definidas em função das condições de contorno. Uma delas depende da definição de potencial elétrico, que determina que o potencial é nulo quando $r$ tende a infinito, portanto, $B$ deve ser nula. A outra constante é determinada calculando a corrente que flui a partir de uma fonte pontual. 
Sabendo que o mio e isotrópico e homogêneo, a densidade de corrente $\vec{J}$ deve ser uniforme medida sobre uma superfície esférica Scentrada na fonte pontual. Assim a corrente elétrica $I$ pode ser expressa como:

$$
I=\int \vec{J} \cdot d \vec{s}
$$

que pela Lei de Ohm

$$
\int \vec{J} \cdot d \vec{s}=\int \sigma \vec{E} \cdot d \vec{s}
$$

Como o campo elétrico é o gradiente do potencial e pela equação (20):

$$
\int \sigma \vec{E} \cdot d \vec{s}=\int \frac{\sigma A}{r^{2}} \cdot d \vec{s}=\frac{\sigma A}{r^{2}} \int \vec{n} \cdot d \vec{s}=-4 \pi \sigma A
$$

Lembrando que a resistividade é o inverso da condutividade, temos que:

$$
I=-4 \pi \sigma A=\frac{-4 \pi A}{\rho}
$$

Resolvendo esta equação e substituindo o valor de $A$ na equação (21) chegamos a:

$$
V=\frac{I \rho}{4 \pi r}
$$

que é o potencial devido a uma fonte pontual.

A Figura 12 ilustra o caso de uma fonte pontual colocada na superfície do terreno. Nessa configuração temos uma situação em que o semiespaço superior pode ser considerado perfeitamente isolante (ar). Dessa maneira, as linhas de corrente fluem somente pelo semiespaço inferior de resistividade $\rho$ e o potencial terá a seguinte expressão:

$$
V=\frac{I \rho}{2 \pi r}
$$




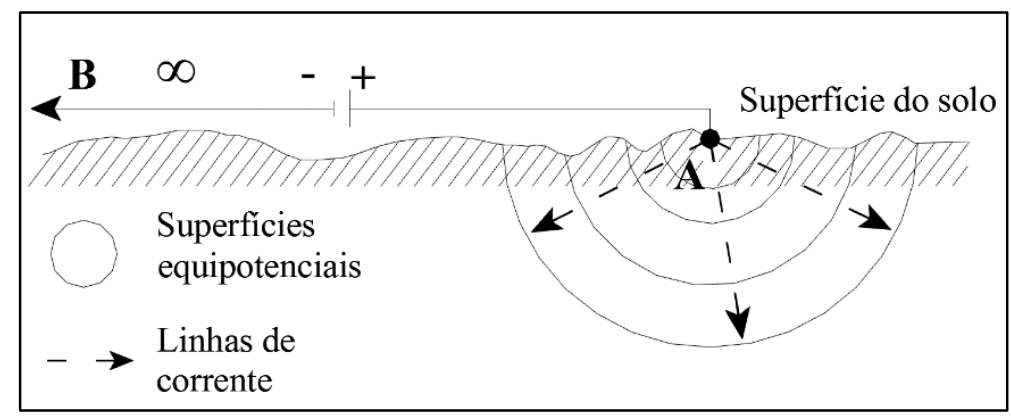

Figura 12. Fonte pontual de corrente situada na superfície de um semiespaço homogêneo e isotrópico. Modificado de Telford et al., 1990.

Por ser uma grandeza escalar, o potencial pode ser somado de forma algébrica. Dessa forma, o potencial medido em um ponto será a superposição das contribuições de cada uma das fontes, consideradas de forma independente. Ou seja, para $n$ fontes distribuídas na superfície de um semiespaço isotrópico e homogêneo, o potencial medido em um ponto $M$ será:

$$
V_{M}=\frac{I \rho}{2 \pi}\left[\frac{I_{1}}{r_{1}}+\frac{I_{2}}{r_{2}}+\cdots+\frac{I_{n}}{r_{n}}\right]
$$

Para aplicar esse resultado na realidade do campo, observemos o arranjo esquematizado na Figura 13. Pelo princípio de superposição, o potencial nos pontos $M$ e $N$ é dado por:

$$
\begin{aligned}
& V_{M}=\frac{I \rho}{2 \pi}\left[\frac{1}{r_{1}}-\frac{1}{r_{2}}\right] \\
& V_{N}=\frac{I \rho}{2 \pi}\left[\frac{1}{r_{3}}-\frac{1}{r_{4}}\right]
\end{aligned}
$$

Porém, nos levantamentos de campo é medida a diferença de potencial entre os eletrodos $M$ e $N$. Dessa forma temos que:

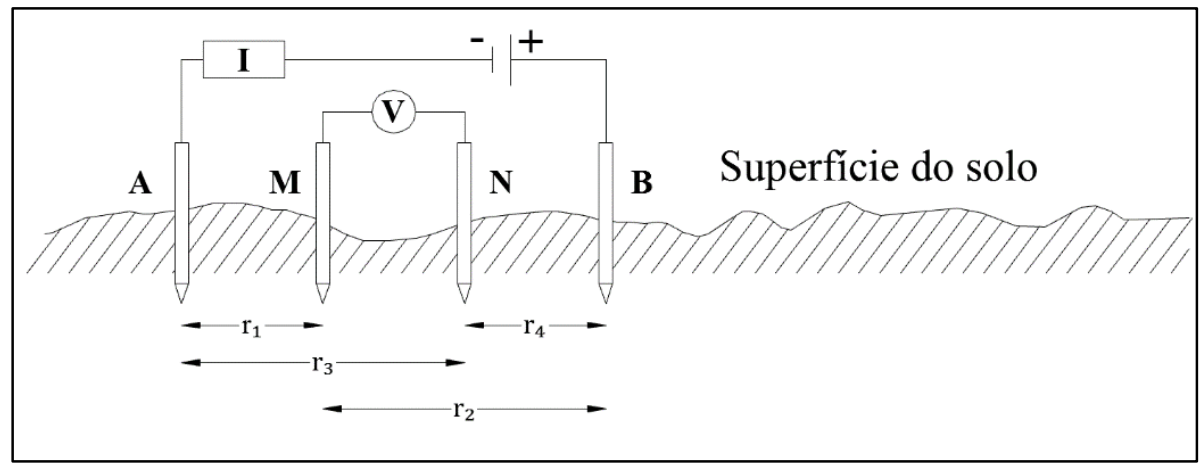

Figura 13. Arranjo para aquisição de dados de eletrorresistividade. A corrente circula entre os dipolo A-B e a tensão é medida entre os eletrodos M-N. 


$$
V_{M}-V_{N}=\frac{I \rho}{2 \pi}\left[\frac{1}{r_{1}}-\frac{1}{r_{2}}-\frac{1}{r_{3}}+\frac{1}{r_{4}}\right]=\frac{I \rho}{2 \pi}\left[\frac{1}{A M}-\frac{1}{B M}-\frac{1}{A N}+\frac{1}{B N}\right]=\Delta V
$$

isolando a resistividade:

$$
\rho=2 \pi \frac{\Delta V}{I}\left[\frac{1}{A M}-\frac{1}{B M}-\frac{1}{A N}+\frac{1}{B N}\right]^{-1}
$$

O fator geométrico $K$ é definido por:

$$
K=2 \pi\left[\frac{1}{A M}-\frac{1}{B M}-\frac{1}{A N}+\frac{1}{B N}\right]
$$

chegando assim à definição de resistividade aparente da equação (8)

$$
\rho=K \frac{\Delta V}{I}
$$

\subsection{Arranjo Schlumberger reverso ou recíproco}

No Imageamento Geoelétrico bidimensional, o arranjo é deslocado na mesma linha do alinhamento dos eletrodos, mantendo-se constante a distância entre cada um dos elementos que compõem o arranjo.

O emprego desta técnica permite mensurar variações de resistividade elétrica em diferentes níveis de profundidade definidos pelo espaçamento entre os eletrodos. $\mathrm{O}$ arranjo utilizado no presente estudo foi o Schlumberger reverso, ou recíproco como também é conhecido. Este arranjo se caracteriza por uma alta sensibilidade a variações verticais de resistividade.

A escolha do arranjo foi baseada na observação, durante a aquisição, das seções de campo (Figura 14) que mostravam pouca variação da resistividade com a profundidade. Sua disposição geométrica é apresentada na Figura 15. 


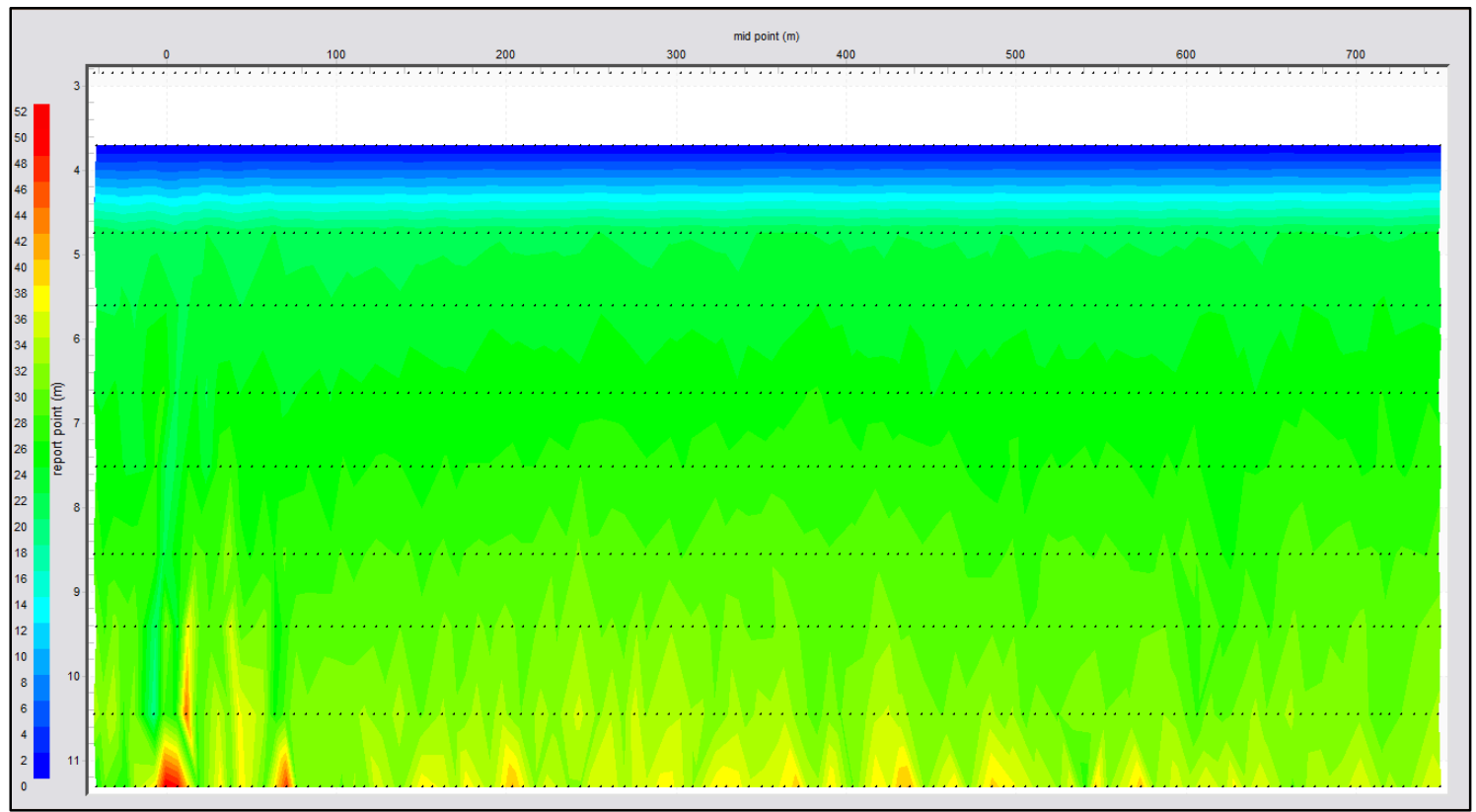

Figura 14: Seção de campo. Este é o tipo de pseudoseção de resistividade observada durante a aquisição dos dados.

No arranjo Schlumberger reverso esquematizado na Figura 15, observa-se que enquanto o espaçamento entre os eletrodos responsáveis pela injeção de corrente (AB) permanece constante, são feitas sucessivas trocas de pares de eletrodos MN, até atingir o máximo nível de investigação previsto. A profundidade de investigação cresce com a distância $\mathrm{MN}$ e teoricamente corresponde a MN/4.

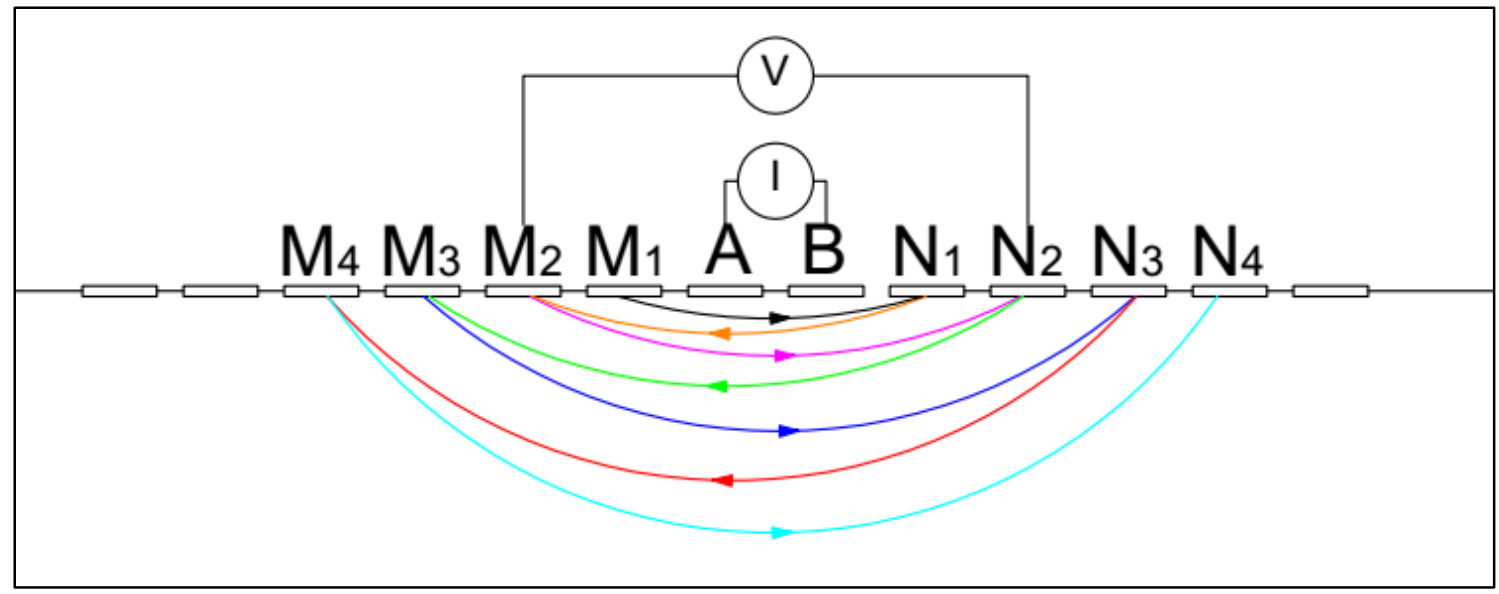

Figura 15: Diagrama do arranjo de eletrodos Schlumberger reverso. Os eletrodos de injeção de corrente AB permanecem estáticos com relação aos eletrodos de leitura de potencial MN.

As setas coloridas na Figura 15 indicam como é executada a sequência de medidas, conforme as seguintes combinações de quadripolos: 
$\mathrm{AB} \mathrm{M}_{2} \mathrm{~N}_{2}$

$\mathrm{AB} \mathrm{N}_{2} \mathrm{M}_{3}$

$\mathrm{AB} \mathrm{M}_{3} \mathrm{~N}_{3}$

Informações adicionais sobre arranjos de eletrodos podem ser encontradas em Gandolfo (2007).

Cada sequência de medições foi realizada em um intervalo de $250 \mathrm{~ms}$, tempo durante o qual é aplicada a corrente através do dipolo AB. A cada $5 \mathrm{~m}$ de avanço contínuo do arranjo, essa série de medidas é repetida, obtendo-se a amostragem do espaço representada pelos pontos da Figura 16.

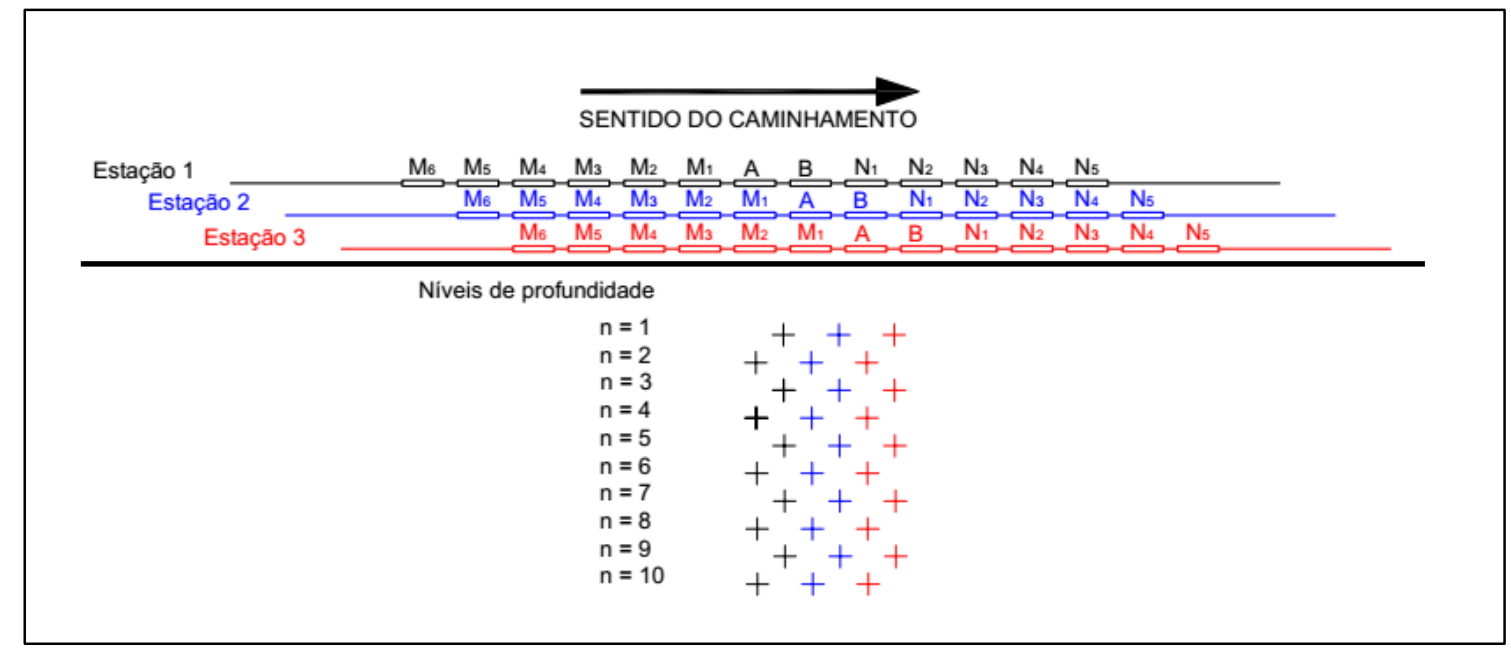

Figura 16: Representação esquemática dos pontos amostrados em subsuperfície, por meio da execução de um caminhamento elétrico. As cruzes indicam os pontos teóricos de leitura de resistividade aparente.

As seções elétricas obtidas por caminhamento elétrico também são chamadas de pseudoseções (Figura 17).

A denominação de pseudoseção é escolhida porque as medições feitas em cada nível de investigação não representam valores reais de resistividade elétrica, mas o efeito integrado do semiespaço sobre o qual é feita a medida. A resistividade aparente somente é igual à resistividade real em um modelo de terra homogênea. 


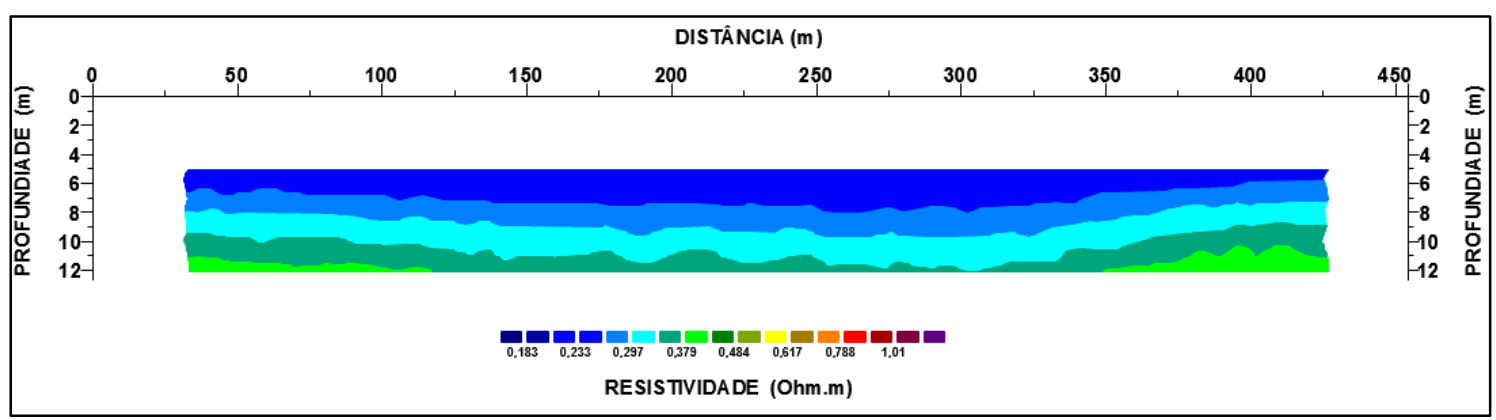

Figura 17: Pseudoseção de resistividade. A resistividade aparente varia de 0,183 a 0,373 Ohm.m

\subsection{Aquisição de dados}

Serão apresentados dados coletados em quatro campanhas. A primeira foi realizada no mês de fevereiro de 2009, quando foram adquiridos cerca de $27 \mathrm{~km}$ de perfis sísmicos. Em janeiro de 2014, foi realizado um segundo levantamento acústico cobrindo a mesma área da campanha prévia, mas sobre uma malha mais densa (Benites et al, 2015). A terceira e última campanha sísmica teve lugar no mês de junho de 2014, ficando restrita apenas ao SM. Finalmente, em meados de abril de 2015 foi feita a aquisição geoelétrica. A Figura 18 mostra a cobertura dos levantamentos que compreenderam uma extensão total de aproximadamente 200 km de linhas sísmicas e $53 \mathrm{~km}$ de linhas de eletrorresistividade. 


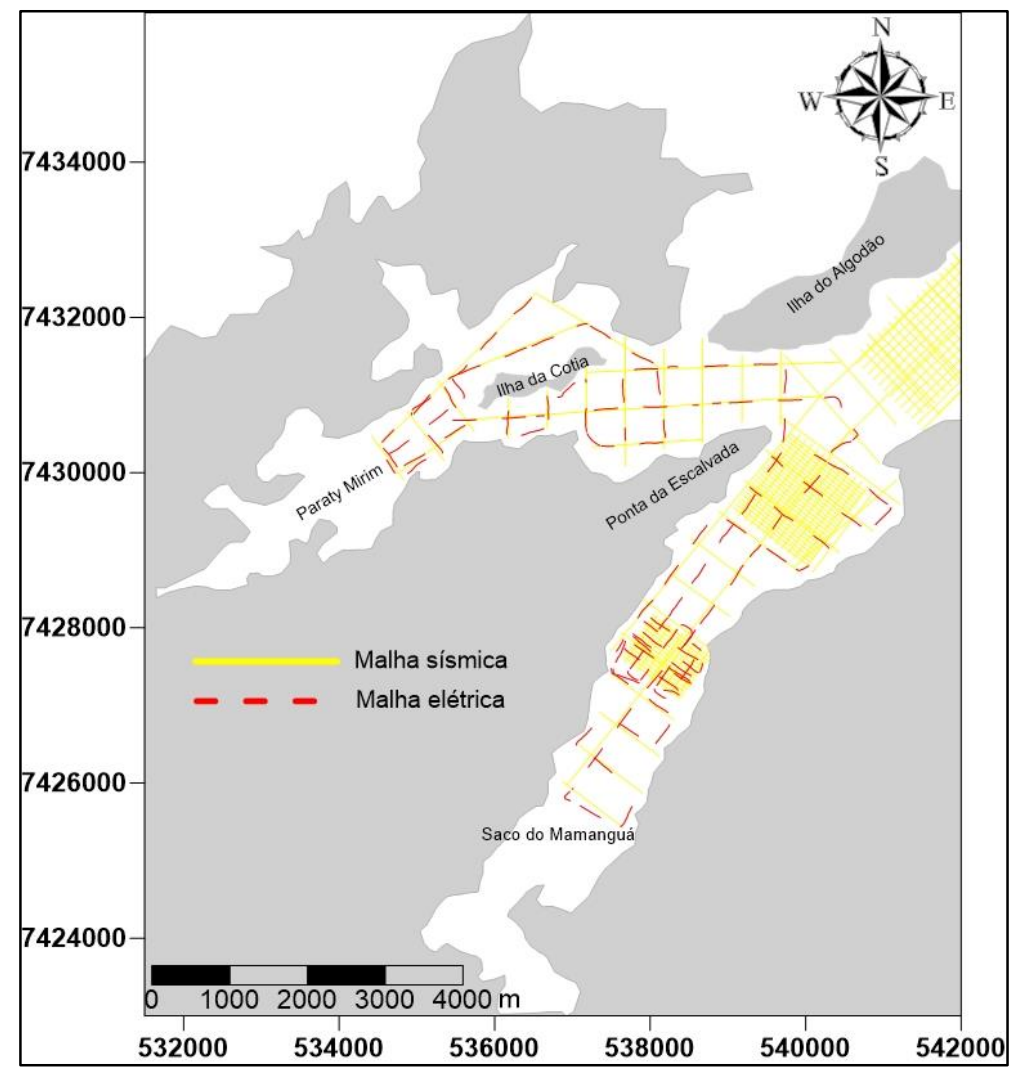

Figura 18: Mapa da área de estudo mostrando a malha de aquisição sísmica (amarelo) e a malha de aquisição de dados de eletrorresistividade (vermelho).

\subsubsection{Sísmica}

Os perfis sísmicos foram adquiridos com uma fonte chirp modelo Meridata 2-9 kHz, fixada na borda da embarcação (Figura 19) e gerenciada pelo programa de aquisição Meridata MDCS 5.2. Uma desvantagem da utilização de fontes acústicas desse tipo é a pouca disponibilidade de ferramentas de processamento do sinal, limitando-se à aplicação de ganho para corrigir o efeito de atenuação por espalhamento geométrico e pela absorção, e à aplicação de algum filtro de remoção de ruídos aleatórios.

O processamento foi feito por meio do programa Meridata MDPS 5.2 e o posicionamento, determinado com o uso de GPS modelo Hemisphere R131, com correção diferencial. 


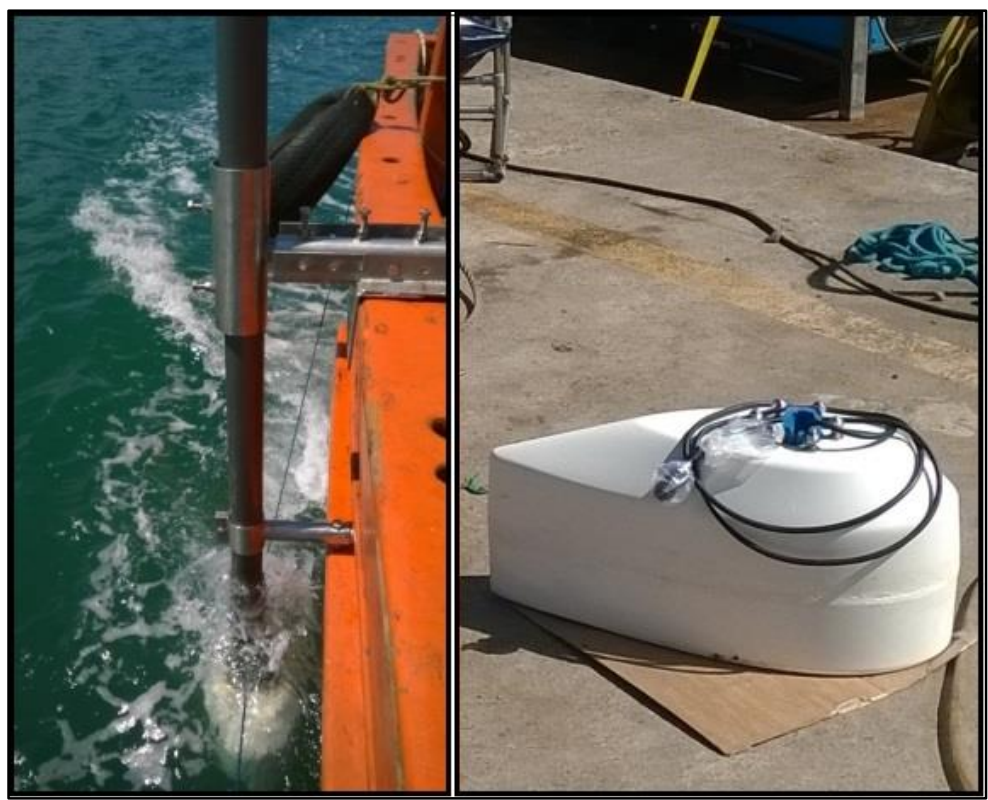

Figura 19: Esquerda, chirp fixado na borda da embarcação; direita, carenagem de proteção do transdutor.

\subsubsection{Resistividade}

Os dados de eletrorresistividade foram adquiridos rebocando na superfície da água um cabo multieletrodos constituído por 13 eletrodos espaçados em $5 \mathrm{~m}$ (Figura 20). Os eletrodos foram configurados no arranjo Schlumberger reverso (Figura 15). Com esta configuração foi possível atingir uma profundidade máxima de investigação de 11,5 m abaixo da superfície da água. 


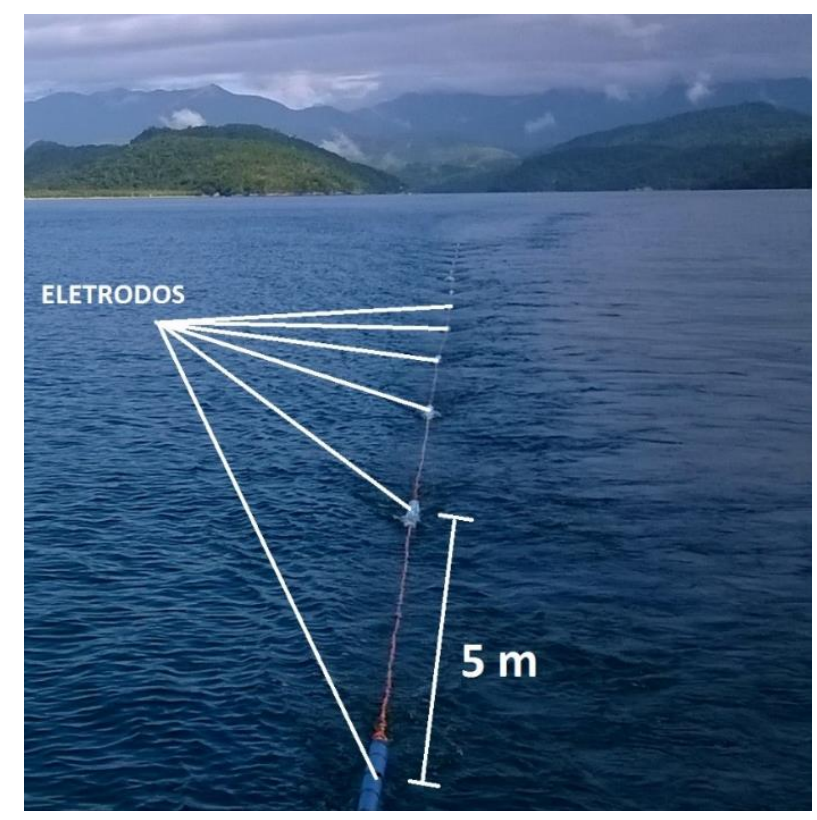

Figura 20: Cabo multieletrodos rebocado na superfície da água.

O cabo multieletrodos foi ligado a um eletrorresistivímetro Syscal Switch Pro, fabricado pela IRIS Instruments (Figura 21), integrado a um sistema de posicionamento DGPS Hemisphere R131 e um ecobatímetro de dupla frequência (50 e 200 kHz) Garmin GPSMAP 298.

Os dados de resistividade, posição e profundidade foram integrados por meio do programa Sysmar da IRIS Instruments, o qual permite também a observação em tempo real da pseudoseção de resistividade elétrica (Figura 14).

Um pulso de corrente de 250 ms de duração e de aproximadamente 1,7 A de intensidade de corrente, era injetado a cada $5 \mathrm{~m}$ de avanço contínuo do arranjo. $\mathrm{O}$ potencial entre o par de eletrodos $\mathbf{A B}$ foi de $12 \mathrm{~V}$ e a distância entre pulsos controlada por meio do cálculo automático em tempo real da distância percorrida, conforme a posição informada pelo DGPS. A velocidade de navegação foi mantida constante em $7 \mathrm{~km} / \mathrm{h}$. 


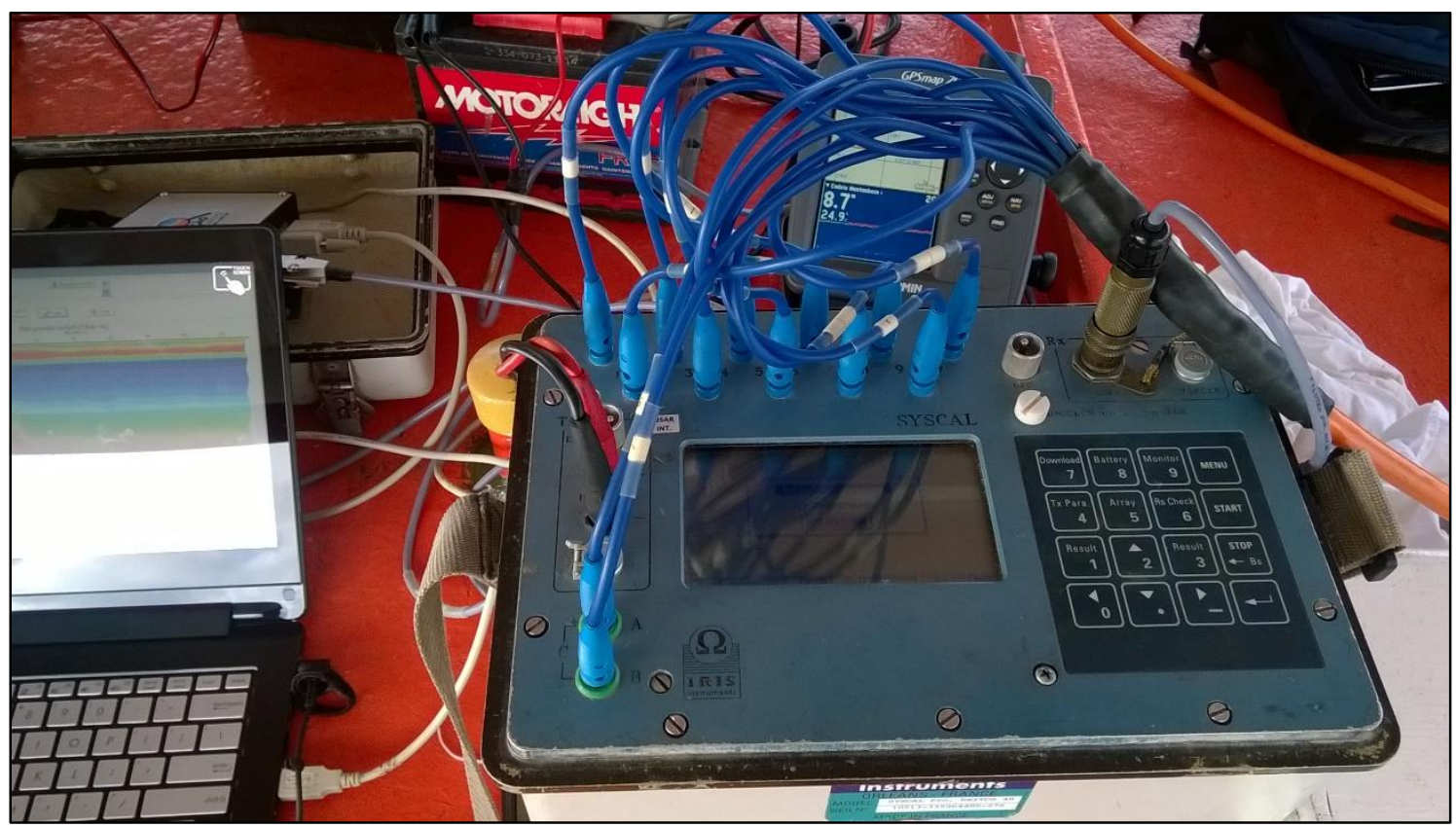

Figura 21: Eletrorresistivímetro Syscal Switch Pro.

\subsection{Inversão dos dados}

Visto que os materiais que compõem o subfundo são heterogêneos, tanto a resistividade quanto a profundidade das camadas geoelétricas são determinadas por meio do processo de inversão.

No presente trabalho foi utilizado o algoritmo RES2DINV - Geotomo Software, desenvolvido por Locke \& Barker (1996), e que se baseia na inversão por mínimos quadrados com vínculo de suavidade ("smoothness constrained least-squares inversion", Sasaki (1992)).

A seção invertida, chamada seção de imageamento geoelétrico (SIG), é o resultado de um processo iterativo no qual são minimizadas, em termos de mínimos quadrados, as diferenças entre valores de resistividade medidos e calculados.

Prévio à inversão propriamente dita, foi realizada a edição dos dados brutos visando a correção e possível eliminação de valores de resistividade menores ou iguais a zero, utilizando o programa Prosys II, da IRIS Instruments.

Como dito anteriormente, cada valor de resistividade aparente é o produto da contribuição da resistividade de cada uma das camadas geoelétricas atravessadas pelas linhas 
de corrente. Por esse motivo, mesmo que em uma interface entre dois meios exista uma variação abrupta de resistividade, esta será 'suavizada' pela influência da resistividade do restante do volume investigado. Dessa maneira, devem ser removidos os pontos cujo valor de resistividade for discrepante com relação ao dos seus vizinhos. A análise é visual e dependente da experiência de que interpreta os dados. Isto é feito manualmente no painel de edição do RES2DINV (Figura 22).

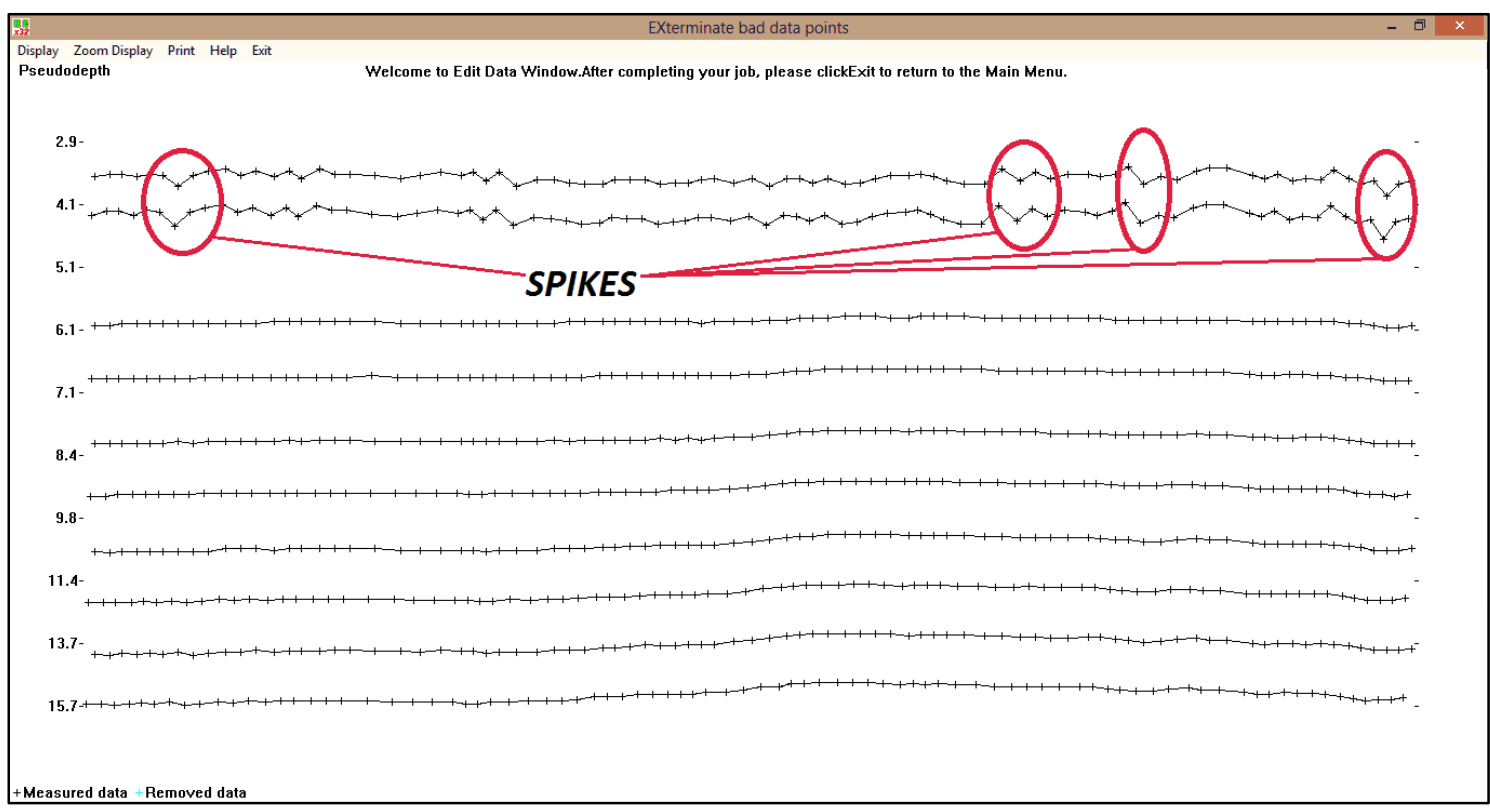

Figura 22: Painel de edição do RES2DINV mostrando dez níveis de investigação. Os pontos que apresentam variações abruptas de resistividade em um mesmo nível (spikes) são removidos.

Finalmente, para a execução da inversão, o semiespaço investigado deve ser 'discretizado' em uma matriz, de forma tal que a cada célula da matriz corresponda apenas um único ponto amostrado em subsuperfície, como exemplificado na Figura 23.

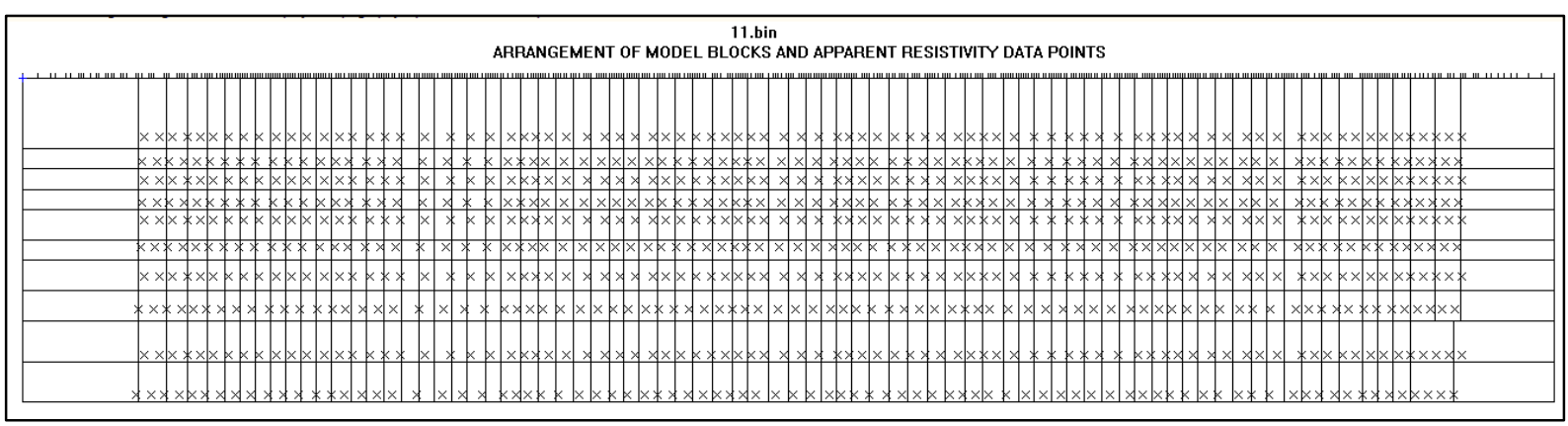

Figura 23: Matriz de discretização dos valores de resistividade aparente amostrados em subsuperfície. Idealmente, a cada célula da matriz corresponderá um único valor de resistividade aparente. 
Uma vez invertidas todas as pseudoseções de resistividade, foram geradas as SIGs utilizando uma escala de cores comum a todas (Figura 24).

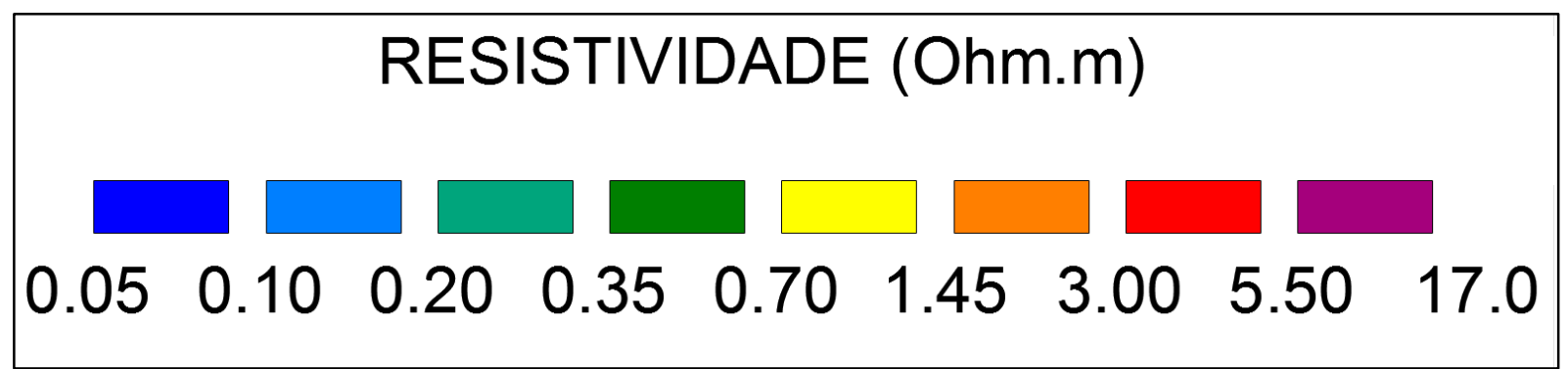

Figura 24: Escala de cores comum a todas as seções de imageamento elétrico. A resistividade elétrica varia de 0.05 Ohm.m, até 17 Ohm.m.

\subsection{Resistividade em testemunhos}

Para efetuar as medições, o testemunho foi dividido em 7 amostras de $6 \mathrm{~cm}$, sendo que cada seção foi ligada em suas extremidades a dois eletrodos de injeção de corrente (AB), de modo a ter contato direto com os sedimentos da amostra (Figura 25).

Foram praticados dois furos separados por $2 \mathrm{~cm}$, simetricamente localizados com relação à seção central de cada porta-amostra, para a inserção dos eletrodos de medição do potencial $(\mathrm{MN})$.

A aquisição dos dados para o cálculo da resistividade elétrica foi realizada através do equipamento SYSCAL-R2 no Laboratório de Instrumentação Geofísica do Instituto de Astronomia, Geofísica e Ciências Atmosféricas (IAG) da Universidade de São Paulo.

Foram utilizados eletrodos de aço inoxidável tanto para a injeção de corrente, quanto para a medição do potencial. 


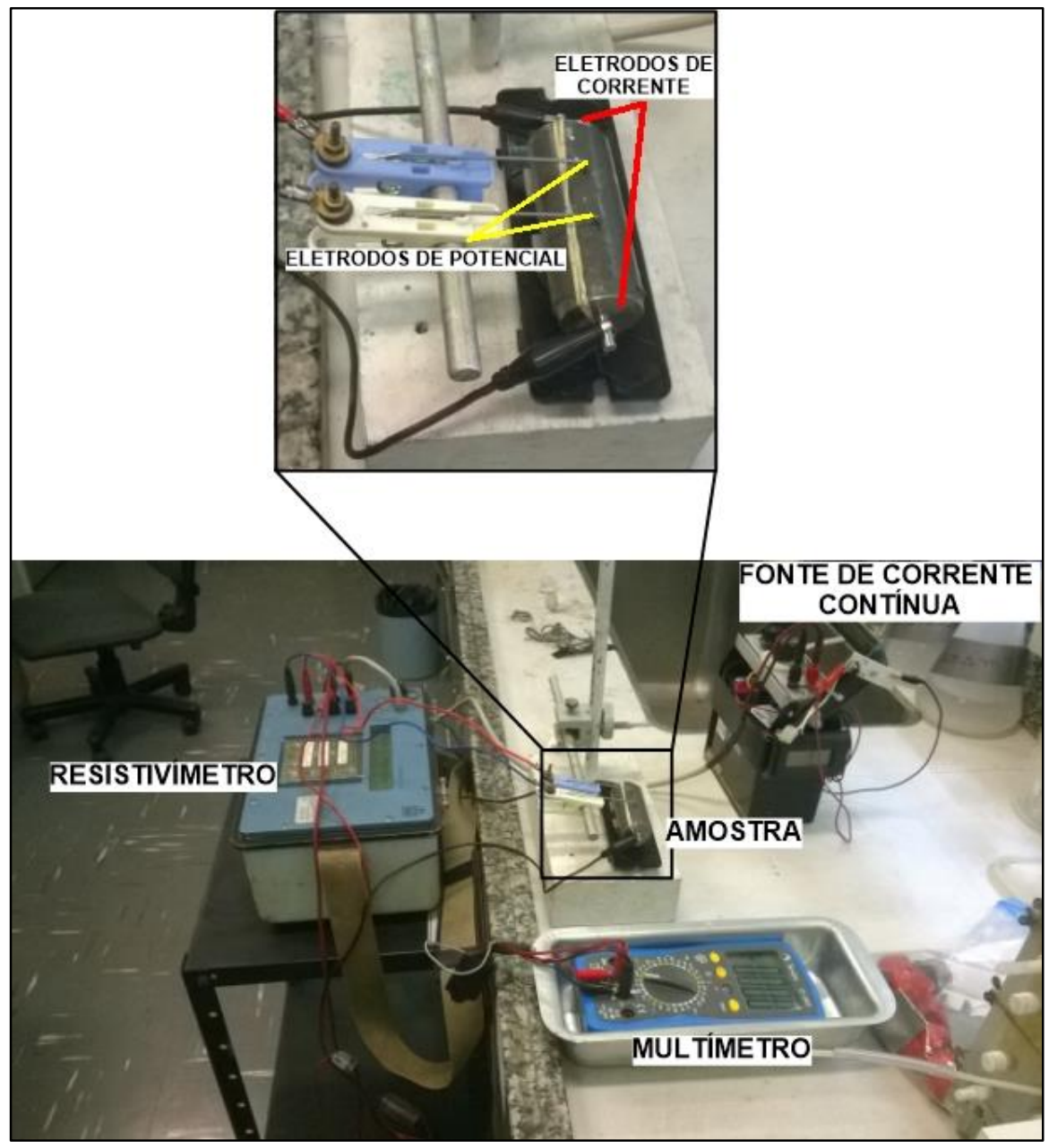

Figura 25 - Arranjo para medição da resistividade elétrica em amostras cilíndricas de sedimentos. O resistivímetro SYSCAL - R2 é utilizado tanto como comutador do sentido da corrente - para evitar que o meio seja polarizado- como para realizar a leitura do potencial entre os eletrodos MN

A partir dos dados de potencial e corrente elétrica foi calculado o valor de resistência elétrica $R$ dada pela seguinte equação:

$$
R=\frac{U}{I}
$$

onde $U$ é o potencial elétrico e $I$ a corrente.

Com o valor da resistência $R$, a resistividade $\rho$ da amostra é calculada por meio da equação 13

$$
\rho=\frac{R A}{L}
$$

onde $A$ é a área da seção transversal da amostra e $L$ a distância entre os eletrodos MN. 


\subsection{Susceptibilidade magnética}

A susceptibilidade magnética $\kappa$ é uma propriedade adimensional que fornece uma medida da capacidade dos materiais de serem magnetizados (Dunlop \& Özdemir, 1997), e é definida pela razão entre a magnetização induzida $M$ e o campo indutor $H$ (Equação 36).

$$
\kappa=\frac{M}{H}
$$

A equação acima representa a susceptibilidade por unidade de volume. A susceptibilidade magnética pode ser expressa como susceptibilidade normalizada pela massa $\chi$ e é obtida dividindo $\kappa$ pela densidade $\rho$ (Equação 37).

$$
\chi=\frac{\kappa}{\rho}
$$

As medidas de $\kappa$ são utilizadas em estudos de magnetismo ambiental devido a sua capacidade de fornecer informação relacionada com a ocorrência de minerais ferromagnéticos, diamagnéticos, paramagnéticos e superparamagnéticos, em uma amostra de material. Essa informação pode ser correlacionada com eventos deposicionais controlados por mudanças paleoclimáticas (Jovane et al., 2007; Jovane \& Verosub, 2011).

Foi medida a susceptibilidade magnética de 3 amostras do testemunho MAM07AT: topo, $33 \mathrm{~cm}$ e $93 \mathrm{~cm}$ de profundidade, mediante o uso de um susceptômetro Kappabridge MFK1-FA. O campo indutor aplicado foi de $200 \mathrm{Am}^{-1}$, de $976 \mathrm{~Hz}$ de frequência. Os valores de $\kappa$ foram normalizados pelo peso de cada amostra.

\subsection{Parâmetros que incidem na variação da resistividade}

Os testemunhos que estão disponíveis para medição direta da resistividade não atingem uma profundidade suficiente para correlacionar a variação da resistividade, principalmente, com a presença de gás e o teor de água do mar. Dessa forma, foi necessário realizar experimentos que permitissem analisar como esses parâmetros influenciam as medidas de resistividade, de modo a embasar a interpretação das seções geoelétricas com argumentos quantitativos. 


\subsubsection{Presença de gás}

A ocorrência de gás foi simulada por meio da inserção de miçangas de acrílico aproximadamente cilíndricas, que chamaremos genericamente de bolhas, na matriz da amostra (Figura 26). No total, foram adicionadas, 100 bolhas em 10 vezes de 10 bolhas cada, medindose a resistividade a cada passo. $\mathrm{O}$ volume total adicionado foi de $0,6 \mathrm{~cm}^{3}$.

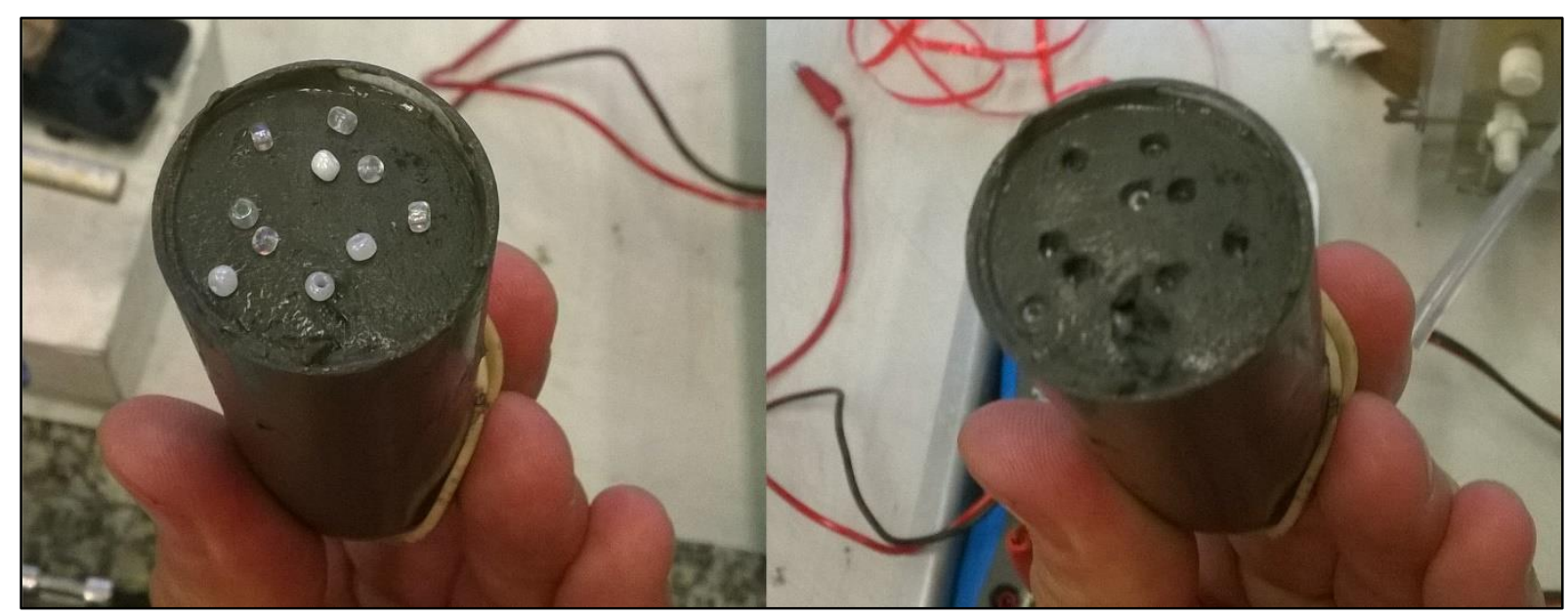

Figura 26: Adição de bolhas de acrílico na amostra, para simulação de bolhas de gás.

A profundidade de inserção das bolhas na matriz da amostra não tem como ser controlada com precisão suficiente, para garantir que todas fiquem no espaço definido entre os pontos de medição do potencial. Além disso, não haveria meios de assegurar que o furo produzido ao inserir a bolha fique completamente obturado, adicionando mais uma fonte de incerteza na medição do volume do espaço isolante.

Dessa forma, o potencial foi medido sobre os próprios eletrodos de injeção de corrente, nas extremidades do porta-amostra. Isso teve como consequência a aparição do efeito de duplacamada elétrica na interface entre os eletrodos e a amostra (Verwey \& Overbeek, 1948), falseando a medida do potencial e, por conseguinte, fazendo com que o valor de resistividade calculado diferisse do valor medido com os eletrodos no centro da amostra. Dessa maneira, os resultados desta experiência têm apenas valor qualitativo, sem que os valores de resistividade obtidos possam ser utilizados como valores de referência. 


\subsubsection{Influência da água do mar}

A experiência para avaliar a influência da água do mar consistiu na medição da resistividade e susceptibilidade magnética em três amostras que não foram alteradas pelo manuseio durante as medidas de resistividade iniciais, conforme o seguinte procedimento:

1. Medição da resistividade elétrica e susceptibilidade magnética da amostra inalterada;

2. Dispersão da amostra em 1,0 1 de água deionizada;

3. Centrifugação;

4. Medição da susceptibilidade magnética e medição de resistividade; 


\section{Resultados}

\subsection{Seções de campo}

Nesta seção são apresentados em forma conjunta as SIGs e os perfis sísmicos com os quais foram correlacionadas, assim como os resultados das análises e medidas feitas em laboratório.

Os resultados foram organizados em dois grupos correspondentes a dados coletados na EPM (linhas 01 a 13) e no SM (linhas 14 a 33) (Figura 27).

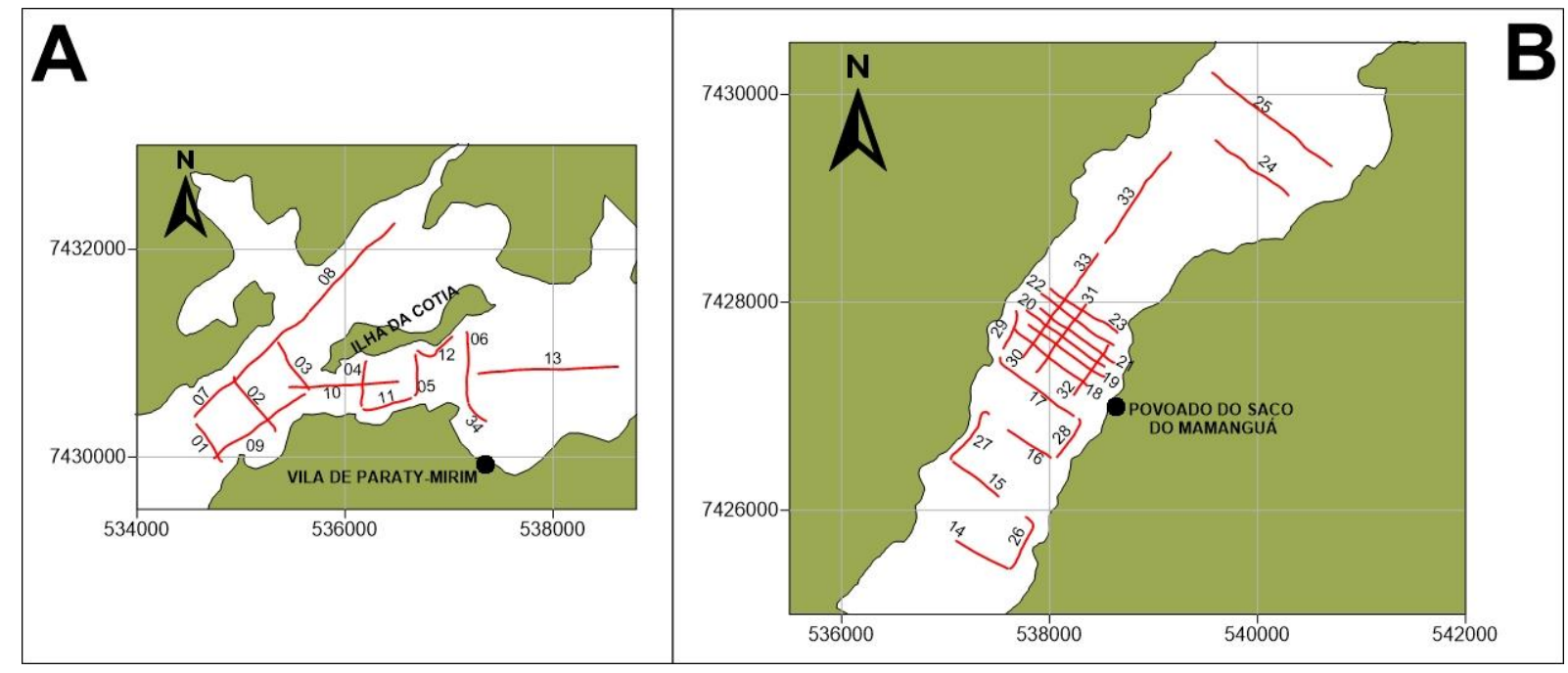

Figura 27: Localização das linhas analisadas: A - Enseada de Paraty-Mirim. B - Saco do Mamanguá.

A profundidade máxima de investigação do método elétrico foi de $11,5 \mathrm{~m}$, incluindo a lâmina d'água. Dessa forma, a espessura mapeada no pacote sedimentar variou de $1 \mathrm{~m}$ até $8 \mathrm{~m}$. Os valores de resistividade obtidos após a inversão oscilam entre 0,05 Ohm.m e 17 Ohm.m.

Em cada figura, as SIGs aparecem duplicadas, uma vez com a escala de cores da saída automática do programa de inversão RES2DINV, e outra vez com uma escala de cores simplificada e comum a todas as SIGs (Figura 24). Essa opção permite, por um lado, a análise seção por seção, de modo que seja possível observar variações internas de resistividade e, por outro, pode-se fazer uma comparação entre diferentes seções. Os perfis sísmicos estão alinhados com as SIGs de modo tal que a sobreposição seja o mais próxima possível da realidade. 
No mapa-chave ao pé de cada figura, aparecem em vermelho as linhas de navegação do levantamento geoelétrico, excetuando a linha correspondente ao perfil da figura, que aparece em azul.

A fim de facilitar a exibição numa mesma página tanto dos perfis sísmicos, quanto das SIGs, os perfis sísmicos foram truncados em torno de $15 \mathrm{~m}$ e $20 \mathrm{~m}$ de profundidade. Esse procedimento não compromete a interpretação das seções sísmicas, já que as únicas feições que podem ser observadas são aquelas associadas à ocorrência de gás, preservadas nos perfis sísmicos. As ocorrências de gás marcadas nas seções geoelétricas foram delimitadas por meio da correlação com os perfis sísmicos.

Devido à inexistência de sondagens diretas que alcancem profundidades comparáveis à investigada, e, consequentemente, à ausência de informação direta da coluna estratigráfica, a interpretação será feita de forma genérica em função de 'camadas geoelétricas', 'refletores sísmicos' e 'feições acústicas', cuja correlação com camadas litológicas ficará para etapas subsequentes de investigação, que ainda serão efetuadas na área de estudo.

De forma geral, as SIGs apresentam tendência ao aumento da resistividade com a profundidade. Observa-se a ocorrência de uma camada geoelétrica superior uniforme e de resistividade menor que $0.35 \mathrm{Ohm} . \mathrm{m}$, com pouca variação lateral e com base em torno de $9 \mathrm{~m}$ de profundidade. De forma análoga, os perfis sísmicos mostram um pacote sedimentar homogêneo - dentro da resolução do sistema utilizado - perturbado pela ocorrência de gás que se manifesta em plumas intrassedimentares, reflexões reforçadas e turbidez acústica. A espessura do pacote sedimentar acima do topo da camada de gás varia de 6 a $8 \mathrm{~m}$.

\subsubsection{Enseada de Paraty-Mirim}

A SIG L01 (Figura 28) é uma das poucas exceções ao padrão geral observado. Este perfil transversal ao canal representa o limite interno de investigação na EPM. Nessa área, a camada geoelétrica superior afina à medida que se aproxima da parte central e mais profunda do canal, analogamente ao que acontece em quase a totalidade dos perfis transversais. Porém, de forma contrária à norma observada, neste caso aparecem anomalias resistivas com bordas subverticais - apesar de não ter sido utilizada inversão robusta.

No perfil sísmico se observa a ocorrência de plumas intrassedimentares e turbidez acústicas acima do nível de base da SIG e algumas reflexões reforçadas na metade leste, abaixo 
de $12 \mathrm{~m}$ de profundidade. Não se observam estruturas sedimentares acima de $12 \mathrm{~m}$ de profundidade.

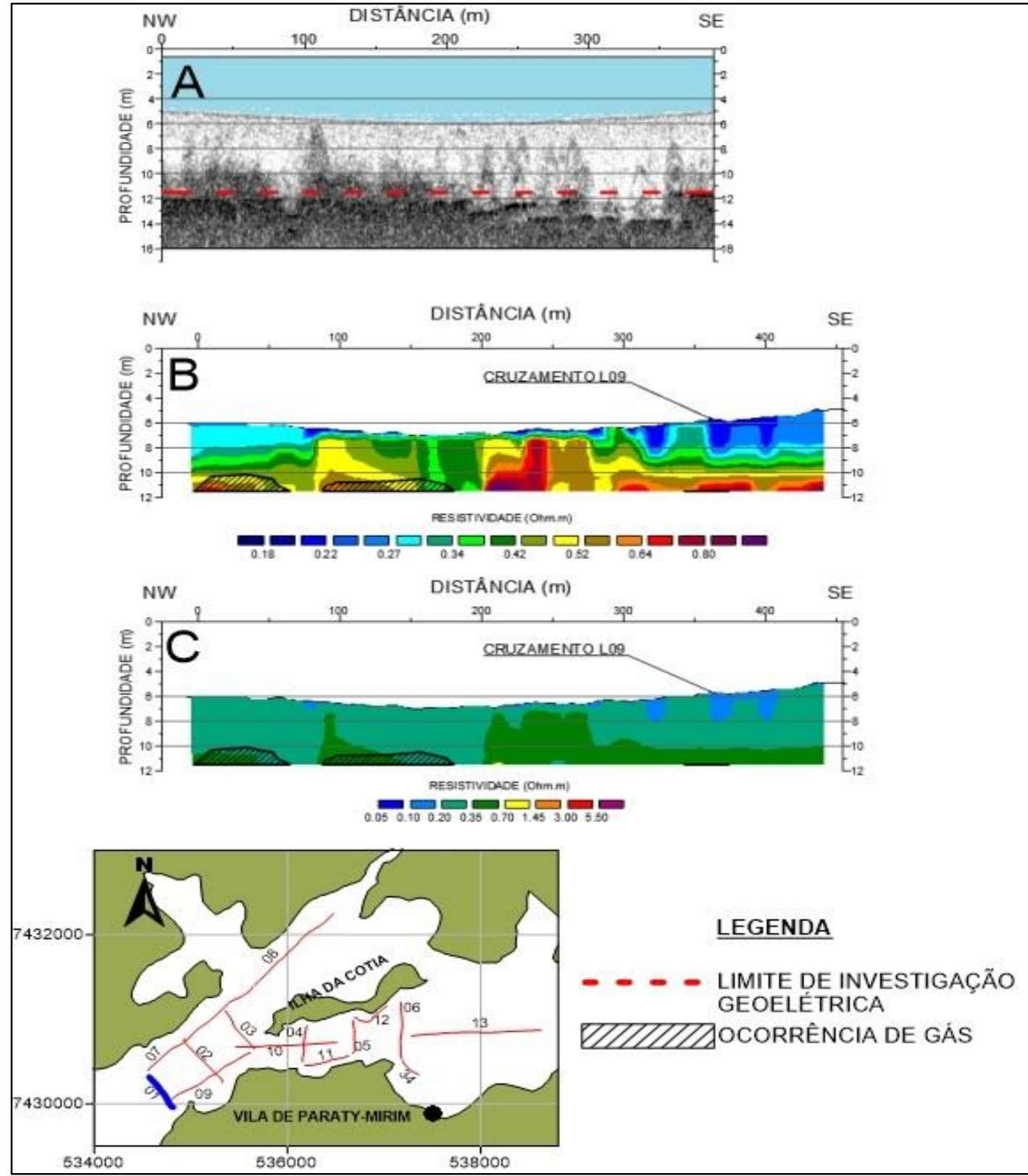

Figura 28: Perfil sísmico (A), SIG em escala de cores automática (B) e SIG em escala de cores comum (C), correspondentes à linha L01. Observa-se a ocorrência de um horizonte de gás em $12 \mathrm{~m}$ de profundidade e plumas de escape na coluna sedimentar. A SIG apresenta relativa heterogeneidade com importante variação lateral quando comparada com SIGs adjacentes. A camada superior mais condutiva é mais espessa nas extremidades da seção.

Apesar do perfil sísmico da L02 (Figura 29) apresentar características semelhantes às da L01, dos valores de resistividade das correspondentes SIGs estarem num mesmo intervalo e ocorrer o mesmo espessamento da camada mais condutiva nas porções mais rasas do perfil, na SIG L02 a variação da resistividade se manifesta mais num gradiente vertical do que lateral, 
sem a presença de anomalias relativamente abruptas. Ainda na SIG L02, a camada mais resistiva 'aflora' no ponto de cruzamento com a L09.

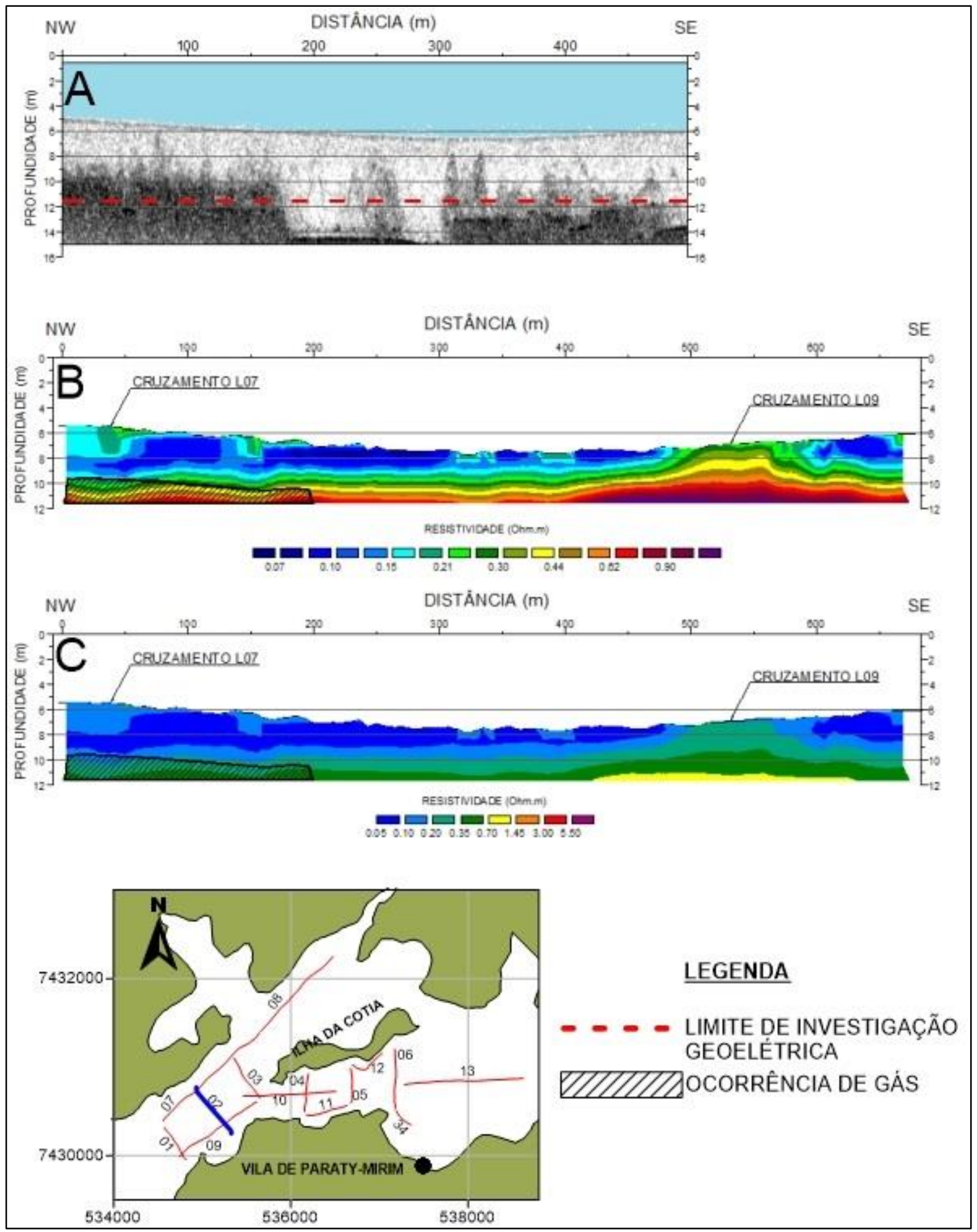

Figura 29: Perfil sísmico (A), SIG em escala de cores automática (B) e SIG em escala de cores comum (C), correspondentes à linha L02. Observa-se a ocorrência de uma cortina acústica abaixo de $10 \mathrm{~m}$ de profundidade e plumas de escape na coluna sedimentar. A SIG apresenta o padrão típico para esta área de aumento da resistividade com a profundidade e espessamento da camada mais condutiva nas extremidades da seção. 
O seguinte perfil transversal ao canal na enseada de Paraty-Mirim (Figura 30) segue o mesmo padrão que o da Figura 29, isto é, pacote sedimentar acusticamente homogêneo, ocorrência de uma camada superior menos resistiva e mais espessa nas áreas mais rasas. Observa-se também em ambas as figuras que o topo da cortina acústica coincide com a interface geoelétrica de 0,20 - 0,35 Ohm.m.

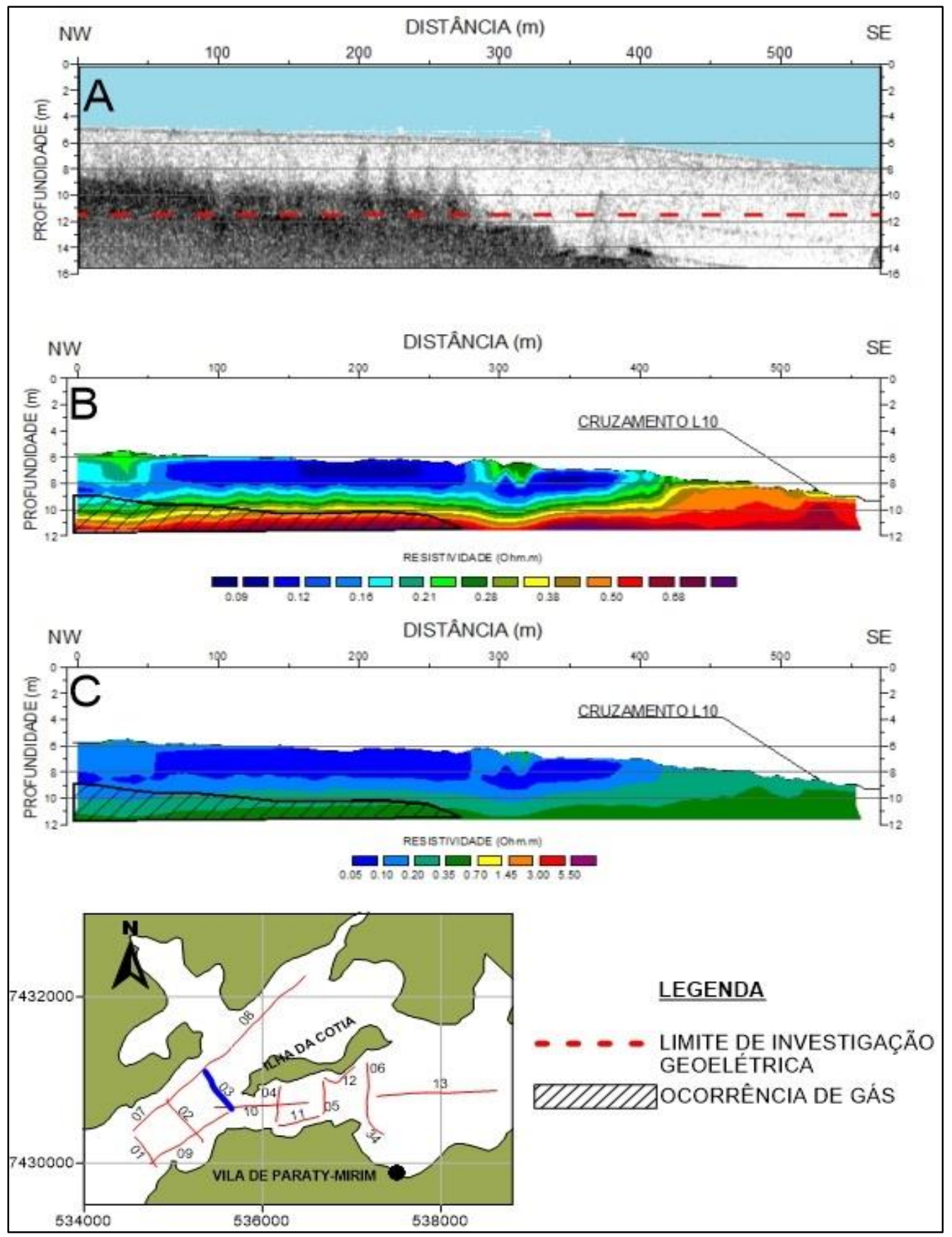

Figura 30: Perfil sísmico (A), SIG em escala de cores automática (B) e SIG em escala de cores comum (C), correspondentes à linha L03. Observa-se a ocorrência de uma cortina acústica abaixo de $10 \mathrm{~m}$ de profundidade e plumas de escape na coluna sedimentar. A SIG apresenta o padrão típico para esta área de aumento da resistividade com a profundidade e afinamento da camada mais condutiva na direção do aumento da profundidade. 
As Figuras 31 a 33 apresentam os últimos três perfis transversais desta área, aquisitados ao Sul da Ilha de Cotia. Diferentemente do que ocorre nas seções das Figuras 28 a 30, praticamente não se observam feições acústicas relacionadas à ocorrência de gás no intervalo de profundidade de investigação do método geoelétrico. Todavia, a variação da resistividade apresenta comportamento semelhante ao das SIGs anteriores: espessamento da camada mais condutiva $(<0,35 \mathrm{Ohm} . \mathrm{m})$ em direção às margens, estando completamente ausente em zonas de lâmina d'água maior que $8 \mathrm{~m}$.

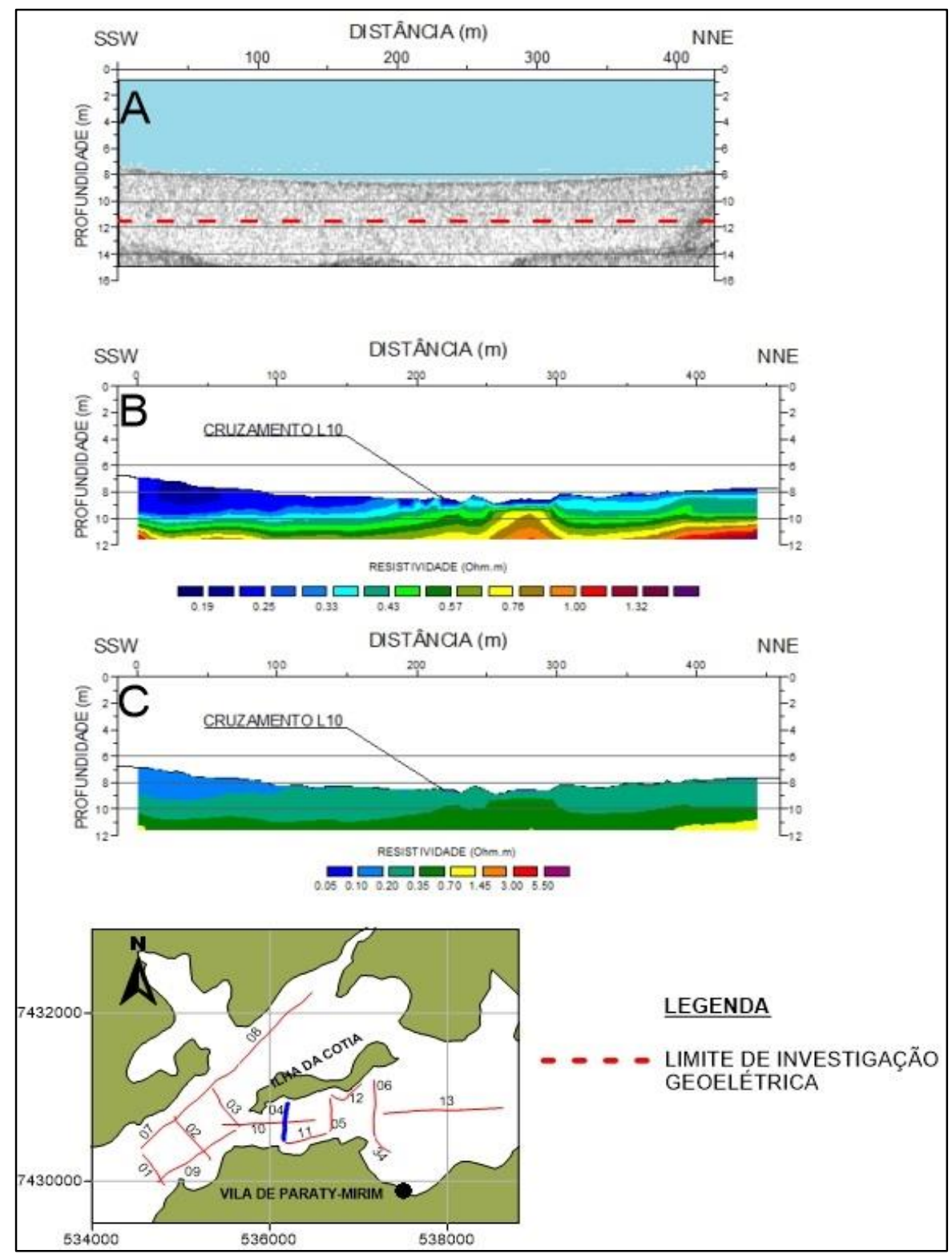

Figura 31: Perfil sísmico (A), SIG em escala de cores automática (B) e SIG em escala de cores comum $(\mathrm{C})$, correspondentes à linha L04. A coluna sedimentar se mostra acusticamente homogênea. Porém, a SIG apresenta o padrão típico para esta área: aumento da resistividade com a profundidade e espessamento da camada mais condutiva nas porções mais rasas. 


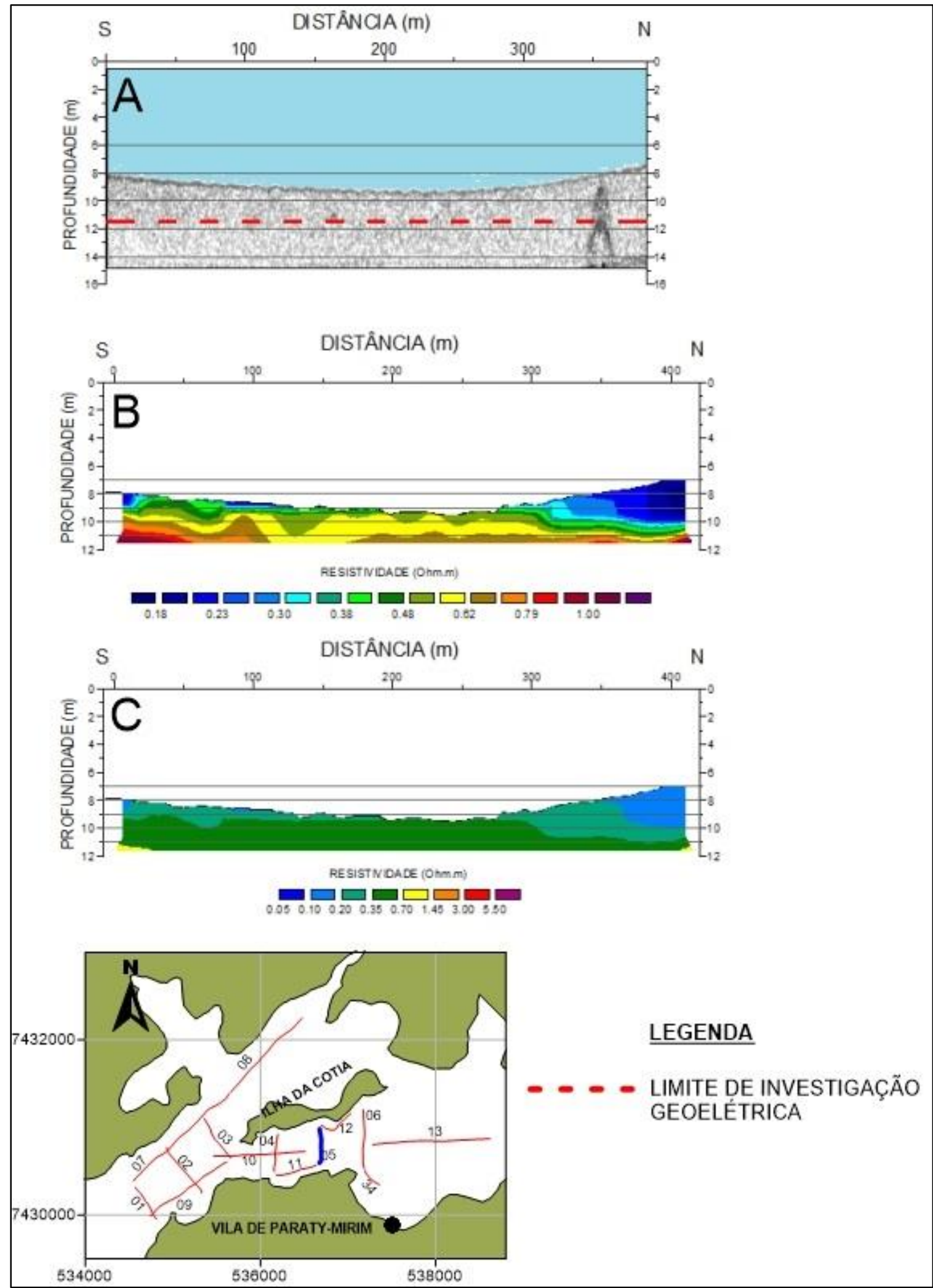

Figura 32: Perfil sísmico (A), SIG em escala de cores automática (B) e SIG em escala de cores comum (C), correspondentes à linha L05. A coluna sedimentar se mostra acusticamente homogênea. Porém, a SIG apresenta o padrão típico para esta área: aumento da resistividade com a profundidade e espessamento da camada mais condutiva nas áreas mais rasas. 


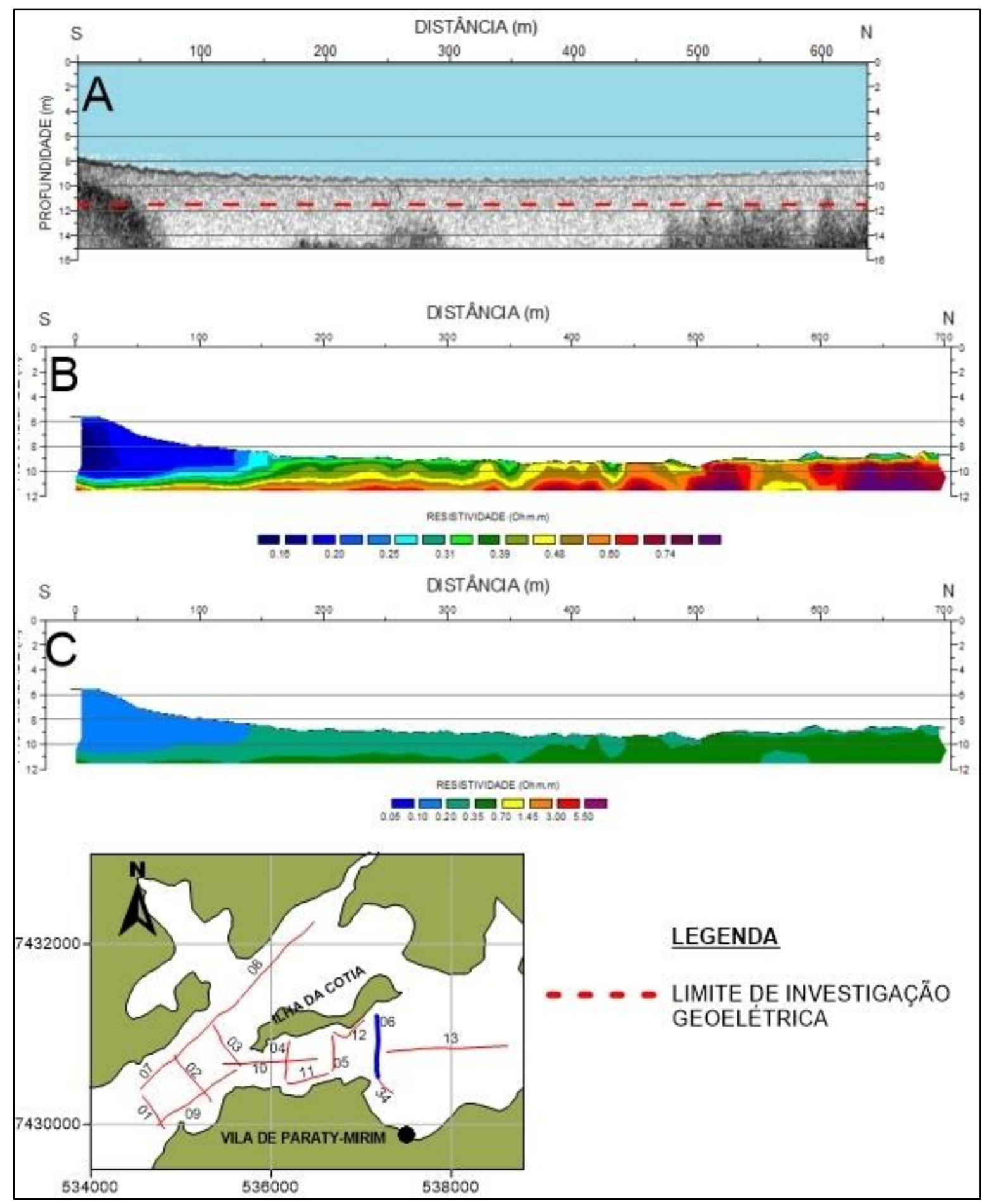

Figura 33: Perfil sísmico (A), SIG em escala de cores automática (B) e SIG em escala de cores comum (C), correspondentes à linha L06. As cortinas acústicas indicativas de presença de gás ocorrem abaixo do limite de penetração do método geoelétrico. 
As seções apresentadas nas Figuras 34 e 35, levantadas ao Norte da Ilha da Cotia, são o exemplo padrão desta região tanto no que diz respeito à ocorrência de gás, como à variação da resistividade elétrica na coluna sedimentar. Ao longo dos perfis sísmicos ocorrem as três feições acústicas relacionadas com a presença de gás mapeadas na região.

Na L07 (Figura 34) observa-se a ocorrência de turbidez acústica, com topo em aproximadamente $9 \mathrm{~m}$ de profundidade e plumas intrassedimentares principalmente nos primeiros 450 m. Já na L08 (Figura 35) predomina uma reflexão reforçada bem definida em torno de $11,5 \mathrm{~m}$ de profundidade.

Por sua vez, as SIGs apresentam uma camada condutiva, de resistividade menor que 0,35 Ohm.m, cuja base coincide com o topo da turbidez acústica e, a despeito da variação lateral na ocorrência das feições acústicas, a resposta geoelétrica é uniforme ao longo de todo o perfil. 

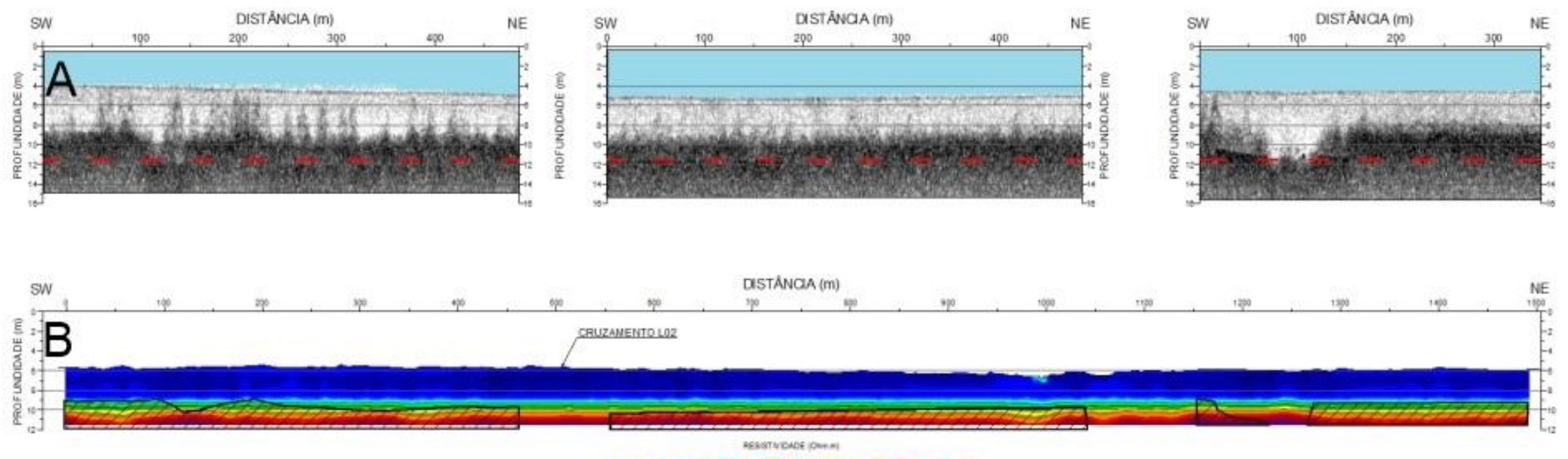

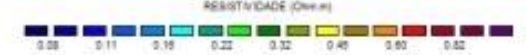
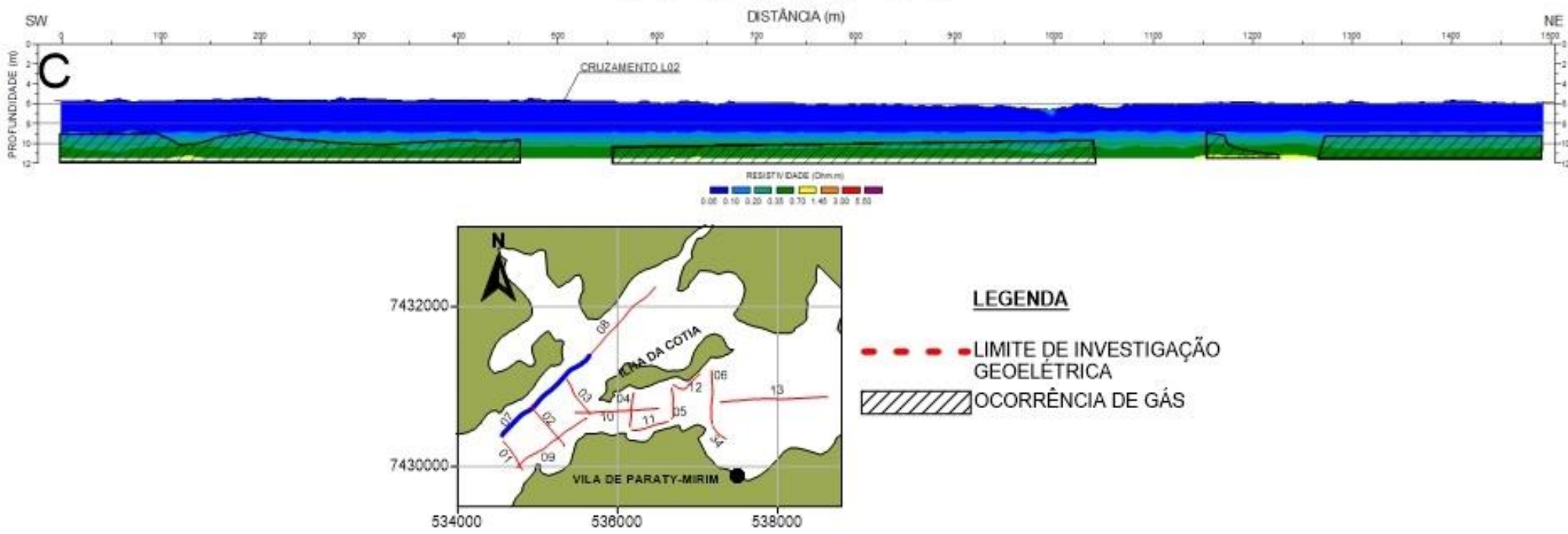

Figura 34: Perfil sísmico (A), SIG em escala de cores automática (B) e SIG em escala de cores comum (C), correspondentes à linha L07. A ocorrência de lumas intrassedimentares está mais concentrada nos $450 \mathrm{~m}$ inicias. A cortina acústica ocorre abaixo de $9 \mathrm{~m}$ de profundidade, coincidindo com a interface de $0.35 \mathrm{Ohm} . \mathrm{m}$ 


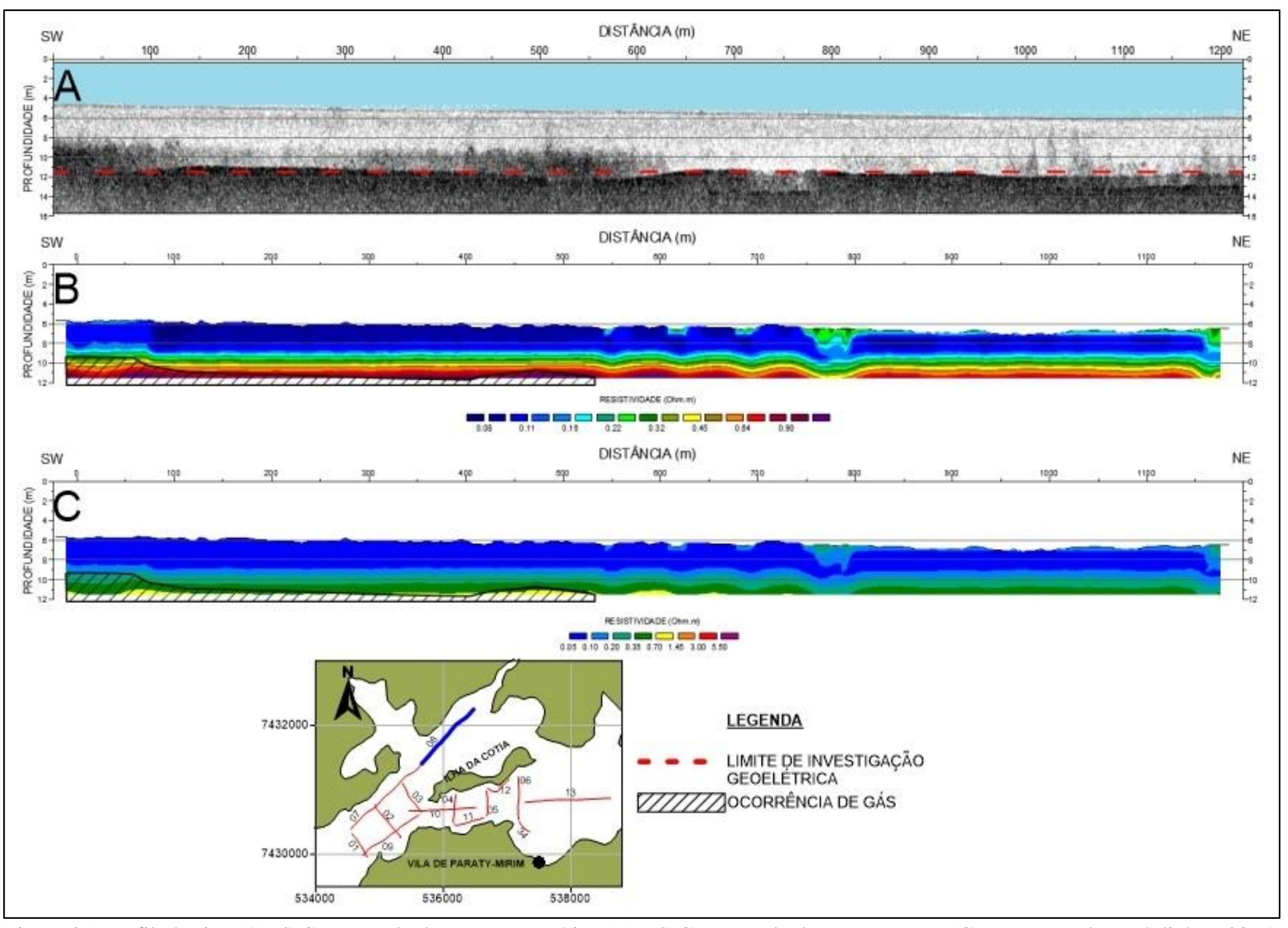

Figura 35: Perfil sísmico (A), SIG em escala de cores automática (B) e SIG em escala de cores comum (C), correspondentes à linha L08. A

$11,5 \mathrm{~m}$ de profundidade, coincidindo com 0 aumento lateral no valor $\mathrm{A}$ a resistividade, da camada geoelétrica com base em $9 \mathrm{~m}$ 
No perfil sísmico da Figura 36 observa-se uma mudança no pacote sedimentar. A homogeneidade da camada de capeamento do gás é interrompida por dois domos com ápices em 7 e $10 \mathrm{~m}$ de profundidade. O contraste entre essas duas estruturas e a cortina acústica que ocorre entre elas são indicativos de alguma variação litológica, cuja assinatura geoelétrica não é evidente. Porém, ao comparar o valor máximo da resistividade da SIG L09 (> 1,45 Ohm.m) com o máximo das SIGs adjacentes L01, 02, 03 e 07 (< 1,45 Ohm.m), tem-se algum indício dessa variação.

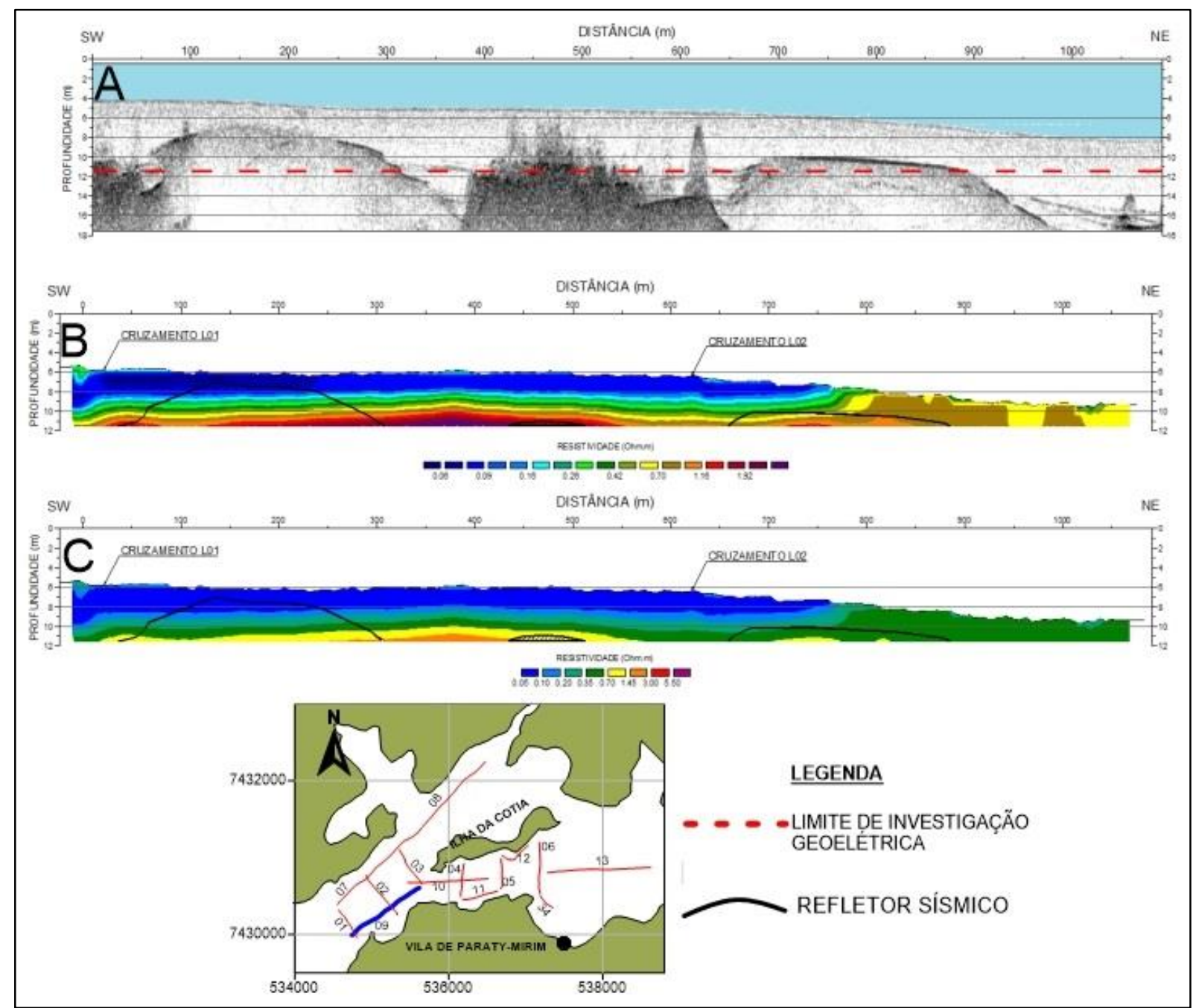

Figura 36: Perfil sísmico (A), SIG em escala de cores automática (B) e SIG em escala de cores comum (C), correspondentes à linha L09. A resposta acústica do meio não tem correspondência direta com as SIGs. 
O perfil da Figura 37 é o primeiro perfil longitudinal a ser adquirido em quase sua totalidade sobre uma lâmina d'água de mais de $8 \mathrm{~m}$. Este fato torna mais evidente o limite inferior da camada de resistividade menor que $0,35 \mathrm{Ohm} . \mathrm{m}$, que neste caso está limitada ao trecho oeste. Observa-se uma tendência de aumento da resistividade de W para E, no mesmo sentido do declive do fundo.

Essa variação lateral de resistividade não encontra correspondência no perfil sísmico, que mostra um pacote sedimentar homogêneo até a profundidade de $14 \mathrm{~m}$, onde ocorrem algumas feições associadas à presença de gás.

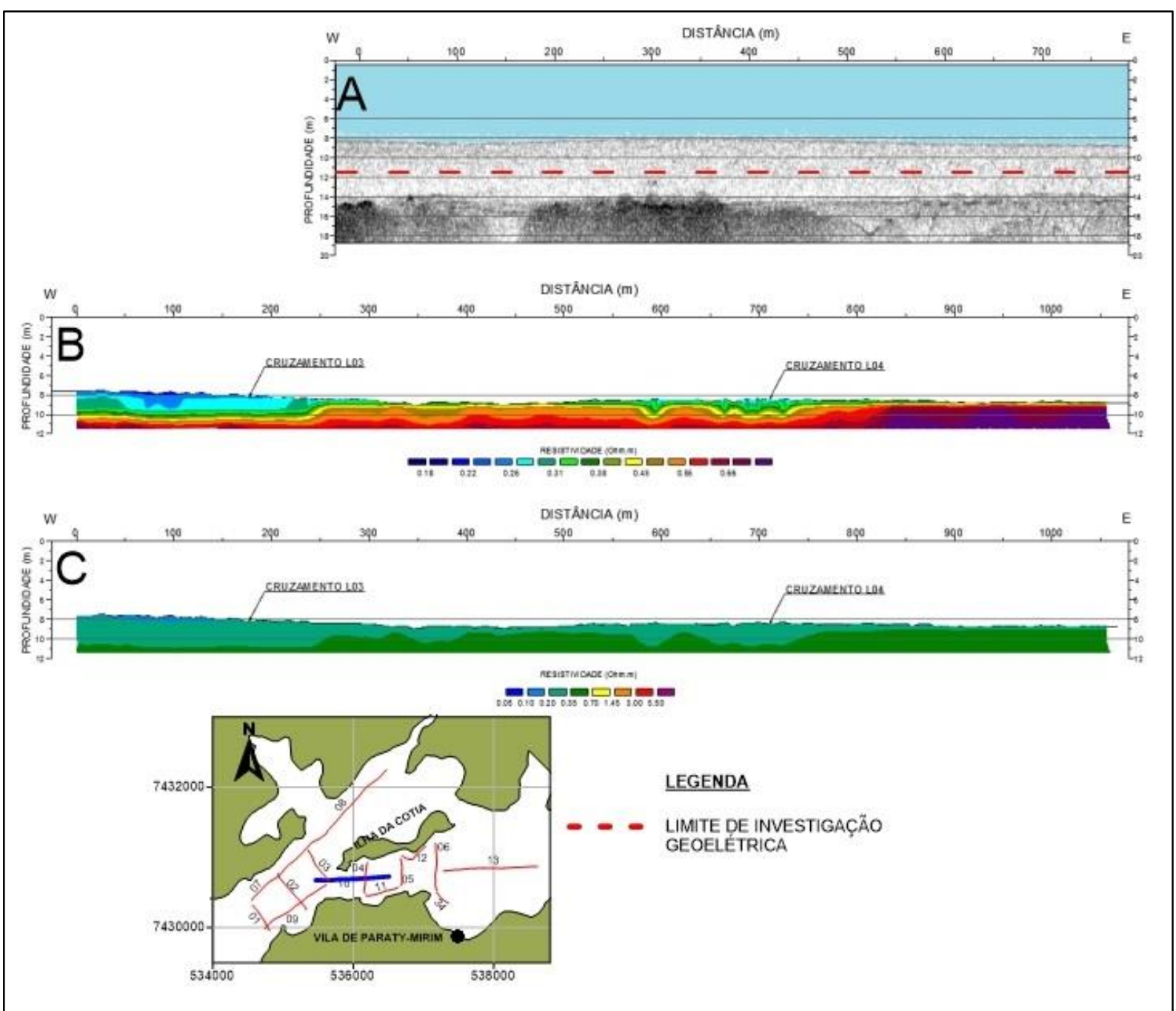

Figura 37: Perfil sísmico (A), SIG em escala de cores automática (B) e SIG em escala de cores comum (C), correspondentes à linha L10. A camada geoelétrica menos resistiva está ausente. 
Nos 150 m iniciais do perfil sísmico da L11 (Figura 38), a tonalidade mais escura na superfície do fundo é fruto de uma maior refletividade do material presente nessa porção da seção, indicando maior dureza/compactação, granulometria mais grossa, ou ambas. Na SIG correspondente, aparece uma anomalia resistiva correlacionada com essa variação da resposta acústica.
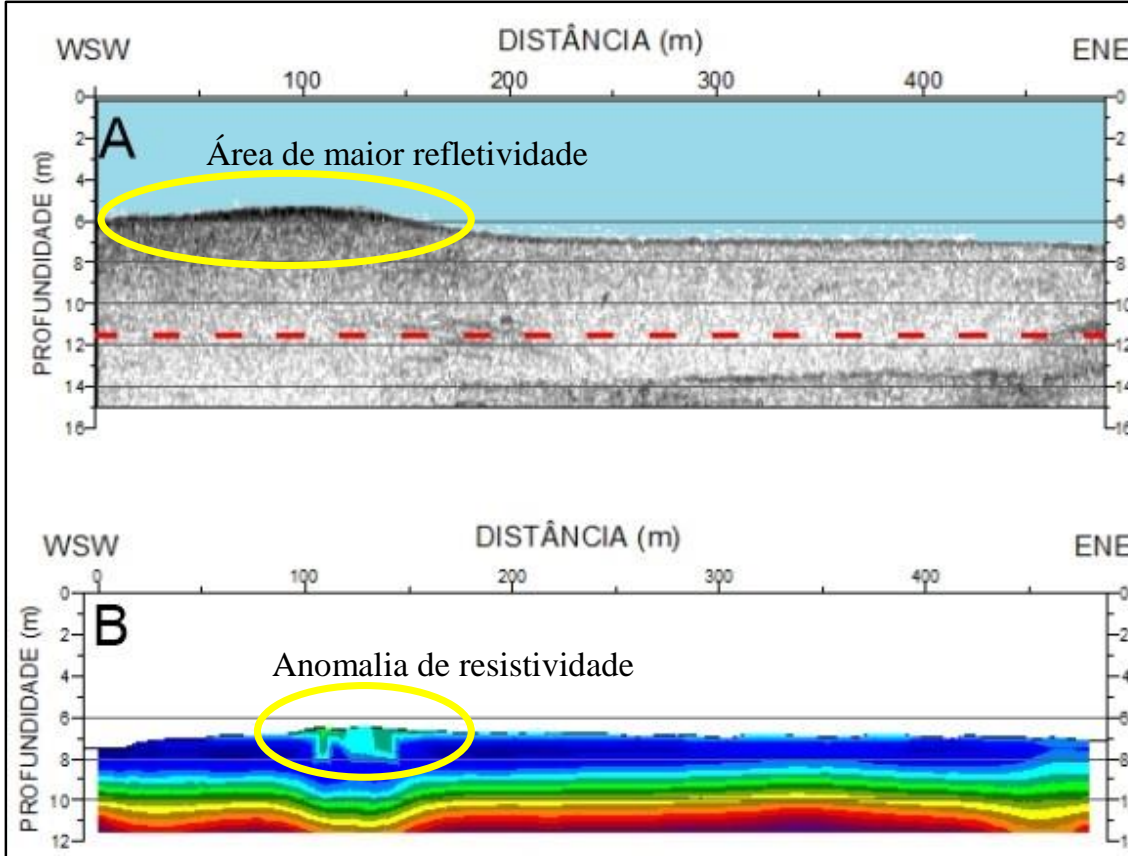

RESISTIVIDADE (O $\mathrm{hmm}$ )
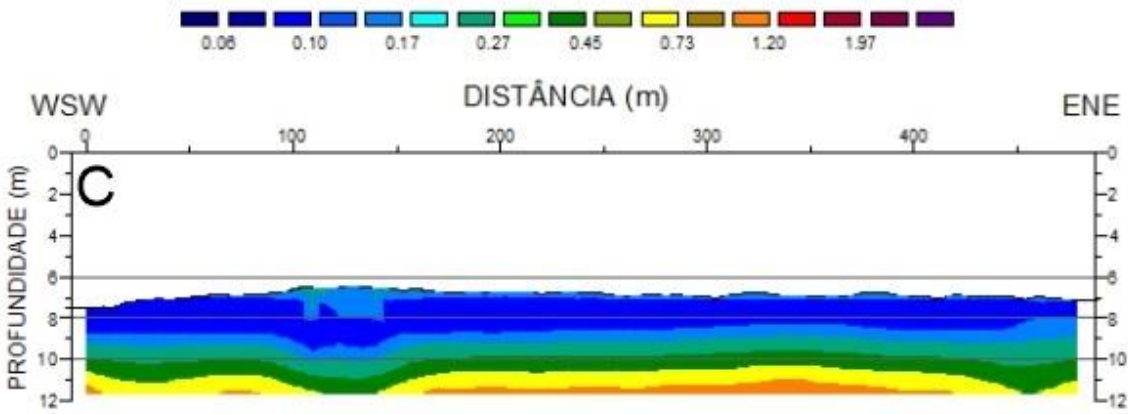

RESISTIVIDADE (Ohm.m)

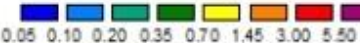

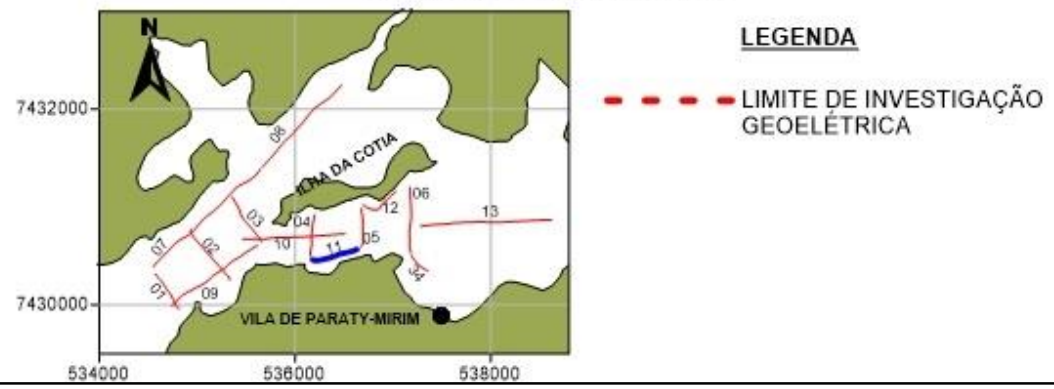

Figura 38: Perfil sísmico (A), SIG em escala de cores automática (B) e SIG em escala de cores comum $(\mathrm{C})$, correspondentes à linha L11. Observa-se boa correlação entre a variação de refletividade acústica e a resistividade. 
A linha L13 foi adquirida na área menos abrigada da EPM. Nesta região observa-se que o gás não está confinado abaixo de uma profundidade bem definida, mas seu topo varia de forma irregular entre 2 e 4 metros abaixo da superfície do fundo. A SIG correspondente apresenta variação lateral de resistividade relativamente alta, com ocorrência localizada de valores menores que 0,20 Ohm.m. 


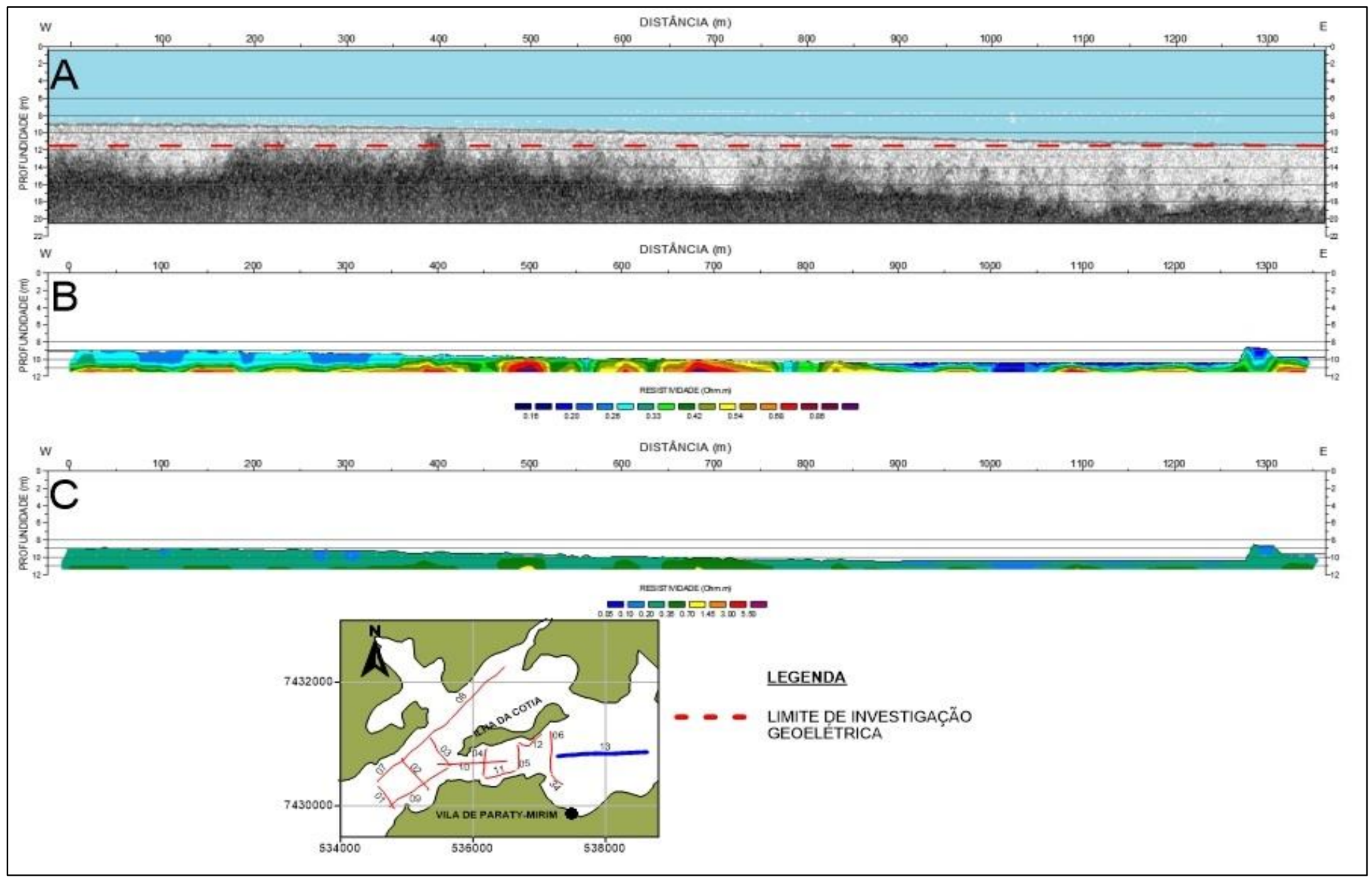

correlação entre a variação de refletividade acústica e a resistividade. 


\subsubsection{Saco do Mamanguá}

A análise das seções adquiridas no SM será subdividida em três áreas (Figura 40). A primeira, mais interna e rasa, caracteriza-se acusticamente pela ocorrência de reflexões reforçadas bem definidas, assim como refletores sísmicos associados a interfaces litológicas. Do ponto de vista dos perfis geoelétricos, observa-se um gradiente vertical de resistividade, sendo que esta é a área onde foram medidos seus maiores valores, sempre associados a camadas mais profundas.

Os perfis geoelétricos transversais da área intermediária apresentam o padrão típico de espessamento da camada superior condutiva em direção às bordas, assim como nos longitudinais a resistividade aumenta no mesmo sentido da declividade do fundo. Nos perfis sísmicos, as feições observadas são menos variadas que na área interna e estão praticamente limitadas a turbidez acústica.

Finalmente, nas seções levantadas na parte externa, mais profunda, a turbidez acústica ocorre junto de plumas intrassedimentares e a resposta geoelétrica do meio muda do gradiente vertical observado na área interna, para um alta variação lateral, com valores mínimos acima de 0,20 Ohm.m.

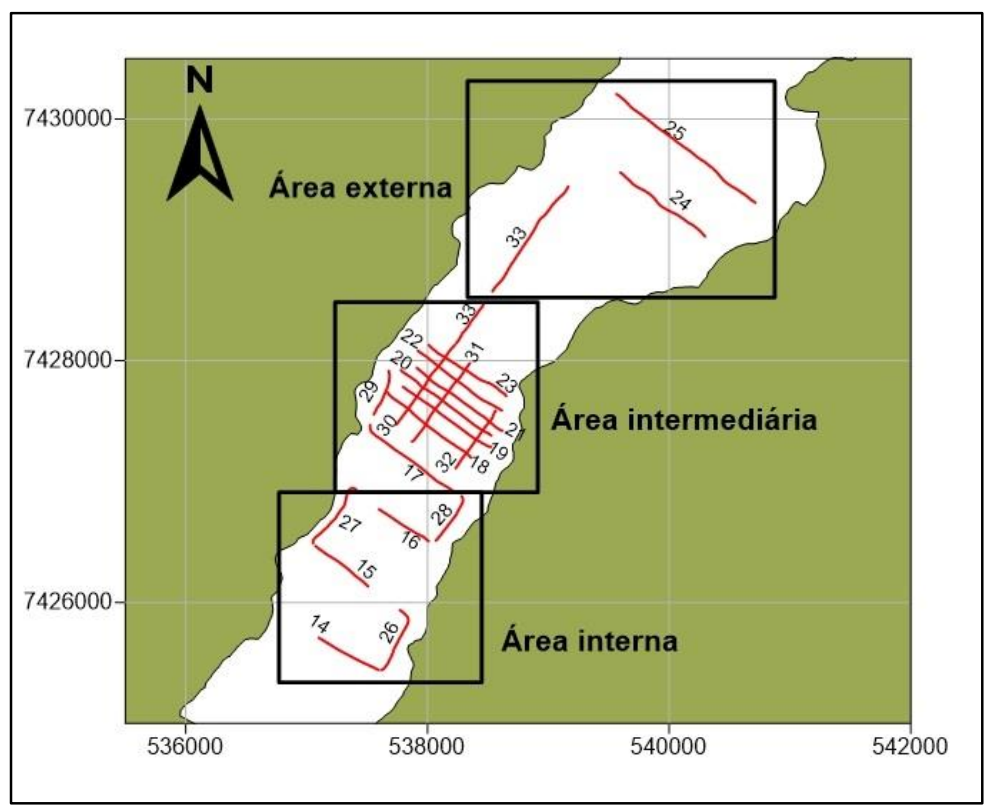

Figura 40: Divisão do Saco do Mamanguá em setores de análise. 


\subsubsection{1 Área interna}

Na SIG L14 (Figura 41), chamam a atenção principalmente dois elementos: a continuidade da interface geoelétrica de 0,20 Ohm.m em $8 \mathrm{~m}$ de profundidade, e o alto valor da resistividade na base do perfil, quando comparado com as demais seções. No perfil sísmico da L08 (Figura 35), também se observa um refletor reforçado em torno de $12 \mathrm{~m}$ de profundidade. Porém, o valor da resistividade na base da SIG correspondente é 5 vezes menor que o observado na SIG L14. Não se observa resposta geoelétrica relacionada com a turbidez acústica que aparece entre 400 e $500 \mathrm{~m}$.

De forma diferente à aparente falta de correlação entre as feições acústicas e a assinatura geoelétrica da SIG L14, na parte inferior das extremidades da SIG L15 (Figura 42) observa-se certa tendência ao aumento da resistividade, coincidente com áreas de ocorrência de gás.

Os perfis transversais L16 e L17 (Figuras 43 e 44) mostram de forma bastante clara o afinamento da camada superior mais condutiva à medida que aumenta a espessura da coluna d'água. Inclusive, é possível delimitar com certa facilidade uma espécie de 'canal' definido pelo ‘afloramento' da camada geoelétrica entre 0,20 e 0,35 Ohm.m. 


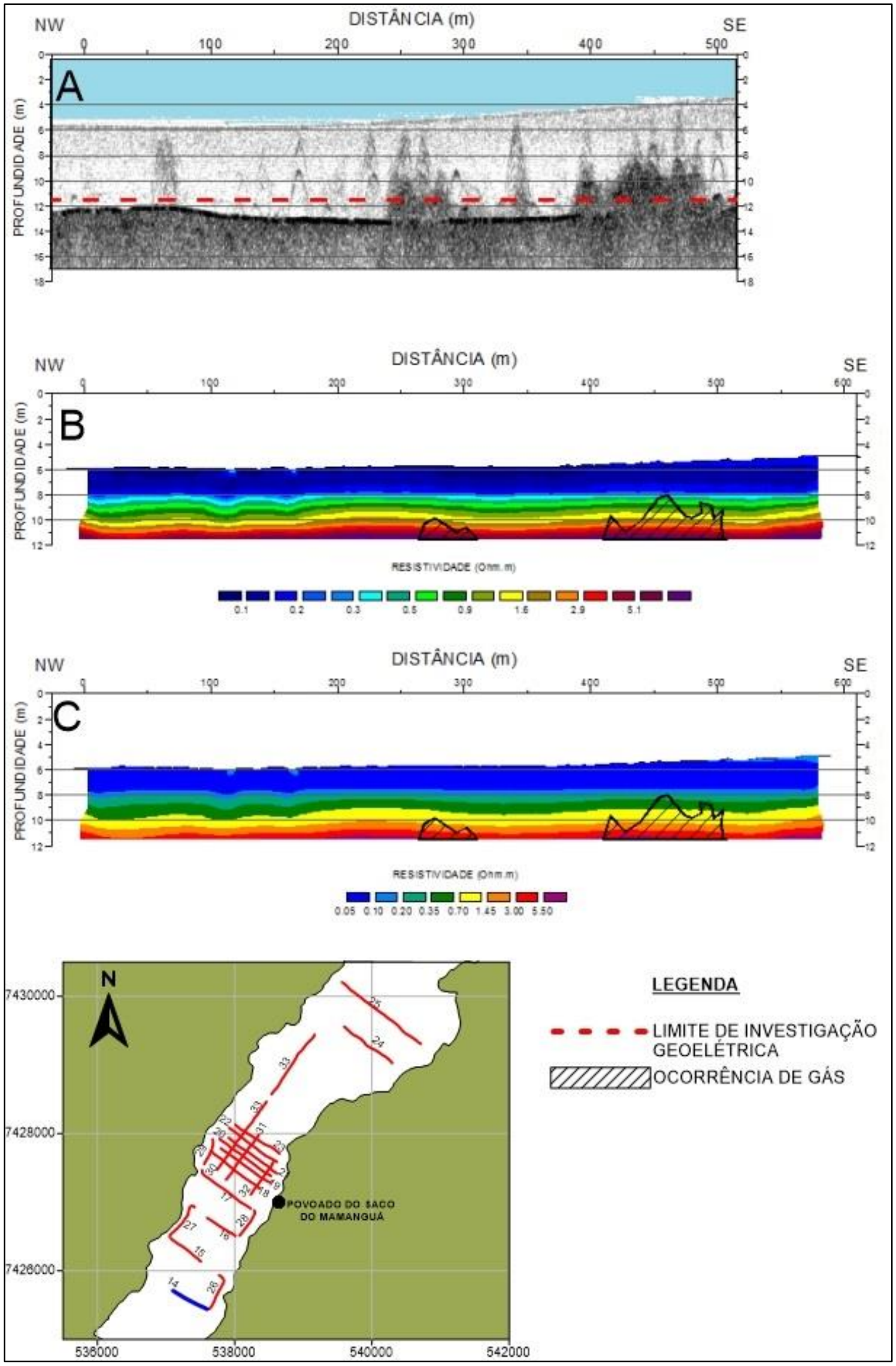

Figura 41: Perfil sísmico (A), SIG em escala de cores automática (B) e SIG em escala de cores comum (C), correspondentes à linha L14. 


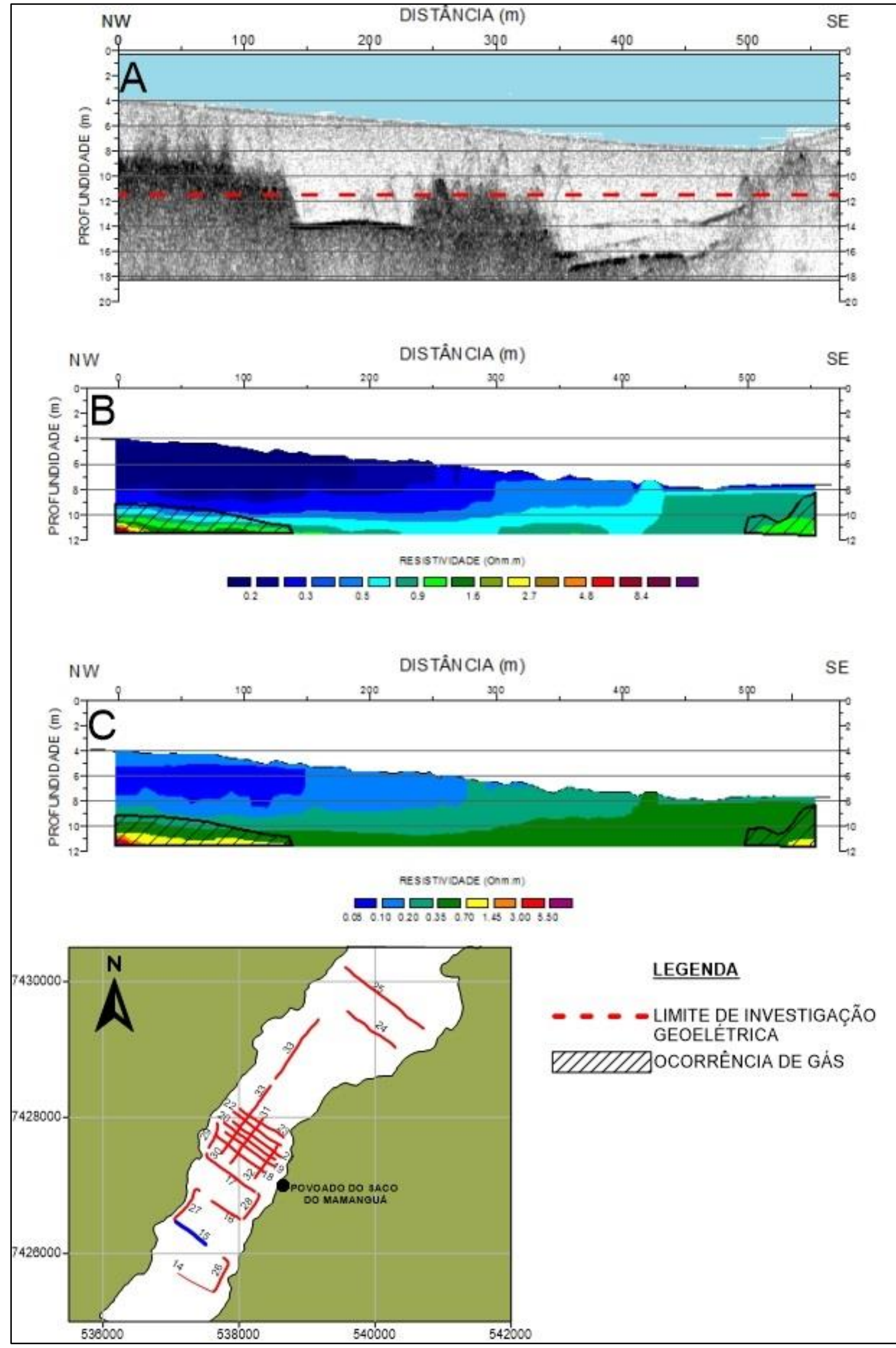

Figura 42: Perfil sísmico (A), SIG em escala de cores automática (B) e SIG em escala de cores comum (C), correspondentes à linha L15. O aumento de resistividade observado nas extremidades inferiores da SIG pode estar relacionado à ocorrência de gás observada no perfil sísmico. 


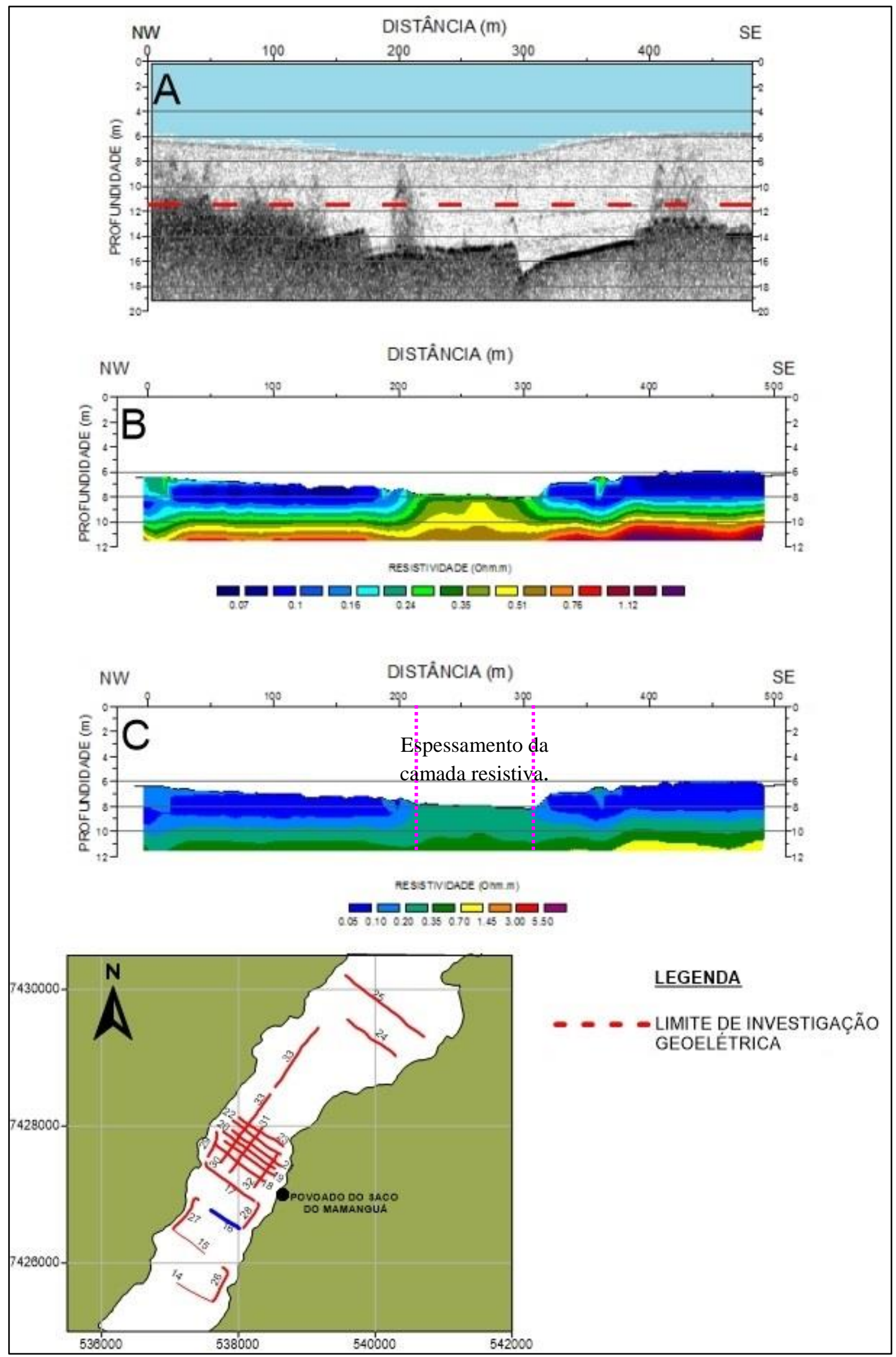

Figura 43: Perfil sísmico (A), SIG em escala de cores automática (B) e SIG em escala de cores comum (C), correspondentes à linha L16. A camada de resistividade maior que 0,20 Ohm.m aparece espessada em um canal. 


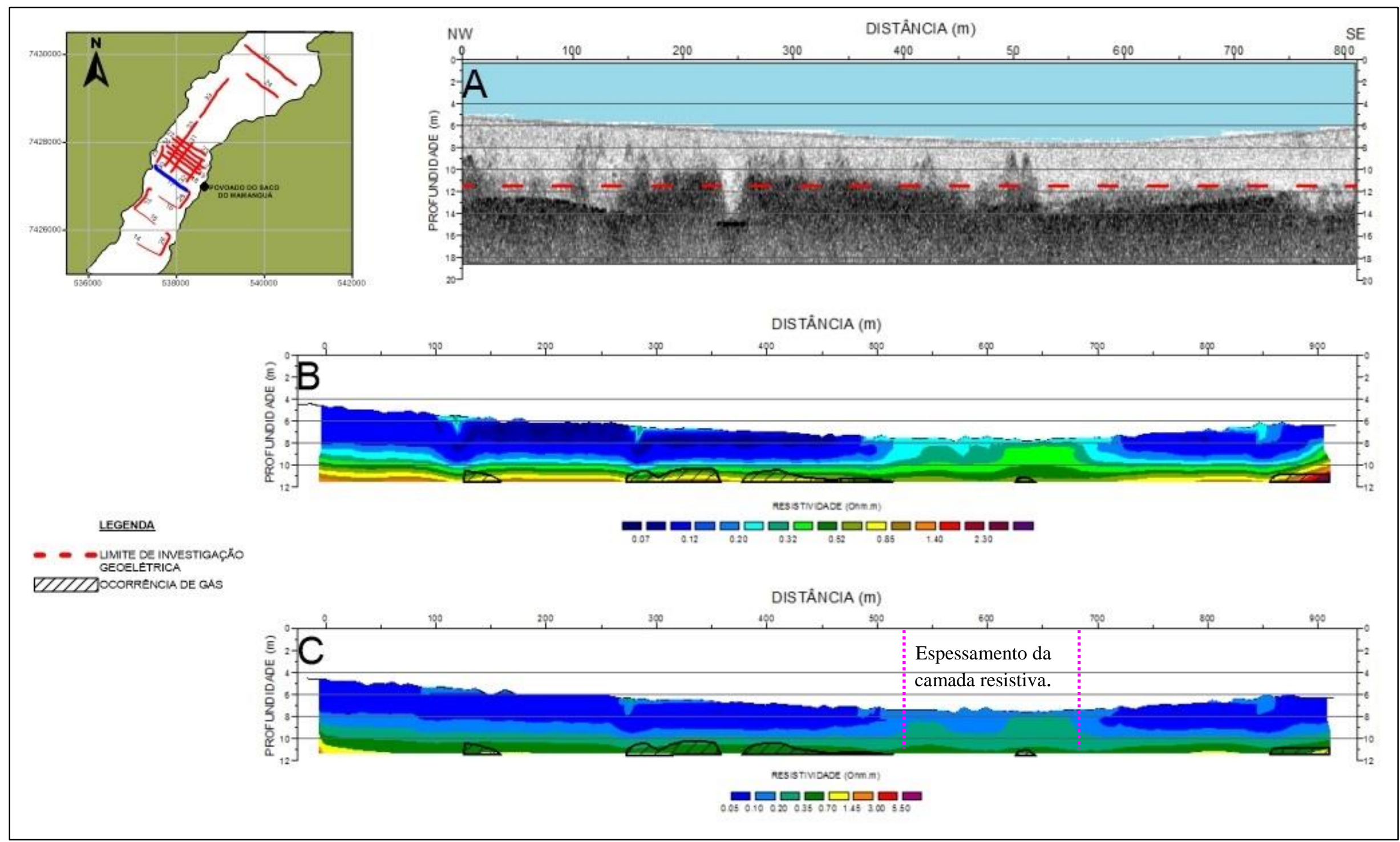

Figura 44: Perfil sísmico (A), SIG em escala de cores automática (B) e SIG em escala de cores comum (C), correspondentes à linha L17. A camada de resistividade maior que 0,20 Ohm.m aparece espessada na porção mais profunda da seção. 
O exemplo apresentado na SIG L26 (Figura 45) é semelhante ao da SIG L14 (Figura 41), adjacente a ela. Em ambos os casos, além da camada condutiva superior espessa e uniforme, aparece uma camada geoelétrica basal de relativamente altos valores de resistividade (superiores a 15 Ohm.m). Nos 250 m finais do perfil sísmico, se observam algumas hipérboles de difração que parecem estar mais relacionadas com pontos de subida do embasamento do que com ocorrências de gás.

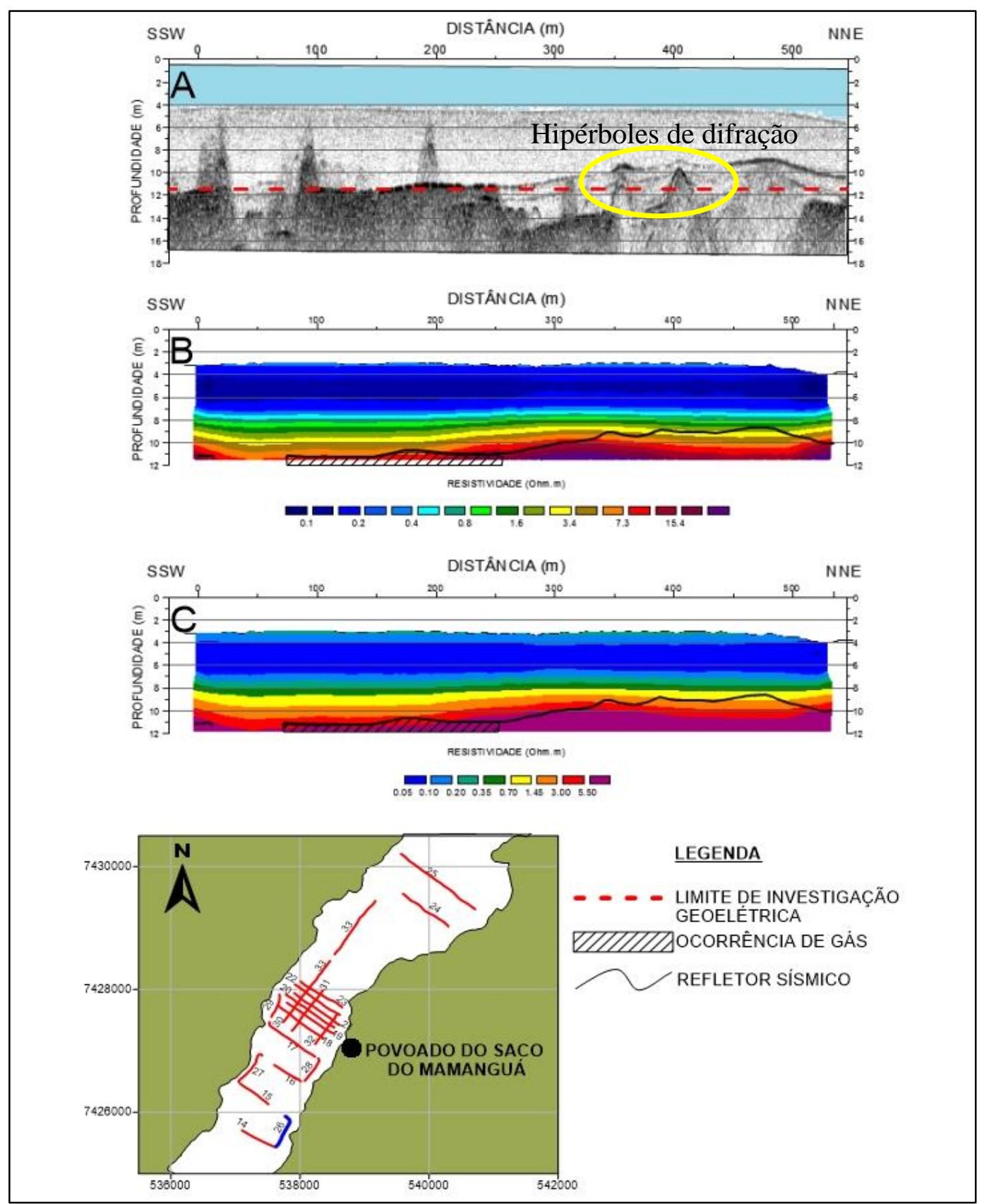

Figura 45: Perfil sísmico (A), SIG em escala de cores automática (B) e SIG em escala de cores comum (C), correspondentes à linha L26. 
As SIGs L27 e L28 (Figuras 46 e 47) são um bom exemplo da não correlação entre as feições acústicas do gás e a assinatura geoelétrica. No perfil sísmico da L27, uma cortina acústica com topo em $8 \mathrm{~m}$ de profundidade ocupa os $200 \mathrm{~m}$ iniciais da seção e é interrompida abruptamente, dando lugar uma reflexão reforçada em 11,5 m de profundidade, e reaparecendo pouco depois dos $450 \mathrm{~m}$. Já no perfil da L28, predomina uma estrutura em domo que aflora na superfície do fundo entre 120 e $180 \mathrm{~m}$, cujo ápice se aproxima a $5 \mathrm{~m}$ de profundidade.

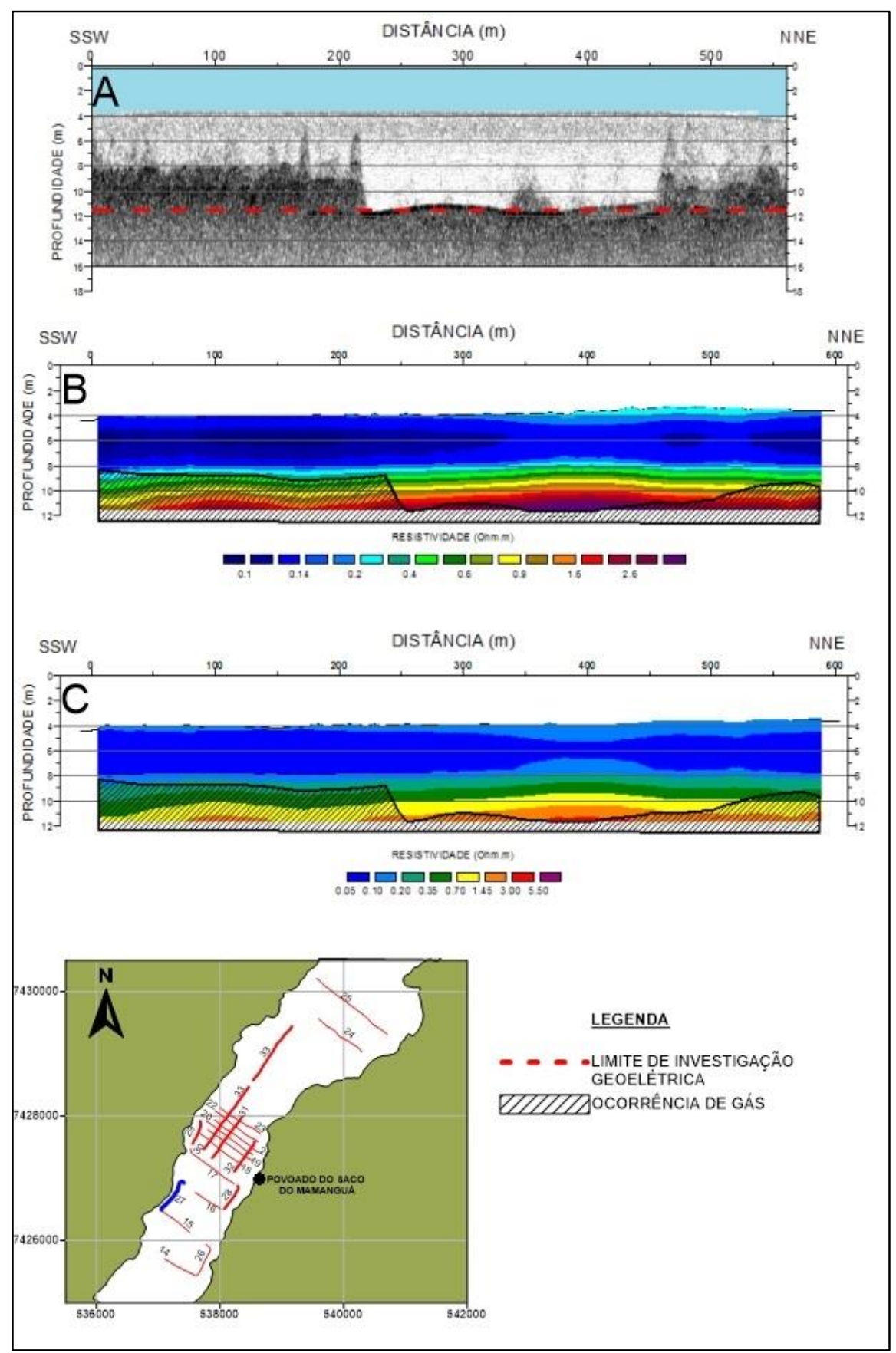

Figura 46: Perfil sísmico (A), SIG em escala de cores automática (B) e SIG em escala de cores comum $(\mathrm{C})$, correspondentes à linha L27. A variação lateral das feições acústicas não tem correspondência na assinatura elétrica. 
A única diferença perceptível entre as respectivas SIGs é uma anomalia resistiva que aparece na camada superior da SIG L28, justamente na região onde aflora a estrutura em domo acima descrita. No entanto, na porção abaixo de $8 \mathrm{~m}$ de profundidade de cada uma das SIGs não se observam diferenças significativas nem na forma em que varia a resistividade, nem no valor.

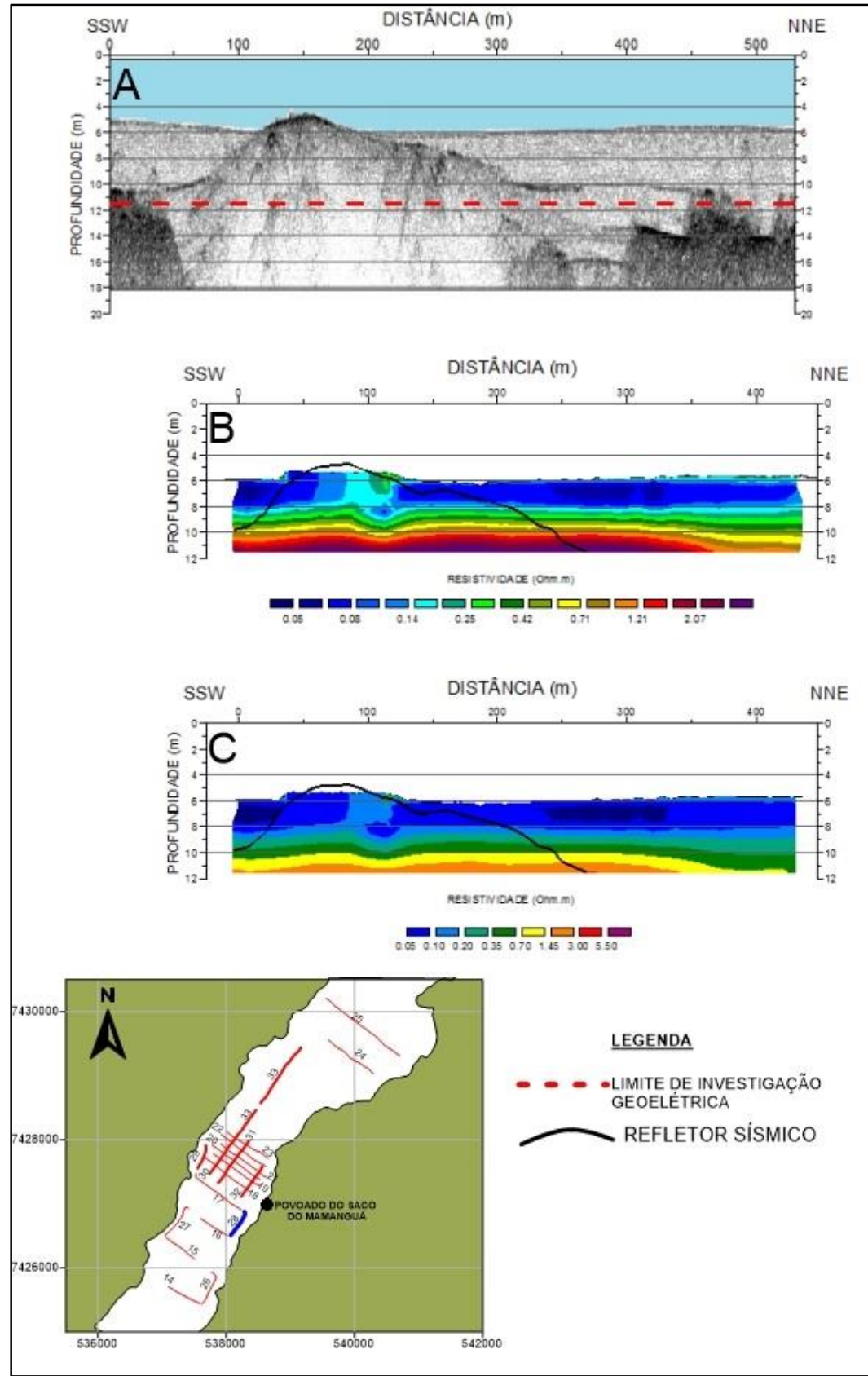

Figura 47: Perfil sísmico (A), SIG em escala de cores automática (B) e SIG em escala de cores comum (C), correspondentes à linha L28. A anomalia resistiva observada na camada superior da SIG coincide com a área de afloramento da estrutura em domo do perfil sísmico. 


\subsubsection{2 Área intermediária}

A penetração na coluna de sedimentos, alcançada nesta área pelo método elétrico, fica restrita a uma camada acusticamente homogênea, na qual não se observam feições sísmicas associadas a interfaces sedimentares e que é alterada apenas pela presença de plumas intrassedimentares, originadas na turbidez acústica confinada em estratos inferiores.

Tanto as seções transversais escolhidas para representar esta área (Figuras 48 e 49), quanto as longitudinais (Figuras 50 e 51), apresentam valores de resistividade inferiores a 1 Ohm.m e assinatura elétrica caracterizada pela ocorrência de duas camadas de resistividade bem definidas: uma superior (acima de $8 \mathrm{~m}$ de profundidade) de resistividade menor que 0,20 Ohm.m, e uma camada inferior, mais resistiva, que sofre espessamento à medida que aumenta a espessura da coluna d'água.

A exceção a essa norma é observada na L29 (Figura 50). Trata-se de uma seção longitudinal, próxima da margem $\mathrm{N}$, adquirida sobre lâmina d'água de espessura em torno de 5 m. Na coluna sedimentar ocorre uma estrutura em domo que não aflora na superfície do fundo e cujos flancos são realçados pela presença de gás. A SIG L29 segue o mesmo padrão das SIGs da área interna, porém com valores de resistividade que não passam de 3 Ohm.m.

A linha de aquisição sísmica e a elétrica estão afastadas em até 100 m; dessa maneira, é provável que a estrutura observada no perfil sísmico não se estenda até as proximidades do local da SIG. 


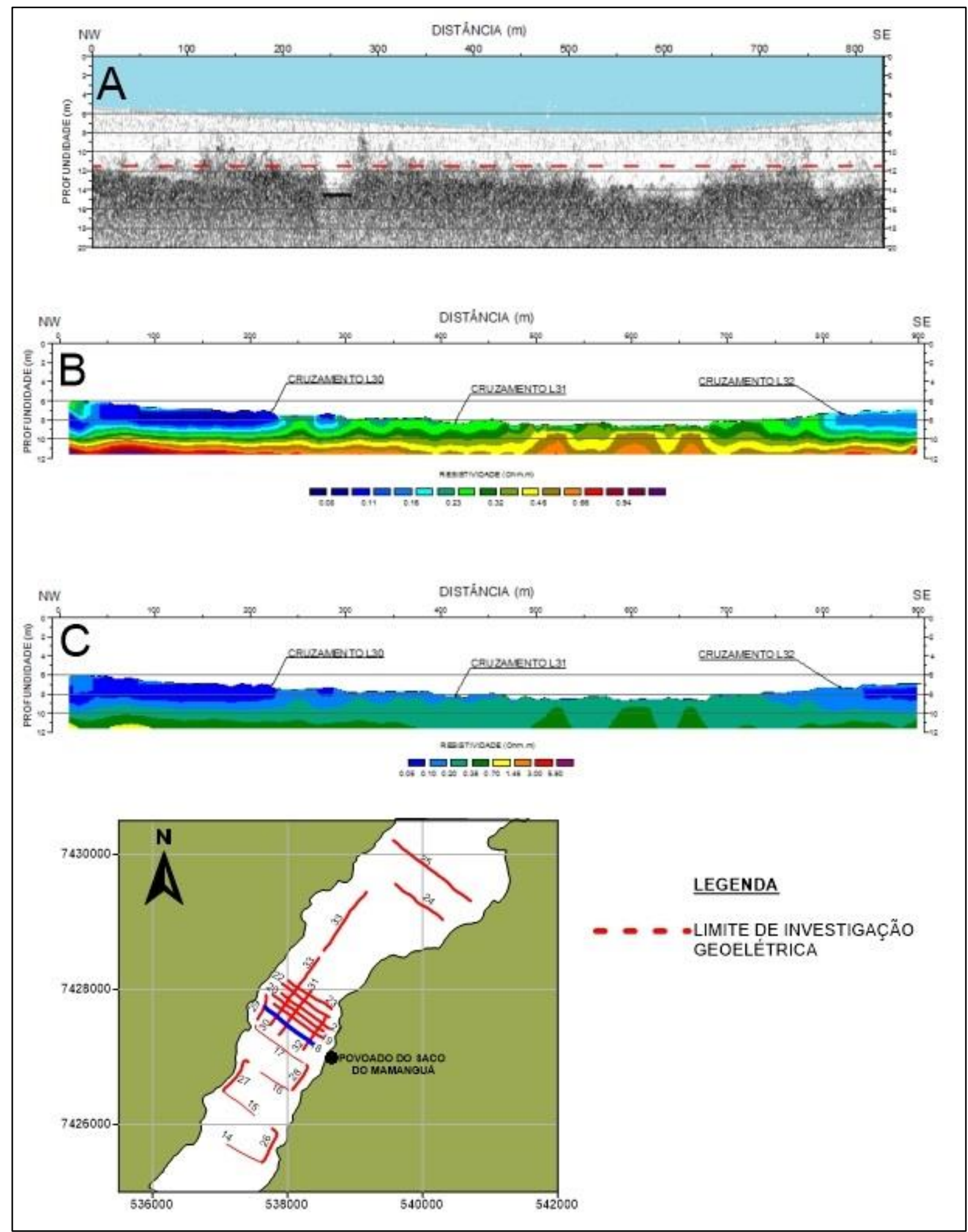

Figura 48: Perfil sísmico (A), SIG em escala de cores automática (B) e SIG em escala de cores comum (C), correspondentes à linha L18. A SIG apresenta variações de resistividade que não possuem correlação com a resposta sísmica homogênea da camada sedimentar. 


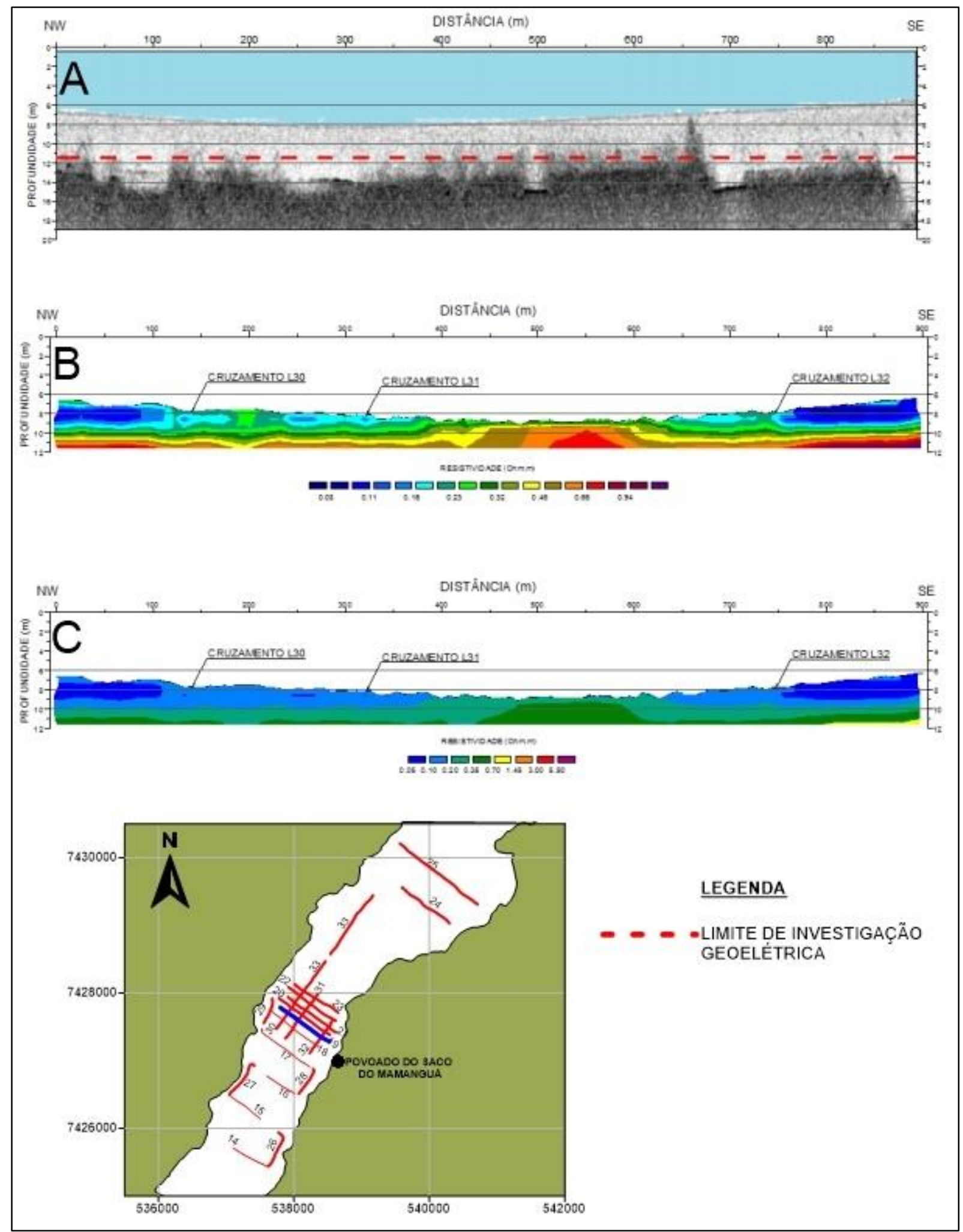

Figura 49: Perfil sísmico (A), SIG em escala de cores automática (B) e SIG em escala de cores comum (C), correspondentes à linha L19. A SIG mostra variações de resistividade que não possuem correlação com a resposta sísmica homogênea da camada sedimentar. 


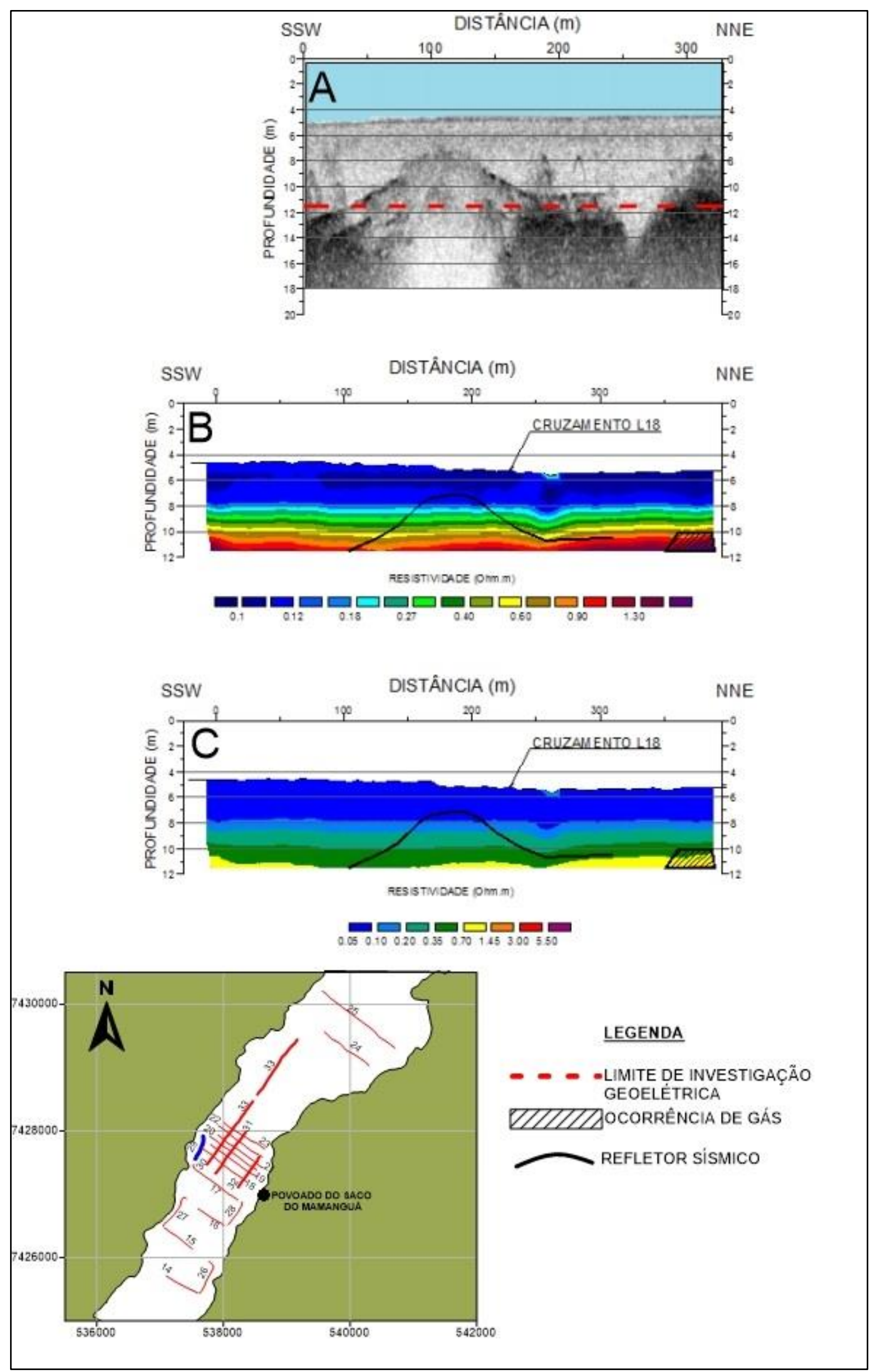

Figura 50: Perfil sísmico (A), SIG em escala de cores automática (B) e SIG em escala de cores comum (C), correspondentes à linha L29. A uniformidade lateral da seção geoelétrica não se corresponde com a ocorrência da feição acústica observada no perfil sísmico. 


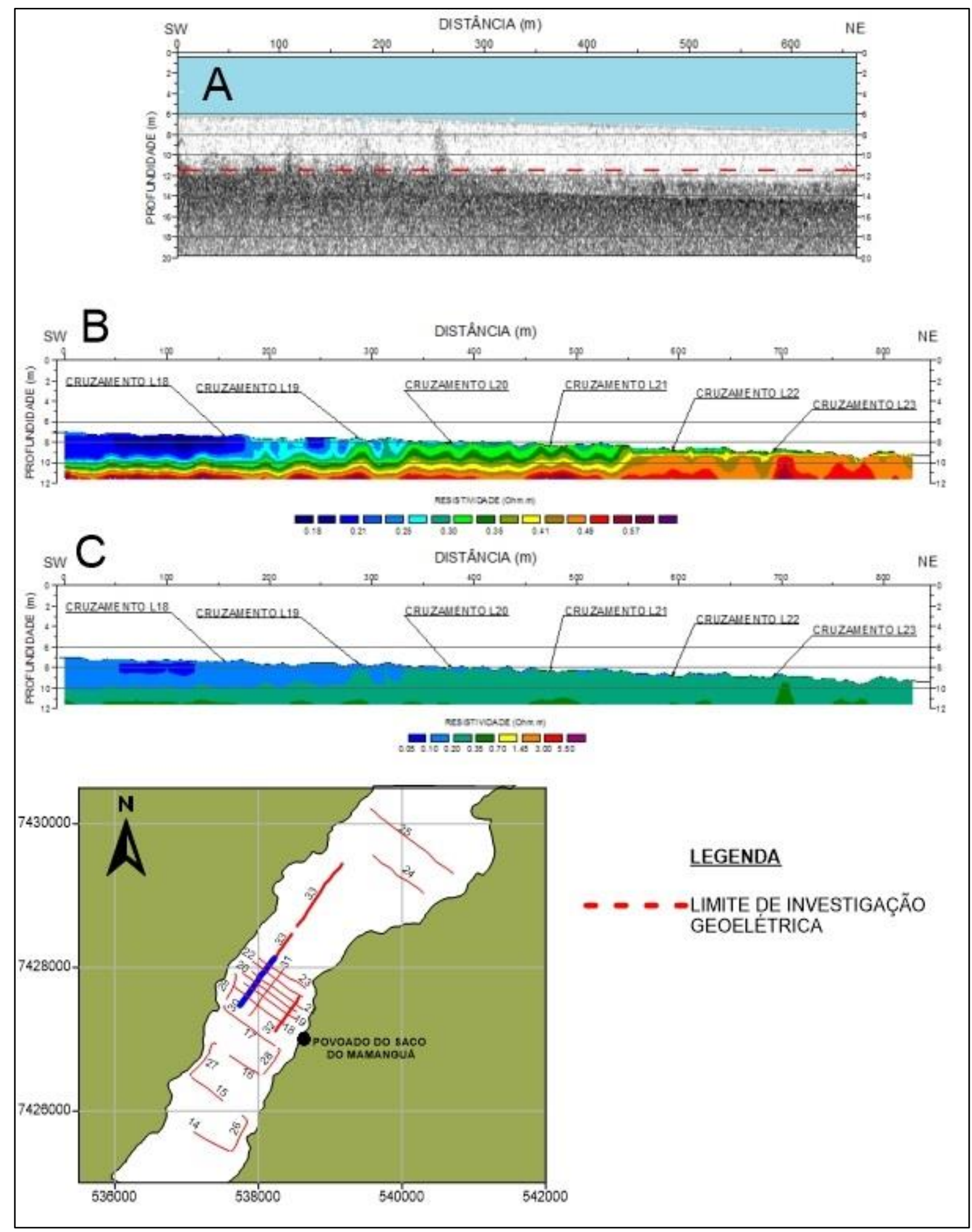

Figura 51: Perfil sísmico (A), SIG em escala de cores automática (B) e SIG em escala de cores comum (C), correspondentes à linha L30. A comparação das linhas transversais e longitudinais nos respectivos pontos de cruzamento, mostra uma boa coerência entre os valores de resistividade. A resistividade aumenta no sentido da declividade do fundo. 


\subsubsection{3 Área externa}

Igual ao que se observa na porção externa da EPM, as seções levantadas na parte mais desabrigada do SM (Figuras 52 e 53) mostram a ocorrência de turbidez acústica, associada a plumas intrassedimentares que alcançam a superfície do fundo. Paralelamente, as seções geoelétricas mostram maior variação lateral de resistividade do que observado nas seções mais internas. Particularmente, chama a atenção na SIG L24 (Figura 52), a presença de anomalias de resistividade de bordas subverticais, semelhantes às observadas na SIG L01 (Figura 28).

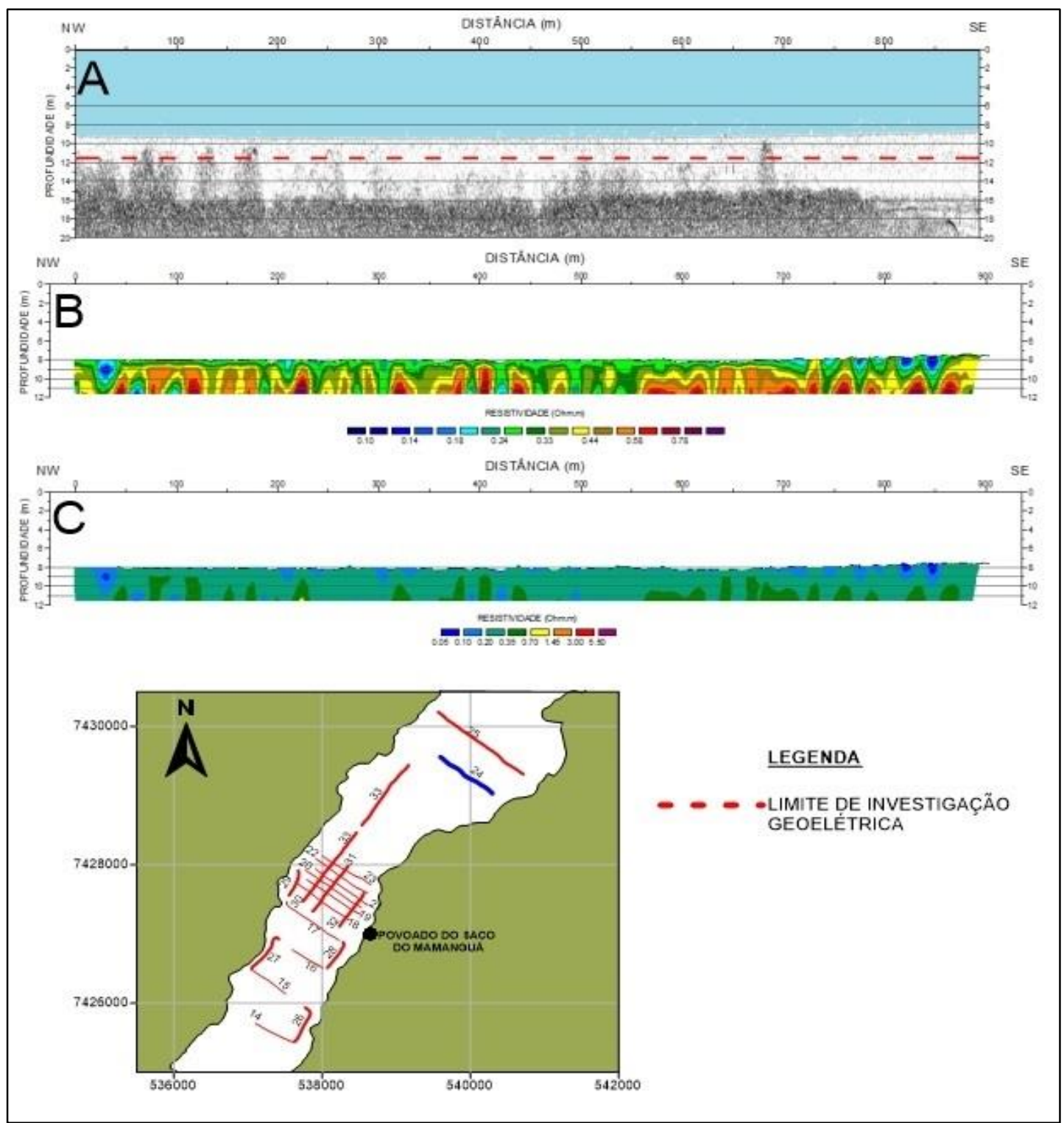

Figura 52: Perfil sísmico (A), SIG em escala de cores automática (B) e SIG em escala de cores comum (C), correspondentes à linha L24. A SIG apresenta anomalias resistivas em fundo de 0,20-0,35 Ohm.m. 


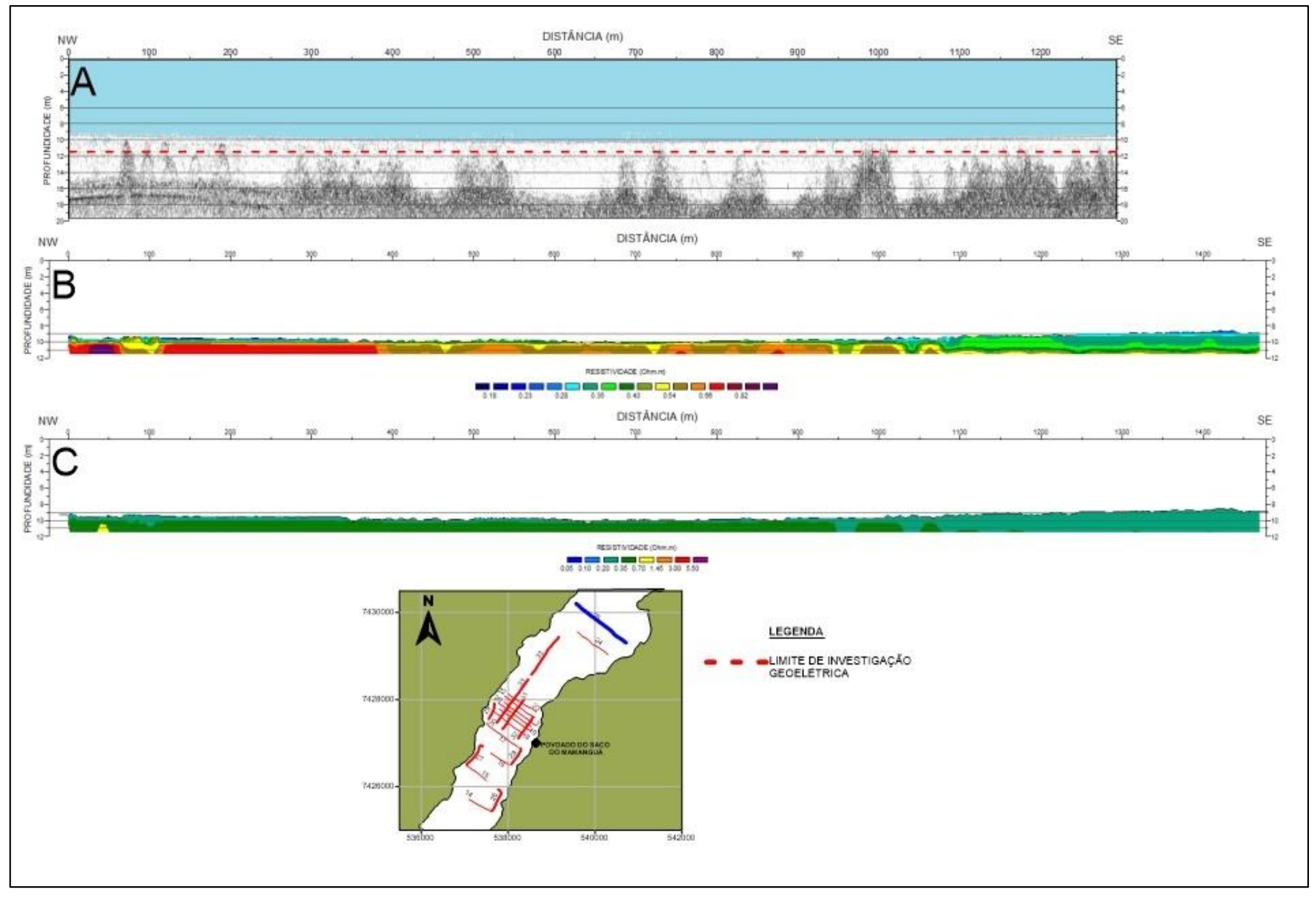

Figura 53: Perfil sísmico (A), SIG em escala de cores automática (B) e SIG em escala de cores comum (C), correspondentes à linha L25. A resistividade diminui com sentido SE. 


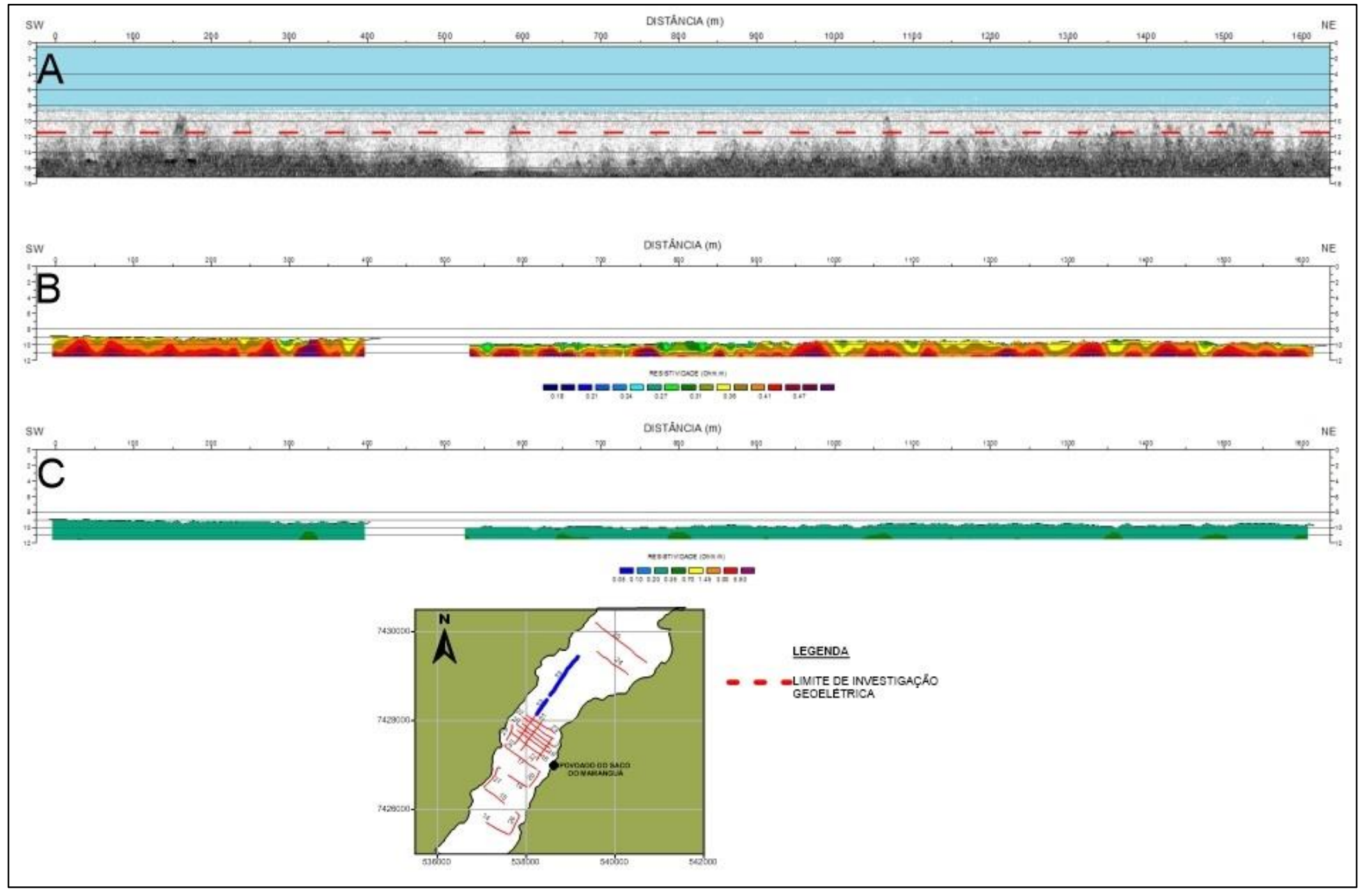

Figura 54: Perfil sísmico (A), SIG em escala de cores automática (B) e SIG em escala de cores comum (C), correspondentes à linha L33. 


\subsection{Resistividade em amostras}

As experiências realizadas nas amostras retiradas do testemunho MAM07AT tiveram como objetivo analisar a variação da resistividade em função de dois parâmetros passíveis de controle em laboratório: presença de bolhas de gás na matriz siltosa, neste caso simuladas mediante a inserção de miçangas de acrílico, e diminuição do teor de água salgada, obtido pela dessalinização das amostras com água deionizada.

Os gráficos da Figura 55 apresentam as três situações analisadas: variação da resistividade com a profundidade nas amostras inalteradas, variação da resistividade em função do volume de gás simulado pela inserção de bolhas e medição da resistividade de amostras dessalinizadas.

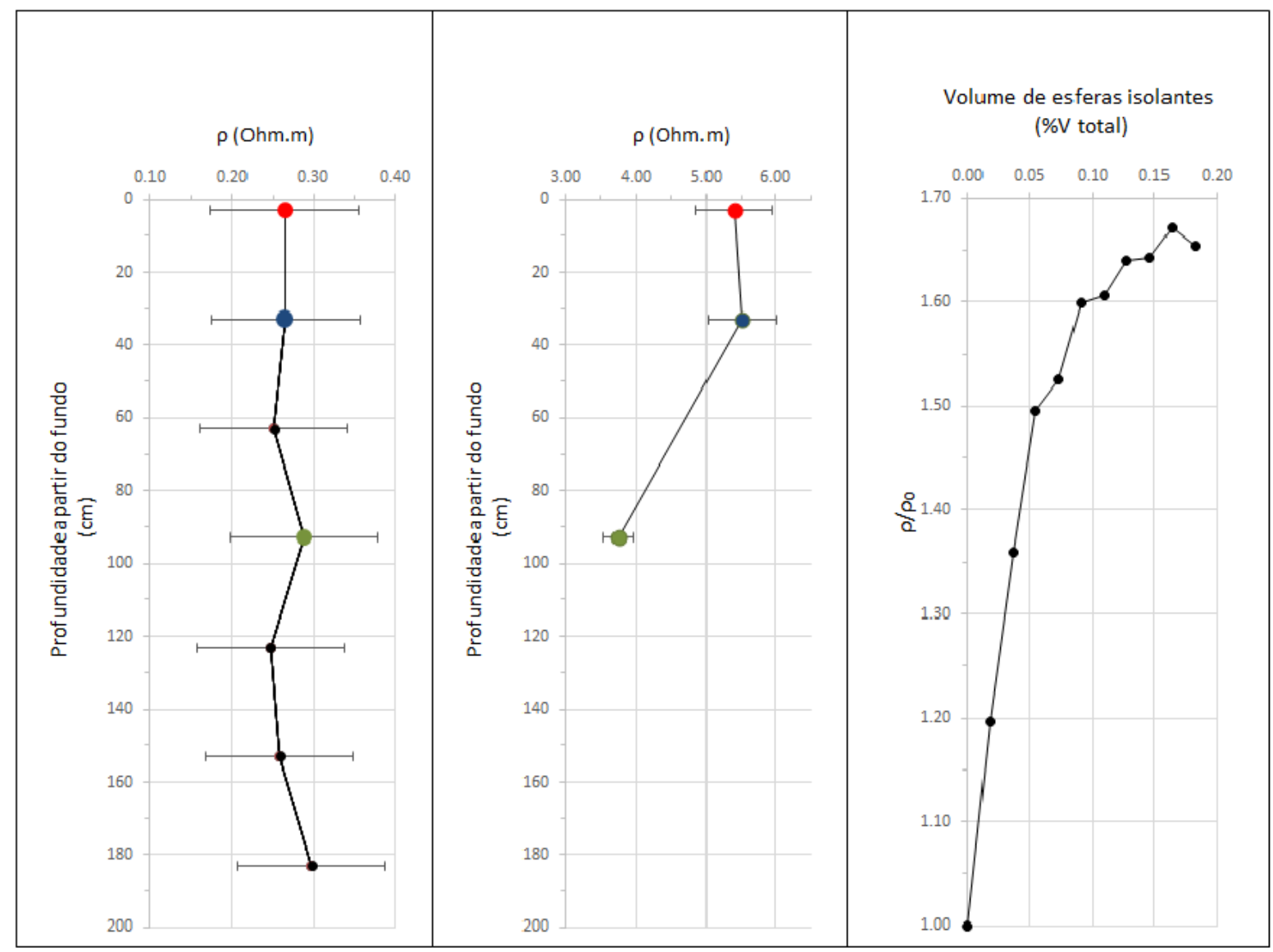

Figura 55: Esquerda: Gráfico da variação da resistividade elétrica em função da profundidade a partir da superfície do fundo para amostras de sedimentos inalteradas. Centro: Gráfico da variação da resistividade em função da profundidade a partir da superfície do fundo para amostras dessalinizadas. Direita: Variação da resistividade, para uma mesma amostra, com a adição de bolhas. 
No gráfico correspondente ao comportamento da resistividade com a profundidade, o que de fato se nota é que não há variação com a profundidade, já que as oscilações observadas na curva têm amplitude menor que a incerteza da medida.

Com relação à experiência de simulação de presença de gás, optou-se por apresentar a variação da resistividade normalizada pela resistividade da amostra ainda sem adição de bolhas. Os resultados desta experiência mostram que apenas uma concentração de 0,20\% em volume de bolhas é suficiente para quase duplicar a resistividade da amostra.

Finalmente, as amostras dessalinizadas mostraram aumento de resistividade de uma ordem de grandeza.

\subsection{Susceptibilidade magnética}

Foi medida duas vezes susceptibilidade magnética de amostras correspondentes a: topo do testemunho, $33 \mathrm{~cm}$ e $93 \mathrm{~cm}$ de profundidade a partir da superfície do fundo. Na primeira vez, as amostras estavam no seu estado original e na segunda série de medidas, as amostras tinham sido dessalinizadas e centrifugadas.

O gráfico da Figura 56 mostra os valores de susceptibilidade antes e depois da dessalinização. Pode-se observar que houve diminuição da susceptibilidade magnética para as três amostras, de 21\%,33\% e 24\% (topo, $33 \mathrm{~cm}$ e $93 \mathrm{~cm}$, respectivamente).

A amostra de menor SM apresenta também o menor valor de resistividade após dessalinização (Figura 55).

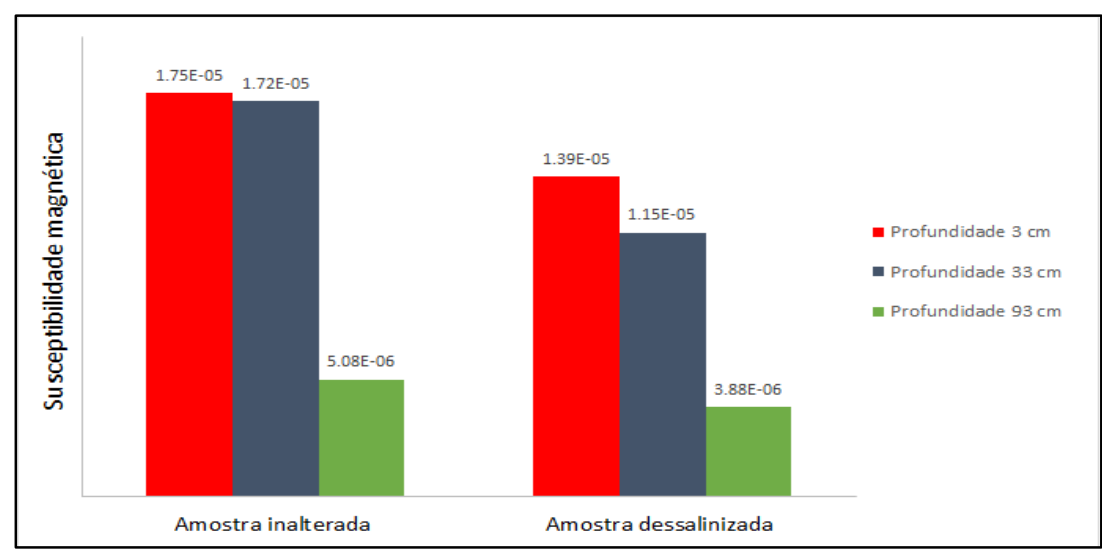

Figura 56: Gráfico de variação da susceptibilidade magnética de três amostras dessalinizadas. As três amostras apresentaram diminuição da susceptibilidade com a retirada do sal. 


\section{Discussão e conclusões}

Um critério de validação dos resultados considerado fundamental nesta dissertação é a análise dos cruzamentos entre linhas de aquisição. A homogeneidade do pacote sedimentar observada nos perfis sísmicos é indicativa de que é razoável esperar um meio eletricamente isotrópico e, portanto, as medições realizadas sobre um mesmo ponto em diferentes direções devem apresentar boa concordância.

Para efetuar essa análise foram escolhidas as linhas aquisitadas na área intermediária do SM (Figura 57 e 58). Os cruzamentos analisados apresentam boa correspondência, indicando que os resultados obtidos possuem coerência interna e sua qualidade não está comprometida por problemas de aquisição.

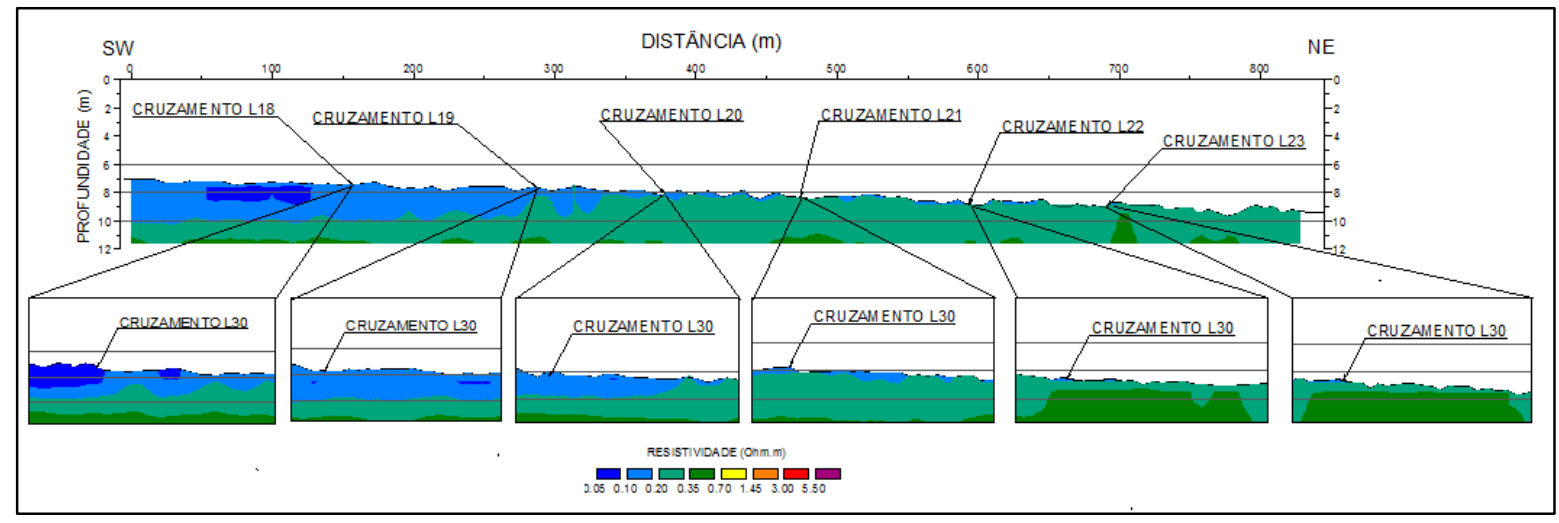

Figura 57: Cruzamentos das SIGs transversais L18 a L23, com a SIG L30.

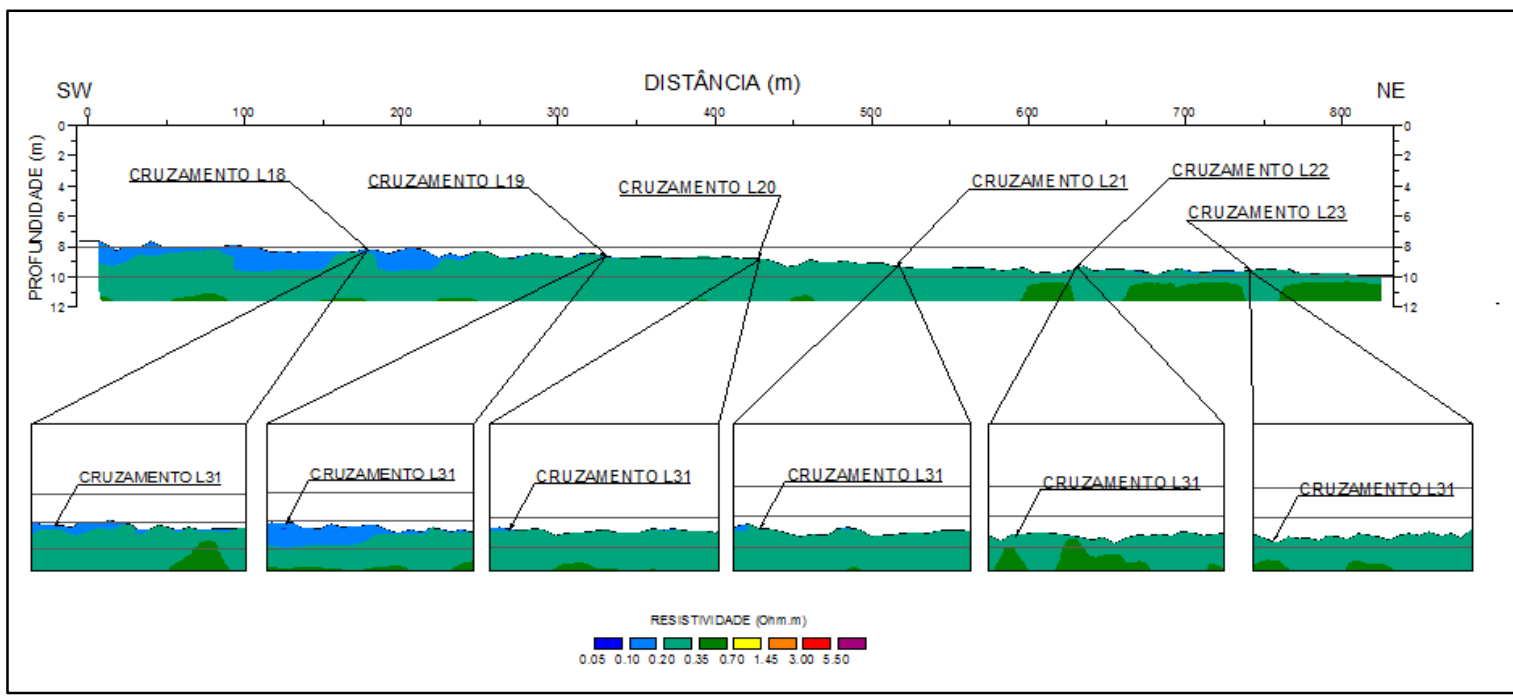

Figura 58: Cruzamentos das SIGs transversais L18 a L23, com a SIG L31. 
Começando a análise das SIGs, pode-se inferir que a camada geoelétrica condutiva, com base em torno de $8 \mathrm{~m}$ de profundidade e que ocorre sistematicamente em quase a totalidade das SIGs, está relacionada a uma camada sedimentar com características diferente das camadas sotopostas. A diferença que gera o contraste de resistividade observado deve também estar associada ao fato de que o topo da turbidez acústica, particularmente nos perfis L07 e L08, coincide com a base da camada mais condutiva.

No entanto, a ausência dessa camada condutiva em perfis adquiridos em coluna d'água maior que $8 \mathrm{~m}$ faz surgir a dúvida se realmente ela é uma resposta dos sedimentos de estratos superiores ou se o algoritmo de inversão força uma interface nessa profundidade.

A seção geoelétrica da Figura 59 mostra que os valores de resistividade acima de 0,35 Ohm.m ocorrem abaixo de $10 \mathrm{~m}$ de profundidade, deixando claro que a interface observada nos sedimentos não é um artefato do processo de inversão.

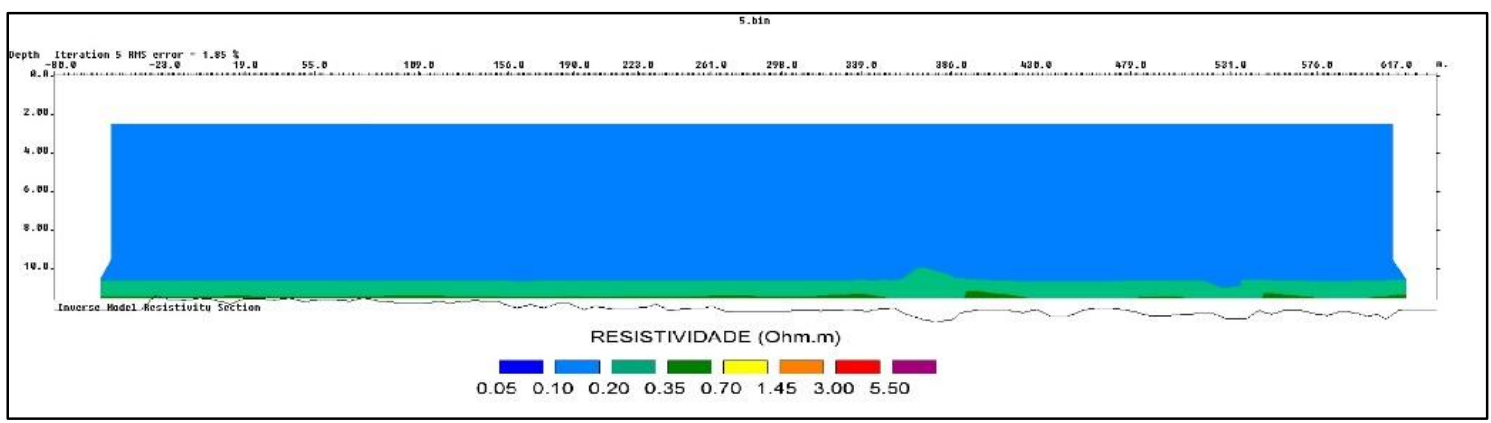

Figura 59: Seção geoelétrica adquirida em trecho de lâmina d'água superior a 11,5 m

A hipótese de que essa interface elétrica é resposta a uma variação da litologia pode ser considerada válida levando em conta as conclusões de Olpe $(2015$, p.101) que, referindo-se ao regime de correntes no SM, afirma que “...é possível observar que nas camadas inferiores a velocidade da corrente é menor que nas camadas superiores...". Dessa forma, a deposição dos sedimentos poderia variar conforme o regime de correntes local, refletindo-se na resposta elétrica.

Todavia, os dados disponíveis de granulometria dos sedimentos superficiais no SM (Figura 60) não mostram uma tendência que possa ser correlacionada com a resposta geoelétrica. 


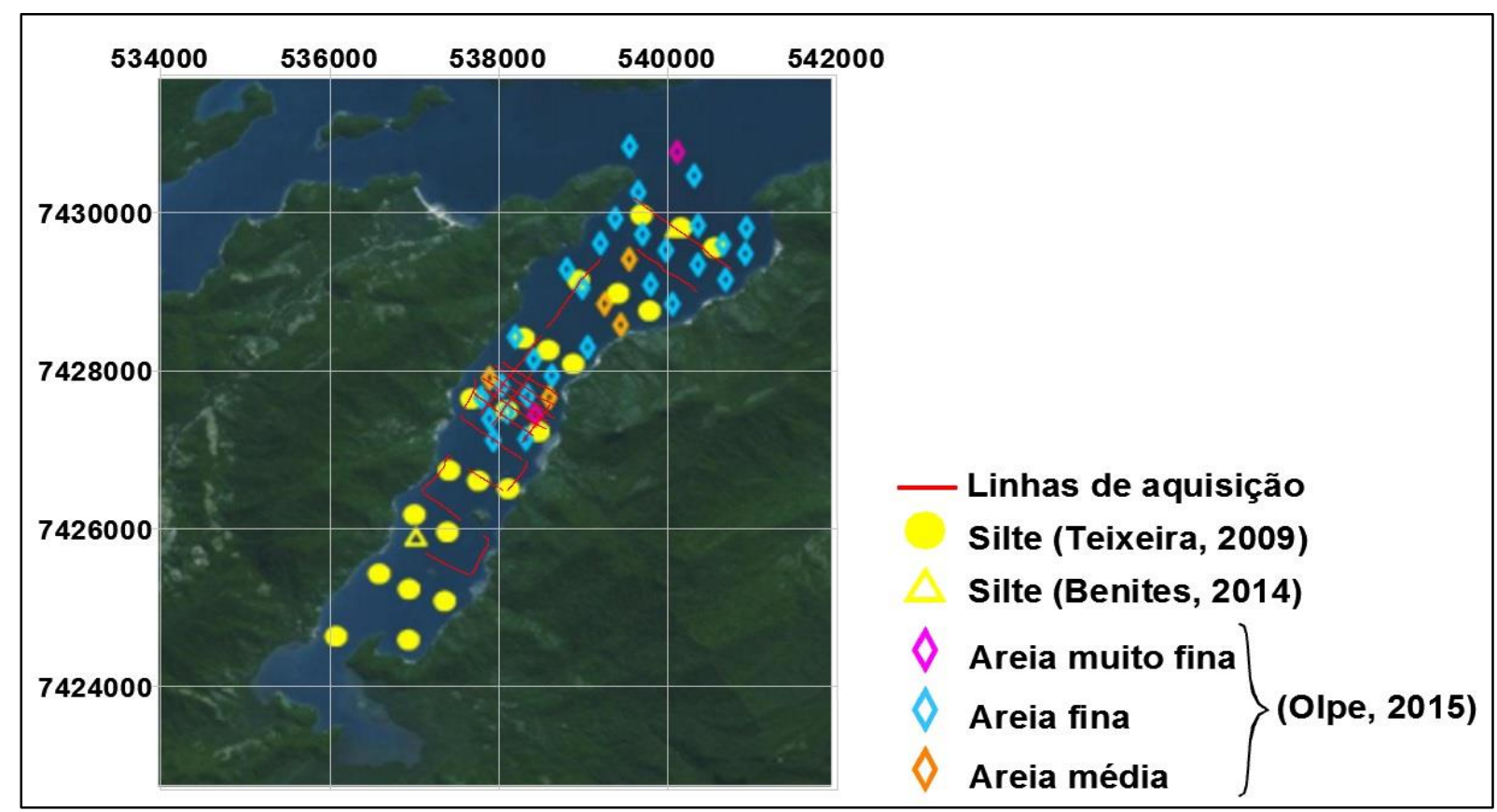

Figura 60: Distribuição granulométrica de sedimentos superficiais no SM. Modificado de Olpe (2015).

Não obstante, a granulometria não é o único fator que pode alterar a resposta elétrica do meio. Fator de formação, teor de argila e presença de matéria orgânica também devem ser levados em conta. Nesse sentido, Ustra (2013), em experimentos controlados, observa que a resistividade diminui com o aumento do teor de argila, e essa diminuição é mais acentuada quanto mais condutiva for a matriz aquosa.

Com relação a possíveis variações mineralógicas, as análises feitas até o momento apontam uma boa uniformidade pelo menos nos dois metros superiores da coluna de sedimentos, com predomínio de quartzo, biotita e albita, oriundos dos processos intempéricos das rochas circundantes (Rodelli et al, submetido).

$\mathrm{Na}$ tentativa de avaliar alguma possível correlação entre teor de argila e o valor da resistividade medida na camada superficial, os valores de teor de argila obtidos por Teixeira (2009) foram plotados no mapa da Figura 61. Nas imediações do povoado do Saco do Mamanguá, observa-se que os menores teores de argila ocorrem na região central do canal. 


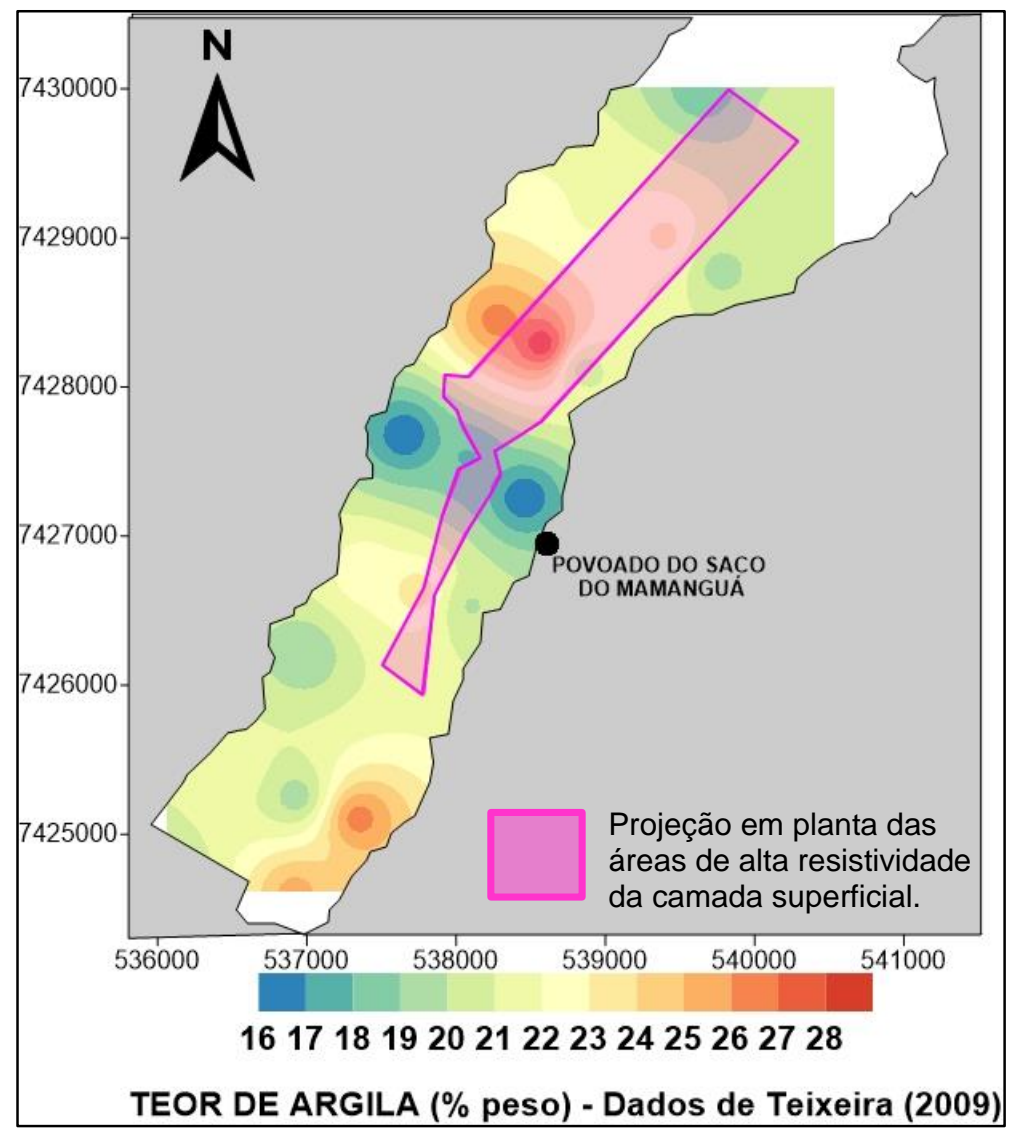

Figura 61. Mapa do teor de argila de sedimentos superficiais.

A variação não uniforme da resistividade após a dessalinização das amostras (Figura 55) indica que a resistividade do meio é dominada pela resistividade da água do mar. Ainda, somente após a retirada da água do mar se observa que amostra de $93 \mathrm{~cm}$ é a menos resistiva e também a de menor susceptibilidade magnética (Figura 56). Não obstante, recomenda-se que essa análise seja feita em mais amostras para que os resultados possam ser considerados conclusivos.

Esse domínio da água do mar na resposta elétrica do meio parece ter como consequência a suavização de anomalias de resistividade, como pode ser observado nas Figuras 38 e 47.

Nos perfis sísmicos dessas figuras, a superfície do fundo mostra maior refletividade no ápice dos domos, relacionada com material mais compacto ou de granulometria maior que nas áreas adjacentes. Nesses locais também se observa aumento da resistividade, mas sempre dentro do valor esperado para a água do mar. Uma consequência direta dessa 'suavização' é que durante a comparação entre perfis sísmicos e seções geoelétricas, deve-se levar em conta que o 
comprimento de onda das anomalias de resistividade será, como norma, maior que o das feições acústicas correspondentes.

Ainda conforme Kaufhold et al (2014), só a partir de teores de água < 60\% as interações entre partículas da argila começam a dominar os mecanismos de condução elétrica. Dessa maneira, parece razoável supor que as medidas de resistividade dos níveis mais profundos sejam mais representativas das propriedades dos materiais do que as medidas superficiais.

Pelo exposto acima, as conclusões podem ser resumidas da seguinte forma:

Do ponto de vista da coerência interna, o método geoelétrico apresentou resultados satisfatórios. Porém, para eliminar as ambiguidades na interpretação, é necessária tanto a execução de sondagens diretas que atinjam profundidades comparáveis com a mapeada quanto a análises físico-químicas em amostras coletadas sobre um transepto coincidente com uma SIG.

De forma semelhante à resposta acústica do pacote sedimentar, as SIGs não exibem variações laterais de resistividade significativas. Esse fato ligado à coincidência de anomalias resistivas rasas com pontos de alta refletividade acústica na superfície do fundo (Figuras 38 e 47), atestam a confiabilidade do método eletrorresistivo como ferramenta de estudos de ambientes marinhos rasos.

Apesar de que a presença de uma pequena fração de material isolante (bolhas de acrílico) em uma matriz siltosa produza altas variações de resistividade, não ficou clara a relação entre a ocorrência de gás nos sedimentos e assinatura geoelétrica das SIGs.

A penetração do método empregado foi menor que o esperado. Seções geoelétricas observadas na literatura consultada (p. ex. Kwon et al., 2005; Apostolopoulos, et al., 2007) mostram seções geoelétricas de mais de $20 \mathrm{~m}$ de profundidade com arranjo semelhante ao empregado neste trabalho, mas após a inversão dos dados observou-se uma penetração total máxima de $11,5 \mathrm{~m}$. Isso é devido a que a alta condutividade da água do mar produz um confinamento das linhas de corrente na lâmina coluna d'água, sendo que apenas uma parcela dessas linhas é refratada nas camadas de sedimentos. Assim, não foi possível mapear a base da área fonte do gás. Para esse fim, existem cabos multieletrodos de maior comprimento, mas que requerem o emprego de uma embarcação de apoio e o auxílio de mergulhadores. Essas necessidades teriam inviabilizado economicamente os trabalhos de campo 
Apesar do confinamento da turbidez acústica a estratos inferiores a $8 \mathrm{~m}$ de profundidade, não foi observado nenhum refletor sísmico associado a uma camada sedimentar selante. Porém, a interface observada nas SIGs indica que nessa profundida ocorre uma mudança de alguma propriedade dos sedimentos, possivelmente aumento do teor de matéria orgânica, mas que precisa ser determinada mediante sondagens diretas.

Finalmente, no presente trabalho considera-se como hipótese mais plausível que o aumento da resistividade com a profundidade é produto da compactação dos sedimentos e a conseguinte diminuição do teor de água. Dessa forma, o gradiente vertical de resistividade e a sua baixa variabilidade lateral condizem com assinatura elétrica esperada para um ambiente deposicional de baixa energia e constância na fonte dos sedimentos. 


\section{Referências Bibliográficas}

Almeida, F. F. M., Carneiro, C. D., 1998. Origem e evolução da Serra do Mar. Revista Brasileira de Geociências. 28(2):135-150

Apostolopoulos, G., Amolochitis, G., Stamataki, S., 2006. Marine resistivity tomography prior excavation works in port construction. In: EAGE 69th Conference, Londres. 11-14 de junho, 2007. p. E006

Benites, M, Pavani, D. A., Maly. M. S., Jovane, L., 2015. Shallow gas occurrence in a Brazilian ría (Saco do Mamanguá, Rio de Janeiro) inferred from high-resolution seismic data. Cont Shelf Res. 108:89-96. DOI 10.1016/j.csr.2015.08.022

Bernardes, R. A. Estrutura e dinâmica da ictiofauna do Saco do Mamanguá (Paraty-RJ). Tese de doutorado. Instituto Oceanográfico. Universidade de São Paulo. São Paulo, 1995,

Bird, E. Coastal Geomorphology - An Introduction, $2^{\text {nd }}$ ed. John Wiley \& Sons. Ltd, Chichester, 2008. 436p.

Boyce, R. E., 1968. Electrical Resistivity of Modern Marine Sediments from the Bering Sea. J. Geophys. Res. 73(14):4759-4766

Castaing, P., Guilcher, A., 1995. Geomorphology and sedimentology of Rias. In: Geomorphology and Sedimentology of Estuaries, Perillo, G.M.E. (Ed.), pp. 69-111. DOI 10.1016/S0070-4571(05)80021-4.

Chave, A. D., Constable, S. C., Edwards R. N. Electrical exploration methods for the seafloor, Electromagnetic methods vol. 2, M.N. Nabighian, ed., 1991.

Cheesman, S. J., R. N. Edwards, and A. D. Chave, 1987. On the theory of seafloor conductivity mapping using transient electromagnetic systems. Geophysics, 52:204-21. DOI $\underline{10.1190 \% 2 \mathrm{~F} 1.1442296}$

David, P., Panagiotis, T., Konstantinos, A., 2009. Electrical resistivity tomography mapping of beachrocks: Application to the island of Thassos (N. Greece). Environ Earth Sci. 59:233-240. DOI: $\underline{\text { 10.1007/s12665-009-0021-9 }}$ 
Duarte, H., Pinheiro, L. M., Teixeira, F. C., Monteiro, J. H., 2007. High-resolution seismic imaging of gas accumulations and seepage in the sediments of the Ria de Aveiro barrier lagoon (Portugal). Geo-Mar Lett. 27:115-126. DOI 10.1007/s00367-007-0069-Z

Dunlop, D. J., Özdemir, Ö. Rock Magnetism: fundamentals and frontiers. Cambridge University Press, 1997.

Edwards, R. N., 2005, Marine controlled source electromagnetics: Principles, methodologies, future commercial applications: Surv in Geophys 26:675-700.

Evans, G., Prego, R., 2003. Rias, estuaries and incised valleys: is a ria an estuary? Mar. Geol. 196:171-175. DOI 10.1016/S0025-3227(03)00048-3.

Floodgate, G.D., Judd, A.G., 1992. The origins of shallow gas. Cont Shelf Res. 12:1145-1156.

Gandolfo, O. C. B. Um Estudo do Imageamento Geoelétrico na Investigação Rasa. Tese de doutoramento. Programa de Pós-Graduação em Recursos Minerais e Hidrogeologia. Instituto de Geociências. Universidade de São Paulo, 2007.

García-Gil, S., 2003. A natural laboratory for shallow gas: the Rias Baixas (NW Spain). In: Woodside JM, Garrison RE, Moore JC, Kvenholden KA (eds) Proc 7th Int Conf Gas in Marine Sediments, 7-12 October 2002, Baku, Azerbaijan. Geo-Mar Lett.23 (3/4):215-229.

Jones, E. J. W. Marine Geophysics. Chichester, John Willey \& Sons Ltd., 1999. 466p.

Jørgensen, B. B., Fossing, H., 2011. Baltic Gas Final Scientific Report. Reporting Period: Januray 1, 2009 - December 31, 2011. Disponível em <http://www.bonusportal.org/files/1597/BALTIC_GAS_FINAL_REPORT.pdf>. Acesso em 15/10/2016.

Jovane, L., Florindo, F., Coccioni, R., Dinarès-Turell, J., Marsili, A., Monechi, S., Roberts, A. P., Sprovieri, M., 2007. The middle Eocene climatic optimum event in the Contessa Highway section, Umbrian Apennines, Italy. GSA Bulletin.119(3-4):413-427. DOI $\underline{10.1130 / \mathrm{B} 25917.1}$

Jovane L., Verosub, K. L., 2011. Magnetic Properties of Oligocene-Eocene Cores From SHALDRIL II, Antarctica. Tectonic, Climatic, and Cryospheric Evolution of the Antarctic Peninsula - Special Publication 063 (AGU). 
Judd, A.G., Hovland, M., Dimitrov, L.I., Garcia-Gil, S., Jukes, V., 2002. The geological methane budget at continental margins and its influence on climate change. Geofluids 2:109126. DOI 10.1046/j.1468-8123.2002.00027.x.

Kaufhold, S.; Grissemann, C.; Dohrmann, R; Klinkenberg, M.; Decher, A, 2014. Comparison of three small-scale devices for the investigation of the electrical conductivity/resistivity of swelling and other clays. Clays Clay Miner. 62(1):1-12. DOI http://ccm.geoscienceworld.org/content/62/1/1

Keary, P., Brooks, M., Hill, I. An introduction to geophysical exploration. $3^{\text {rd }}$ ed. Oxford: Blackwell Science Ltd, 2002, 8:183-198.

Kwon, H-S., Kim, J-H., Ahn, H-Y., Yoon, J-S., Kim, K-S., Jung, C-K., Lee, S-B., Uchida, T., 2005. Delineation of a fault zone beneath a riverbed by an electrical resistivity survey using a floating streamer cable. Explor Geophys, 36:50-58.

Lavoie, D; E. Mozley; R. Corwin; D. Lambert; Valent, P., 1987. The used of a towed, direct-current, electrical resistivity array for the classification of marine sediments .Washington, DC, NORDA Stennis Space Center. MS 39529:397-404.

Locke, M. H., Barker, R. D., 1996. Rapid least-squares inversion of apparent resistivity pseudo section by a quasi-Newton method. Geophys Prospect. 44:131-152.

Machado, R. Aplicação do método eletrorresistivo em ambiente aquático para mapeamento do subfundo do Rio São Francisco. Dissertação de Mestrado. Programa de PósGraduação em Recursos Minerais e Hidrogeologia. Instituto de Geociências. Universidade de São Paulo, 2008.

Mahiques, M. M. Considerações sobre os sedimentos de superfície do fundo da Baía da Ilha Grande, Estado do Rio de Janeiro. Dissertação de Mestrado. Volume I. Oceanografia Física. Instituto Oceanográfico. Universidade de São Paulo, 1987.

Mendonça, C. A., Doherty, R., Fornaro, A., Abreu, E. L., Novaes, G. C., Fachin, S. Jr. S., La-Scalea, M. A., 2015. Integrated earth resistivity tomography (ERT) and multilevel sampling gas: a tool to map geogenic and anthropogenic methane accumulation on brownfield sites. Environ Earth Sci. 74:1217-1226. DOI 10.1007/s12665-015-4111-6 
Mosher, D.C. \& Simpkin, P., 1999. Status and trends of marine high-resolution seismic reflection profiling: data acquisition, Geosci. Can. 26:174-188.

Olpe, C. A. Hidrodinâmica e transporte de sedimentos no Saco do Mamanguá (RJ), observações e modelagem numérica. Dissertação de Mestrado. Programa de Pós-Graduação em Oceanografia, área de Oceanografia Geológica. Instituto Oceanográfico. Universidade de São Paulo, 2016.

Orellana, E. S., Prospección geoeléctrica en corriente contínua. Madrid, Paraninfo, 1972. 523p.

Orlando, L., 2013. Some considerations on electrical resistivity imaging for characterization of waterbed sediments. J App Geophys. 95:77-89.

Quinn, R., Bull, J.M., \& Dix, J.K., 1998. Optimal processing of marine high-resolution seismic reflection (chirp) data, Mar. Geophys. Res. 20:13-30, DOI 10.1023/A:1004349805280

Lowrie, W. A student's guide to geophysical equations. Cambridge University Press, Cambride, 2011, 277p.

Reynolds, J. M. An Introduction to Applied and Environmental Geophysics. Baffins Lane, Chichester, John Willey \& Sons Ltd., 1997, p 417-485.

Robinson, E.A. Wave Motion, in Digital Imaging and Deconvolution: The ABCs of Seismic Exploration and Processing. Tulsa, Society of Exploration Geophysicist, 2008, p. 138.

Rodelli, D., Jovane, L., Giorgioni, M., Cornaggia, F., Siciliano, E., Benites, M., Cedraz, P. P., Roberts, A. P. Biogenic magnetite as an indicator of chemical stratification in the sediment column of Mamangua ría (Paraty, Brazil).

Sasaki, Y., 1992, Resolution of resistivity tomography inferred from numerical simulation, Geophys Prospect. 40(4): 453- 463.

Souza, L. A. P. Revisão crítica da aplicabilidade dos métodos geofísicos na investigação de áreas submersas rasas, Tese de Doutorado, área de Oceanografia Química e Geológica. Instituto Oceanográfico. Universidade de São Paulo, São Paulo, 2006. 
Souza, L. A. P. Estratigrafia rasa de ultra-alta resolução na investigação de ambientes submersos. In. $47^{\circ}$ Congresso Brasileiro de Geologia, 2014, Salvador. Apresentação. Disponível em: http://www.47cbg.com.br/apresentacoes/PAP016208.pdf. Acesso em: 27 mar. 2017.

Teixeira, C. L. Caracterização do sedimento superficial de enseadas da Baía de Ilha Grande - RJ, com ênfase na distribuição espacial de metais. Dissertação de Mestrado, Geociências/Geoquímica Ambiental. Universidade Federal Fluminense, Rio de Janeiro, 2009.

Teldford, W. M., Geldart, L. P., Sheriff, R. E. Applied Geophysics. $2^{\text {nd }}$ ed. Cambridge: Cambridge University Press, 1990, 8, p 522-577.

Tóth, Z., Spiess, V., Jensen, J. B., 2014a. Seismo-acoustics signatures of shallow free gas in the Bornholm Basin, Baltic Sea. Cont Shelf Res 88:228-239

Tóth, Z., Spiess, V., Mogollón, J. M., Jensen, J. B., 2014b. Estimating the free gas content in Baltic Sea sediments using compressional wave velocity from marine seismic data. J. Geophys. Res. Solid Earth. 119:8577-8593, DOI 10.1002/2014JB010989

Ustra, A. T. Estudo da resposta IP de solos argilosos contaminados por hidrocarbonetos e chorume. Tese de doutorado, Geofísica/Geofísica Aplicada. Instituto de Astronomia, Geofísica e Ciências Atmosféricas. Universidade de São Paulo, 2013.

Verbeek, N. H. \& McGee, T. M., 1995. Characteristics of high-resolution marine reflection profiling sources. J. Appl. Geophys 33:251-269, DOI 10.1016/0926$\underline{9851(95) 90045-4}$

Verwey, E. J. W. \& Overbeek, J. TH. G. Theory of stability of lyophobic colloids: The interaction of sol particles having an electric double layer. Amterdã, 1948. Elsiever Publishing Company, Inc.

Wilkens, R. H., Richardson, M. D., 1998. The influence of gas bubbles on sediment acoustic properties: in situ, laboratory, and theoretical results from Eckernförde Bay, Baltic Sea. Cont Shelf Res. 18:1859-1892.

Whitman, W.B., Bowen, T.L., Boone, D.R., 2007. The methanogenic bacteria. Prokaryotes. 3:165-207. DOI 10.1007/0-387-30743-5_9 